Check for updates

Cite this: RSC Adv., 2018, 8, 9440

Received 3rd February 2018

Accepted 19th February 2018

DOI: $10.1039 / c 8 r a 01063 c$

rsc.li/rsc-advances

\title{
Discovery and preliminary SAR of 14-aryloxy- andrographolide derivatives as antibacterial agents with immunosuppressant activity $\dagger$
}

\author{
Feng Li,,$^{a}$ Xiao-Min Li,,$^{b}$ Dekuan Sheng, ${ }^{a}$ Shao-Ru Chen, ${ }^{b}$ Xin Nie, ${ }^{a}$ Zhuyun Liu, $\S^{a}$

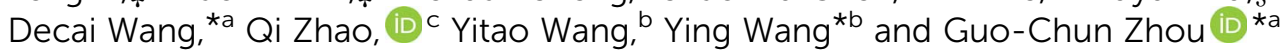

\begin{abstract}
Antibacterials (which restore gut flora balance) and immunosuppressants (which correct immune defects) are two important and effective therapeutic agents for the treatment of inflammatory bowel disease (IBD) in clinical use today. Since the structural skeleton of andrographolide, isolated from Andrographis paniculata, has become known as a natural antibiotic with anti-inflammation and heat-clearing and detoxifying properties, 14-aryloxy andrographolide derivatives have been designed, synthesized, and tested for their antibacterial effects on E. coli, S. aureus, and E. faecalis, which are related to IBD. It has been discovered in this study that the andrographolide skeleton is more selective against $E$. faecalis, the 14-aryloxy group with basicity is important for antibacterial functions, and the 14-(8'-quinolinyloxy) group is a good pharmacophore with antibacterial activity. In addition, we found that $7 \mathrm{~b} 1$ and $8 \mathrm{~b} 1$ are good and selective inhibitors of E. faecalis; two $14 \beta$-( $8^{\prime}$-quinolinyloxy) andrographolide derivatives, $6 \mathrm{~b} 17$ and $9 \mathrm{~b}$, exhibit good activity against E. coli, S. aureus, and E. faecalis. Likewise and importantly, further exploration of immunosuppressant activity for IBD shows that compound $7 \mathrm{~b} 1$ is a selective inhibitor of the TNF- $\alpha / N F-$ $\kappa B$ signaling pathway, whereas $8 \mathrm{~b} 1$ is selectively active against the TLR4/NF- $\mathrm{B} B$ signaling pathway; moreover, the compounds $6 \mathrm{~b} 17$ and $9 \mathrm{~b}$ are active in inhibiting the IL-6/STAT3, TLR4/NF- $\mathrm{KB}$, and TNF- $\alpha$ / $\mathrm{NF}-\mathrm{KB}$ signaling pathways. Based on these results, we have further focused on the development of dual function inhibitors of IBD as antibacterial and immunosuppressant agents by structural modification of andrographolide.
\end{abstract}

\section{Introduction}

Inflammatory bowel disease (IBD) ${ }^{1}$ is an autoimmune disease that is characterized by relapsing and remitting chronic inflammation of the gastrointestinal tract; it is believed to be caused by unbalanced host-commensal microbiota and a common immune defect in addition to genetic predisposition. ${ }^{2}$ Immune responses have been recognized to be related to IBD pathogenesis, ${ }^{3}$ and a recent study demonstrated that the innate immune system is a major determinant of the serum and tissue profiles of IBD, ${ }^{4}$ further explaining the existence of

${ }^{a}$ School of Pharmaceutical Sciences, Nanjing Tech University, Nanjing 211816, PR China.E-mail: gczhou@njtech.edu.cn; dcwang@njtech.edu.cn; Tel: +86-25-58139415 ${ }^{b}$ State Key Laboratory of Quality Research in Chinese Medicine, Institute of Chinese Medical Sciences, University of Macau, Avenida da Universidade, Taipa, Macao SAR, PR China. E-mail: emilyywang@umac.mo

${ }^{c}$ Faculty of Health Sciences, University of Macau, Avenida da Universidade, Taipa, Macao SAR, PR China

$\dagger$ Electronic supplementary information (ESI) available. See DOI: 10.1039/c8ra01063c

\$ These authors contributed equally to this work.

$\S$ Current address: Department of Pharmaceutical and Chemical Engineering, Taizhou Polytechnic College, Taizhou 225300, Jiangsu, PR China. regulatory cytokines that are implicated in immune responses related to IBD. ${ }^{5}$ Especially, overexpression of proinflammatory cytokines, such as interleukin-6 (IL-6), toll-like receptor 4 (TLR4), and tumor necrosis factor- $\alpha$ (TNF- $\alpha$ ), is crucial for IBD onset and progression; these proinflammatory cytokines, as inflammatory mediators, are connected with the activation of nuclear factor of $\kappa$ light polypeptide gene enhancer in B-cells (NF-KB) and signal transducer and activator of transcription 3 (STAT3). ${ }^{5}$ As NF-אB and STAT3 are known to play central roles in regulating inflammatory responses in patients with IBD, they are recognized as important targets for therapeutic intervention of IBD. $^{6}$ Gastrointestinal microbiota are believed to be commensal and mutualistic to humans and animals and to have health benefits for humans and animals in some aspects. ${ }^{7}$ Significant imbalances of gastrointestinal flora are observed in patients with IBD as compared to the case of healthy people; for example, proteobacteria and actinobacteria appear to dominate in people with ulcerative colitis (UC), whereas Enterococcus (E.) faecium and several proteobacteria over-inhabit the gastrointestinal tracts of people with Crohn's disease (CD). ${ }^{8}$ Although the etiology and pathogenesis of IBD are not fully understood, E. coli and E. faecalis are recognized as pathogens of IBD. ${ }^{9}$ It is controversial whether $S$. aureus infection is involved in early 
lesions or established lesions of IBD; however, S. aureus infection occasionally may occur and complicate IBD during the course of the disease. ${ }^{10}$ Metabolites from certain members of the gut flora may have causal contributions to disorders such as obesity and colon cancer by changing host signaling pathways. ${ }^{11}$ In addition, the intrusion of gut flora components into other host compartments can lead to sepsis. ${ }^{11}$ Therefore, immunosuppressants (which correct immune defects) and antibacterials (which restore flora balance) are two important and effective therapeutic agents to treat IBD in clinical use. Considering this, we envisage that it is a meaningful exploration to discover single compounds with dual functions of antibacterial and immunosuppressant activities.

Andrographis paniculata [Burm. F.] Nees, an herb known as a "natural antibiotic", is commonly used in China, India and Southeast Asia for the treatment of a large variety of illnesses, especially infectious diseases, by reducing inflammation and "heat-clearing and detoxifying". Andrographolide (1, Scheme 1), a bicyclic diterpenoid lactone, is a major active component isolated from Andrographis paniculata [Burm. F.] Nees; ${ }^{12}$ its derivatives, ${ }^{13}$ such as "Chuanhuning", ${ }^{14,15}$ have been used in China to treat bacterial and viral infections for many years. Numerous andrographolide derivatives have been designed and synthesized in recent years. ${ }^{16}$ The antibacterial activities of andrographolide and its derivatives are not potent and show only minimal or marginal direct inhibition of bacterial growth; however, it was discovered that andrographolide inhibits the quorum sensing (QS) system $^{17}$ of $P$. aeruginosa and that andrographolide derivatives block biofilm formation ${ }^{18}$ of $P$. aeruginosa, indicating that andrographolide and its derivatives can directly inhibit bacterial growth or/and infection by specific mechanisms and modes of action. On the other hand, some evidence has been found that the anti-inflammatory effects of andrographolide are related to regulation of the immune system $^{19}$ and that andrographolide suppresses TLR4 expression and NF- $\mathrm{BB}$ signaling in multiple myeloma cells. ${ }^{20}$ Multitargeting andrographolide and its analogs have potential use in the prevention and treatment of metabolic syndrome ${ }^{21}$ and stroke $^{22}$ via the NF- $\kappa \mathrm{B}$ signaling pathway. The andrographolide derivative isoandrographolide significantly inhibited the release of NO and prostaglandin E2 and the production of interleukin-1 $\beta$ (IL-1 $\beta$ ) and IL-6 in lipopolysaccharide (LPS)stimulated J774A.1 macrophage cells in a dose-dependent manner. ${ }^{23}$ Andrographolide analog AL-1 improved insulin resistance by down-regulating the NF- $\kappa \mathrm{B}$ signaling pathway. ${ }^{24}$ Our previous report ${ }^{25}$ revealed that some analogs of andrographolide play a role in the attenuation of innate immunity; these were identified as potential immunomodulatory inhibitors of TLR signaling with distinct regulation of NF-KB family members. Furthermore, one compound effectively reduced LPSinduced pulmonary injury in a mouse in vivo study; biochemical results showed that the nucleus translocation of phosphorylated p65 and serum pro-inflammatory cytokines decreased. Based upon these facts, we are interested in developing dualfunction analogs of andrographolide as immunosuppressants to inhibit excessive immunity to "self" gastrointestinal microbiota and also as antibacterial agents to control infection by specific "commensal/mutualistic" gut flora; such compounds should be valuable in the treatment of IBD.

In our search for dual-functional 14-aryloxy andrographolide analogs inhibiting both bacterial growth and innate immunity, we launched a panel of screening platforms of these analogs to
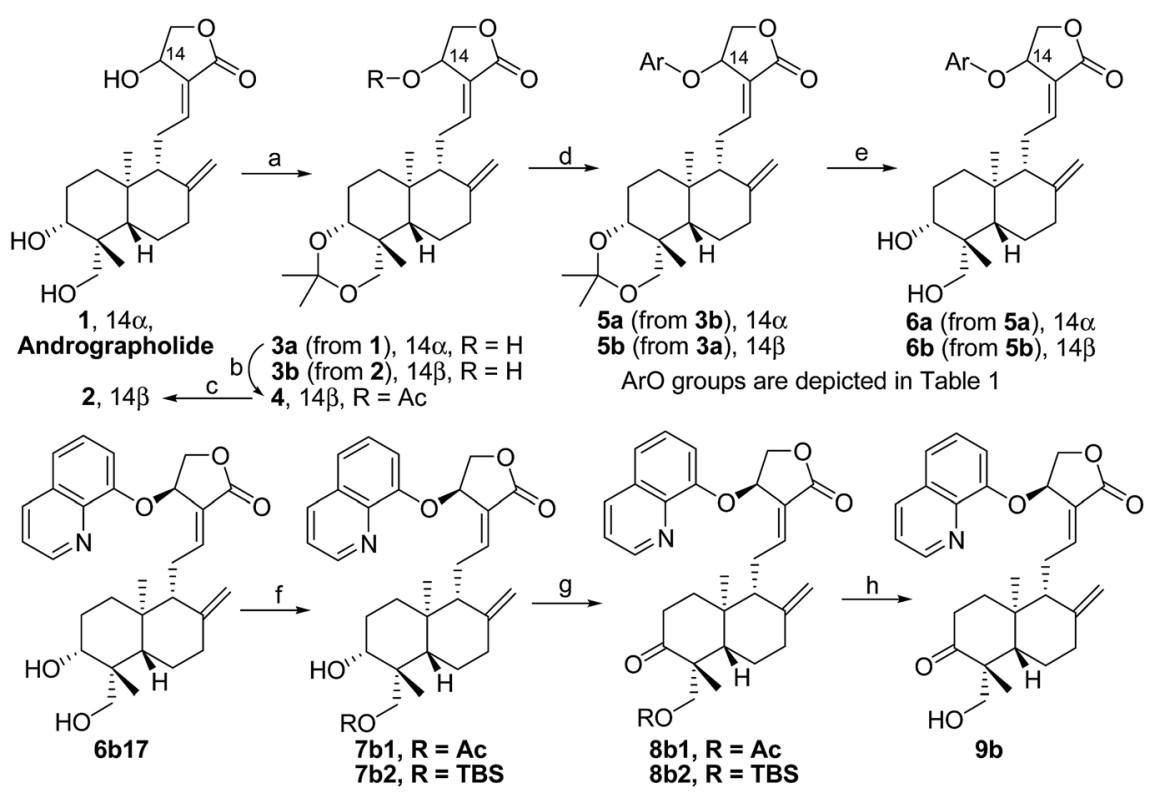

Scheme 1 Reagents and conditions (andro = andrographolide): (a) anhydrous DCM, 2,2-dimethoxypropane, PPTS, $40{ }^{\circ} \mathrm{C} ;(\mathrm{b})$ anhydrous THF; $3 a$ (1.0 eq.), anhydrous $\mathrm{HOAC}$ (1.5 eq.), DIAD (1.5 eq.), $\mathrm{PPh}_{3}$ (1.5 eq.), $0^{\circ} \mathrm{C}$ to room temperature; (c) $\mathrm{MeOH} / \mathrm{H}_{2} \mathrm{O}(4 / 1), \mathrm{TsOH}^{\circ} \mathrm{H}_{2} \mathrm{O}, 40{ }^{\circ} \mathrm{C}$. (d) anhydrous THF; $3 a$ or $3 b$ (1.0 eq.), phenol (1.5 eq.), DIAD (1.5 eq.), $\mathrm{PPh}_{3}\left(1.5\right.$ eq.), $0{ }^{\circ} \mathrm{C}$ to room temperature; (e) $\mathrm{MeOH} / \mathrm{H}_{2} \mathrm{O}(4 / 1), \mathrm{TsOH} \cdot \mathrm{H}_{2} \mathrm{O}, 20{ }^{\circ} \mathrm{C} ;($ f) $\mathrm{AcCl}$, TEA, $0{ }^{\circ} \mathrm{C}, 90 \%$ yield for $7 \mathrm{~b} 1$ or TBSCl, TEA, rt, $89 \%$ yield for $7 \mathrm{~b} 2$; (g) DCM, Dess-Martin periodinane, rt, $90 \%$ yield for $8 \mathrm{~b} 1 \mathrm{or} 86 \%$ yield for $8 \mathrm{~b} 2$; (h) $\mathrm{p}$-TSA, $\mathrm{MeOH}, 40{ }^{\circ} \mathrm{C}, 8 \mathrm{~h}, 80 \%$ yield from $8 \mathrm{~b} 1$ or DCM, TFA, $-20{ }^{\circ} \mathrm{C}, 20 \mathrm{~min}, 81 \%$ yield from $8 \mathrm{~b} 2$. 
study their antibacterial activities against $E$. coli, $S$. aureus and E. faecalis and preliminary structure-activity relationship (SAR) studies as the first step. Selected active anti-bacterial compounds were explored as immunosuppressants to protect the host from abnormal immune response initiated by intestinal commensal/mutualistic bacteria. In this paper, we describe the synthesis and evaluation of a series of 14-aryloxy andrographolide compounds against E. coli, S. aureus and $E$. faecalis as well as against the IL-6/STAT3, TLR4/NF- $\kappa \mathrm{B}$ and TNF$\mathrm{a} / \mathrm{NF}-\kappa \mathrm{B}$ signaling pathways of innate immune response and their preliminary SAR. It was discovered that analogs of andrographolide are more sensitive to E. faecalis and that active antibacterial compounds are greatly superior to andrographolide to attenuate innate immune response. Our results revealed that the andrographolide skeleton has immunosuppressant and antibacterial properties and that these analogs of andrographolide can potentially be used to treat IBD.

\section{Results and discussion}

\subsection{Synthesis}

The title derivatives were synthesized according to our previously reported synthesis $;^{25,26}$ the synthesis is outlined in Scheme 1 (ArO groups are depicted in Table 1). Accordingly, 14 $\alpha-3,19$ acetonylidene-protected andrographolide (3a) was prepared by the reaction of andrographolide (1) with 2,2-dimethoxypropane catalyzed by PPTS, followed by a Mitsunobu reaction with acetic acid, which inverted $14 \alpha-\mathrm{OH}$ of $3 \mathrm{a}$ into $14 \beta$-OAc of 4 . Full hydrolysis of 4 by $\mathrm{TsOH} \cdot \mathrm{H}_{2} \mathrm{O}$ in $\mathrm{MeOH} / \mathrm{H}_{2} \mathrm{O}(4 / 1)$ at $40{ }^{\circ} \mathrm{C}$ afforded 2 as the $14 \beta$-epimer of andrographolide; then, 3,19protection of 2 afforded 14 $\beta$-3,19-acetonylidene andrographolide (3b).

Mitsunobu reactions of $\mathbf{3 a}$ or $\mathbf{3 b}$ with varied aromatic phenols were carried out in general from $0{ }^{\circ} \mathrm{C}$ to room temperature in anhydrous THF to afford $14 \beta$-aryloxy andrographolide 5b (5b1-5b17) or 14 $\alpha$-aryloxy andrographolide 5a (5a15a5, 5a8-5a9, 5a12, 5a15-5a17), respectively, in mild to moderate isolated yield depending on the distinct properties of the phenols. Deprotection of 3,19-acetonylidene from $\mathbf{5 a}$ or $\mathbf{5 b}$ afforded the corresponding alcohol 6a (6a1-6a5, 6a8-6a9, 6a12, 6a15-6a17) or 6b (6b1-6b17). As we noted before, ${ }^{26} 14 \alpha$-aryloxy derivatives are generally much less stable than their corresponding $14 \beta$-isomers, and some $14 \alpha$-aryloxy compounds were not obtained or were obtained in very low yields. Furthermore, mono-acetylation or mono-silylation of $6 \mathrm{~b} 17$ produced $7 \mathrm{~b} 1(\mathrm{R}=$ Ac) or $7 \mathbf{b} 2(\mathrm{R}=\mathrm{TBS})$, which was oxidized into ketone $\mathbf{8 b 1}$ or $\mathbf{8 b 2}$ by Dess-Martin periodinane (DMP); finally, deprotection of $\mathbf{8 b 1}$ or $\mathbf{8 b 2}$ afforded 3-keto-19-alcohol product $\mathbf{9 b}$.

\subsection{Antibacterial activity and SAR analysis}

Numerous bacteriostatic and bactericidal agents have been discovered and developed against bacterial growth and infection; however, bacterial resistance to currently used antibacterial drugs is becoming a major problem in clinical practice, especially hospital-acquired infections by these drug-resistant bacteria. ${ }^{27}$ To meet the demand of clinical medication for the treatment of digestive diseases caused by gastrointestinal bacterial infection, antibacterial drugs with diverse and novel structural origins are required. ${ }^{28}$

On the basis of reported literature studies stating that andrographolide and some of its derivatives may function as antibiotics, we are pursuing the discovery of more potent and specific andrographolide derivatives for the development of chemotherapeutical agents against bacterial infection, especially for inhibiting gastrointestinal bacterial infection in the development of IBD. The strategy in this study was to submit these synthesized compounds to a preliminary screening test against E. coli, S. aureus and E. faecalis (ciprofloxacin was used as a reference compound; see Table 1). Because these andrographolide analogs did not obviously function as bactericidal agents (data not shown), bacteriostatic screening was employed with gradient concentrations and the percent growth was plotted versus test concentration to afford the $\mathrm{IC}_{50}$ values. ${ }^{29}$ The current antibacterial activity results are listed in Table 1.

In our study streamline, 5 series of 20 compounds bearing 14-(4'-nitro)phenoxy groups were first tested. It was found that all of these compounds are more selective against $E$. faecalis than against $E$. coli and $S$. aureus. 14 $\beta-3,19-D i o l$ compounds (6b1-6b5) are more active against $E$. faecalis than the corresponding 14 $\beta$-3,19-acetonylidene protected compounds (5b15b5). Furthermore, 14 $\beta$ - $\left(3^{\prime}\right.$-substituted $4^{\prime}$-nitro)phenoxy-3,19diol compounds $\mathbf{6 b 4}$ and $\mathbf{6 b 5}$ are more sensitive to $E$. faecalis than $14 \beta$-( $2^{\prime}$-substituted 4 -nitro)phenoxy-3,19-diol compounds 6b1, $6 \mathbf{b 2}$ and 6b3. It was observed that the activity patterns of the 14 -( 2 '-fluro- $4^{\prime}$-nitro)phenoxy and $14-\left(2^{\prime}\right.$-carboxylate- $4^{\prime}$-nitro $)$ phenoxy derivatives are quite similar. The activity differences between $14 \alpha$-( $2^{\prime}$-substituted-4'-nitro)phenoxy groups and $14 \beta$ ( $2^{\prime}$-substituted-4'-nitro)phenoxy groups are variable, leading to an order of $5 \mathrm{a} 1>5 \mathrm{~b} 1,5 \mathrm{a} 2>5 \mathrm{~b} 2,6 \mathrm{~b} 1>6 \mathrm{a} 1$ and $6 \mathrm{~b} 2>6 \mathrm{a} 2$ when an electron-withdrawing group (EWG) is at the $2^{\prime}$-position but $\mathbf{6 b 3}<6 \mathbf{6 3}$ when an electron-donating group (EDG) is at the $2^{\prime}$ position. Overall, an EWG at the $2^{\prime}$-position (5a1, 5a2, 6a1, 6a2, $6 \mathrm{~b} 1$ and 6b2) was more favorable for antibacterial activity than an EDG at the $2^{\prime}$-position (5a3, 6a3 and 6b3). Compounds $6 \mathbf{b 4}$ and $6 \mathbf{b 5}$ with $14 \beta-\left(3^{\prime}\right.$-substituted $4^{\prime}$-nitro)phenoxy groups are more active to $E$. faecalis than the corresponding compounds $6 \mathbf{a 4}$ and $6 \mathbf{a} 5$ with $14 \alpha-\left(3^{\prime}\right.$-substituted $4^{\prime}$-nitro)phenoxy groups, respectively.

Then, 2'-nitro compounds and 3 '-nitro compounds were explored; it was discovered that the $14 \beta-3,19$-diol isomers of 14 (2'-nitro)phenoxy analog 6 b6 and 14-(3'-nitro)phenoxy analog 6b7 exhibited mild inhibitory activity to E. faecalis and were more active than the corresponding 3,19-acetonylidene protected compounds $5 \mathbf{b 6}$ and $\mathbf{5 b 7} \mathbf{1 4} \alpha$ - and $14 \beta$-(2'-Carboxyl ester) phenoxy-3,19-diol analogs of $\mathbf{6 a 8}$ and $\mathbf{6 b 8}$ possessed similar but weak inhibitory activities to E. faecalis, indicating that 14stereochemistry is not the key to their activity; meanwhile, their 3,19-acetonylidene protected analogs $5 \mathbf{a 8}$ and $\mathbf{5 b 8}$ were almost inactive. We compared the 14-(2'-carboxyl ester 4 '-nitro)phenoxy analogs $6 \mathbf{a 1}$ and $6 \mathbf{b 1}$ with the 14-(2'-carboxyl ester)phenoxy analogs $6 \mathbf{a 8}$ and $\mathbf{6 b 8}$; the results suggested that the $4^{\prime}$-nitro group enhanced antibacterial activity against $E$. faecalis. A similar inhibition tendency was observed for $4^{\prime}$-carboxyl ester 
Table 1 Antibacterial activities of the synthesized compounds against E. coli, S. aureus and E. faecalis ${ }^{a, b}$

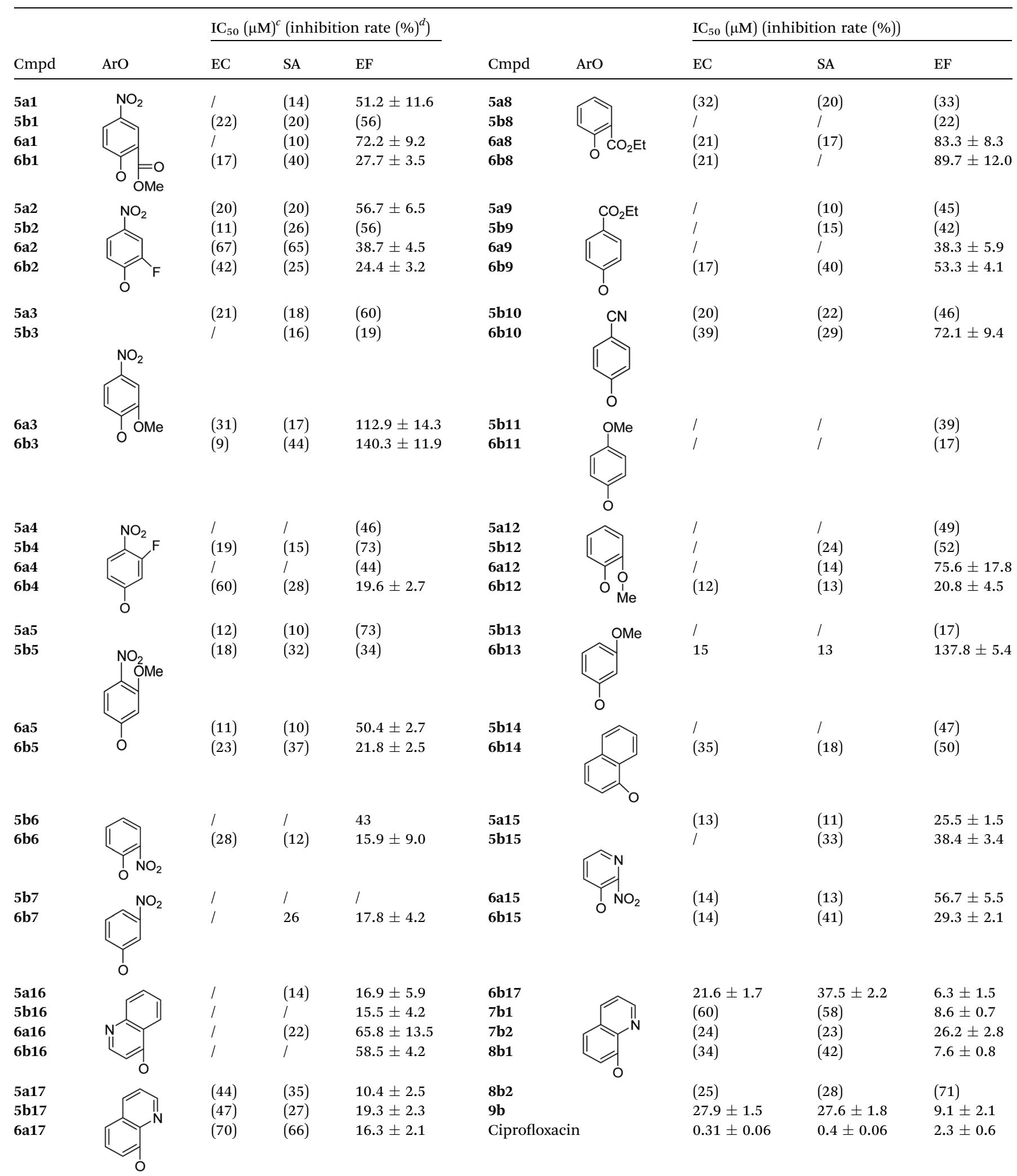

${ }^{a}$ EC: $E$. coli; SA: S. aureus; EF: E. faecalis. ${ }^{b}$ “"”represents no inhibition or lower than $10 \%$ inhibition rate at $250 \mu \mathrm{M}$ of tested compound. ${ }^{c}$ IC $_{50}$ value was generated when the inhibition rate at $250 \mu \mathrm{M}$ of the tested compound was higher than $80 \%{ }^{d}$ The inhibition rate at $250 \mu \mathrm{M}$ of the tested compound is indicated in parentheses. 
phenoxy analogs, where the 4 -carboxyl ester phenoxy-3,19-diol analogs of $6 \mathbf{a 9}$ and $6 \mathbf{b 9}$ exhibited weak activity against E. faecalis, whereas $14 \alpha$-isomer 6 a9 was slightly more active than $14 \beta$-isomer $6 \mathbf{b 9}$ against $E$. faecalis. However, the 4 '-carboxyl ester phenoxy analogs $6 \mathbf{9 9}$ and $6 \mathbf{b 9}$ were more active against E. faecalis than the 2 -carboxyl ester phenoxy counterparts $6 \mathbf{6 8}$ and 6b8. Introduction of a cyano (CN) EWG at the $4^{\prime}$-position did not improve the antibacterial activity, and only $14 \beta$-isomer 6b10 showed very weak activity against E. faecalis. As above, all of these analogs were very weakly active or inactive against E. coli and $S$. aureus.

On the other hand, OMe as an EDG occupying the $2^{\prime}-, 3^{\prime}$ - or $4^{\prime}$-position afforded different results. $4^{\prime}$-OMe derivatives $5 \mathbf{b 1 1}$ and $6 \mathbf{b 1 1}$ showed very weak activity against $E$. faecalis and no antibacterial activity against $E$. coli and $S$. aureus; it is possible that $4^{\prime}$-EDG substitution was not as beneficial to antibacterial activity as $4^{\prime}$-EWG substitution, according to the comparison of $4^{\prime}$-OMe derivatives $5 \mathbf{b 1 1}$ and $\mathbf{6 b 1 1}$ with the $4^{\prime}-\mathrm{CO}_{2}$ Et and $4^{\prime}-\mathrm{CN}$ derivatives 6a9, $6 \mathrm{b9}$ and 6b10. $14 \beta-\left(3^{\prime}-\mathrm{OMe}\right)$ derivative $6 \mathrm{~b} 13$ was very weakly active, while its corresponding $14 \beta-\left(3^{\prime}\right.$-OMe- $4^{\prime}$-nitro $)$ analog $6 \mathbf{b 5}$ possessed mild inhibitory activity toward $E$. faecalis, indicating that the $4^{\prime}$-nitro group enhanced the inhibitory activity toward $E$. faecalis. $14 \alpha-2^{\prime}$-OMe-3,19-diol derivative $\mathbf{6 a 1 2}$ was weakly active against $E$. faecalis and 6 b12 (14 $\beta$ ) showed mild inhibitory activity toward E. faecalis, suggesting that the $14 \beta$ isomer is more stereochemically active for antibacterial activity. Meanwhile, the $4^{\prime}$-nitro group negatively influenced inhibitory activity toward E. faecalis; $6 \mathbf{a 1 2}$ and $\mathbf{6 b 1 2}$ were more active against $E$. faecalis than corresponding the $4^{\prime}$-nitro analogs $6 \mathbf{3} 3$ and $\mathbf{6 b 3}$, respectively.

Based on the above data, further exploration to introduce more complex aryl groups at the 14-position were conducted. $14 \beta$-(1'-Naphthyloxy) compound $\mathbf{5 b 1 4}$ exhibited very weak inhibitory activity only to E. faecalis, and $14 \beta-\left(1^{\prime}\right.$-naphthyloxy) diol compound $\mathbf{6 b 1 4}$ expressed very weak activity against all three bacteria. Interestingly, the introduction of a 2 '-nitropyridinyl-3-oxy group at the 14-position increased the activity of all four derivatives 5a15, 5b15, $6 \mathbf{a 1 5}$ and $6 \mathbf{b 1 5}$ against $E$. faecalis; 14 $\alpha$-3,19-acetonylidene analog $\mathbf{5 a 1 5}$ was the most active, while $14 \alpha-3,19$-diol analog $6 \mathbf{a 1 5}$ was the least active. Moreover, $5 \mathbf{b 1 5}$ was more active than its corresponding $2^{\prime}$-nitro phenoxy derivative 5b6, but $\mathbf{6 b 1 5}$ was less active than $2^{\prime}$-nitro phenoxy analog 6b6. Corresponding to the replacement of phenoxy groups with pyridinyloxy groups, substitution of naphthyloxy by quinolinyloxy was subsequently studied. Unlike $14 \beta$-(1'-naphthyloxy) analogs $5 \mathbf{b 1 4}$ and $6 \mathbf{b 1 4}$, four analogs of 14(4'-quinolinyloxy) derivatives $5 \mathbf{a 1 6}$ ( $\operatorname{clog} P$ 6.8988), 5 b16 (clog $P$ 6.8988), $6 \mathbf{a 1 6}$ ( $\operatorname{clog} P 4.8578)$ and $6 \mathbf{b 1 6}(\operatorname{clog} P$ 4.8578) expressed antibacterial activity against $E$. faecalis; however, none of these was active against $E$. coli, and two $14 \alpha$-isomers, $5 \mathbf{a 1 6}$ and 6a16, were very weak inhibitors of $S$. aureus. The $\operatorname{clog} P$ values of 3,19protected compounds $5 \mathbf{a 1 6}$ and $5 \mathrm{~b} 16$ were higher than 5.0 and higher than those of $6 \mathbf{a 1 6}$ and 6b16; $5 \mathrm{a16}$ and $5 \mathrm{b16}$ were more active against $E$. faecalis than the corresponding 3,19-diol compounds $6 \mathbf{a 1 6}$ and 6b16, respectively. Unlike the activity relationships between 5a15, 5b15, 6a15 and 6b15, the activity variation patterns against E. faecalis of $5 \mathbf{a 1 6}$ and 5 b16 were parallel to those of $\mathbf{6 a 1 6}$ and $\mathbf{6 b 1 6}$ and $14 \beta$-isomers $5 \mathrm{a} 16$ and 6a16 were slightly more active than $14 \alpha$-isomers 5 b16 and 6b16, respectively. These data imply that a positive charge of nitrogen in the 14-aryloxy group under physiological conditions may play a role in antibacterial activity for the substitutions of phenoxy groups by pyridinyloxy groups and of naphthyloxy groups by quinolinyloxy groups.

Continued exploration in the quinolinyloxy line disclosed that 14 -( 8 -quinolinyloxy) derivatives exhibited novel antibacterial activity profiles. In contrast to the 14 -( $4^{\prime}$-quinolinyloxy) derivatives, the 14 - $\left(8^{\prime}\right.$-quinolinyloxy $)$ derivatives were active against all three bacteria; they also showed more selective inhibition of E. faecalis than of E. coli or $S$. aureus, similar to the other series of 14-aryloxy andrographolide derivatives in this work. Specifically, 14 $\alpha-3,19$-acetonylidene compound $\mathbf{5 a 1 7}$ $(\operatorname{cog} P$ 6.77355) was more active against $E$. faecalis than $14 \alpha-$ 3,19-diol compound $6 a 17$ ( $\operatorname{cog} P$ 4.73255), while $14 \beta$-3,19-acetonylidene compound $\mathbf{5 b 1 7}$ ( $\operatorname{cog} P$ 6.77355) was less active against $E$. faecalis than 14ß-3,19-diol compound 6 b17 (clog $P$ 4.73255); this activity pattern against E. faecalis is the same as that of 14-(2'-nitro-pyridinyl-3-oxy) derivatives 5a15, 5b15, $6 \mathbf{a 1 5}$ and 6b15. Importantly, $6 \mathbf{b 1 7}$ expressed good antibacterial activity against all three bacteria (Table 1 ) and was the most potent inhibitor of $E$. faecalis in this paper (Table 1). These data illustrate that the 14 - $\left(8^{\prime}\right.$-quinolinyloxy) compounds showed superior results against all three bacteria compared to their corresponding 14-(4'-quinolinyloxy) compounds. 19-Acetylated 7 b1 (clog $P$ 5.64055) and its 3-ketone 8 b1 ( $\log P$ 5.37725) had almost no inhibitory activity toward $E$. coli and $S$. aureus but were still very active against E. faecalis. However, 19-silylated $7 \mathbf{b 2}$ (clog $P$ 8.10955) had decreased inhibitory activity toward all three bacteria and possessed only mild activity against $E$. faecalis, while the antibacterial activity of 3-ketone $8 \mathbf{b 2}(\operatorname{clog} P$ 7.85675) was very weak against all three bacteria. It is interesting that 3-keto-19-alcohol compound 9b ( $\log P$ 4.47495) regained the same antibacterial activity against all three bacteria (Table 1) as 6b17, although its inhibitory activity toward E. faecalis was slightly less potent than that of $6 \mathbf{b 1 7}$. By combining these data, it is suggested that in addition to the importance of the andrographolide skeleton, the 14 -( $8^{\prime}$-quinolinyloxy) group is essential to antibacterial activity; moreover, modifications at the 3-or/and 19-positions are not ignorable, and 19-acetylation greatly reduced inhibitory activity to $E$. coli and $S$. aureus while transformation of 3-alcohols into 3-ketones slightly influenced the antibacterial activity.

\subsection{Inhibition of innate immune response and SAR analysis}

Considering that initiation of a dysregulated immune response within the intestinal mucosa by "self" gut flora and/or food is due to immune defects in IBD, reduction of over-immunity is an effective treatment of IBD. ${ }^{3,30}$ TNF- $\alpha$, the best studied NF- $\kappa$ B activator, is correlated with transformation of NF- $\kappa \mathrm{B}$ by various stimuli from its inactive form to its active form. TLRs are involved in the regulation of innate and adaptive immunity, ${ }^{31}$ and LPS-activated TLR4 regulates the expression and nucleus translocation of NF- $\kappa \mathrm{B} .{ }^{32}$ IL-6 is a crucial pathogenic mediator 
in IBD that functions by triggering cellular effects and functions via STAT3 signaling. The proinflammatory IL-6/STAT3dependent biological network is upregulated in active IBD patients and is considered to be an important pathogenic factor in IBD onset ${ }^{33}$ and progression. ${ }^{34}$ Based on these facts, immunosuppressants, corticosteroids and anti-TNF- $\alpha$ antibodies have become commonly used drugs in IBD treatment; they may affect IBD progression by interfering with cellular oxidative stress and cytokine production. ${ }^{35}$

We utilized luciferase reporters bearing the promoter regions of TNF- $\alpha / \mathrm{NF}-\kappa \mathrm{B}$, TLR4/NF- $\mathrm{B}$, and IL-6/STAT3 (ref. 25) to examine the activities of the antibacterial active andrographolide analogs in the regulation of signaling pathways that govern inflammatory response (Table 2). It was noted that these derivatives did not show obvious cytotoxicity to AD-293 cells; DCB-3503 was used as a positive compound ${ }^{36}$ (Table 2). Our previous study revealed that compound $\mathbf{6 b 3}$ is active against the TNF- $\alpha / N F-\kappa B$ and TLR4/NF- $\kappa$ B signaling pathways; ${ }^{25}$ however, $6 \mathbf{b 3}$ does not have antibacterial activity (Table 1). 14 $\alpha$ Compounds 5a17 and $\mathbf{6 a 1 7}$ are active against the IL-6/STAT3 signaling pathway but do not inhibit the NF- $\kappa \mathrm{B}$ signaling pathways. 14 $\beta$-Compounds $5 \mathbf{b 1 7}$ and $\mathbf{6 b 1 7}$ are active to suppress the three signaling pathways (Table 2), suggesting that 3,19-acetonylidene does not obviously affect the inhibition of these signaling pathways; although the feature of 3,19-acetonylidene may contribute to the distinct activities of $5 \mathbf{b 1 7}$ and $\mathbf{6 b 1 7}$ against $E$. faecalis, $\mathbf{6 b 1 7}$ is also 3 times more active than $5 \mathbf{b 1 7}$ against $E$. faecalis. Compounds $7 \mathbf{b} \mathbf{1}$ and $\mathbf{8 b 1}$ possess similar inhibitory activities to E. faecalis; however, 3-alcohol-19acetylated compound $7 \mathbf{b} 1$ shows selective anti-TNF- $\alpha / \mathrm{NF}-\kappa \mathrm{B}$ activity, while 3-keto-19-acetylated compound $\mathbf{8 b 1}$ is selectively active against the TLR4/NF- $\mathrm{B}$ signaling pathway. Like their similarity in inhibitory activity against E. faecalis, E. coli and $S$. aureus (Table 1), 3-keto-19-alcohol compound 9b1 suppresses three signaling pathways in the same fashion as $\mathbf{6 b 1 7}$ (Table 2). These interesting data suggest that dual-functional analogs of andrographolide can behave as antibacterial and immunosuppressant agents and possibly have synergistic effects in IBD treatment.

\section{Conclusion}

Bacterial infections have long been regarded as a formidable enemy of mankind. Bacterial pathogens dramatically affect the normal function of host cells, including immune response, for their own benefit during infection; eventually, they destroy or damage host cells. As reconstitution of gut flora balance and correction of immune defects are two important strategies for IBD treatment, we attempted to discover dual-functional andrographolide analogs for use as antibacterial and immunosuppressant agents that could synergize ultimate efficacy.

In this study, 14-aryloxy andrographolide derivatives were designed, synthesized and tested against the growth of E. coli, $S$. aureus and E. faecalis. Preliminary data suggest that the andrographolide skeleton is primarily more selective against $E$. faecalis; modifications at the 3- or/and 19-positions are not ignorable; the 14-aryloxy moiety strongly determines essential efficacy against bacteria growth; $14 \alpha$ - and $14 \beta$-isomers exhibit different antibacterial activities; and the substitution positions at the phenoxy groups and the structural features of the substitution groups may alter the inhibitory activities of the compounds. The current data imply that nitrogen-containing 14-aryloxy arenes may play an enhanced role in antibacterial activity upon the substitution of phenoxy groups by pyridinyloxy groups and of naphthyloxy groups by quinolinyloxy groups, suggesting the possibility that the nitrogen of the arene group is charged under physiological conditions. Moreover, it was revealed that the 14 - $\left(8^{\prime}\right.$-quinolinyloxy $)$ group is an important pharmacophore for antibacterial activity and that $14 \beta-\left(8^{\prime}\right.$-quinolinyloxy) andrographolide derivatives exhibit superb inhibitory activity toward E. faecalis. Importantly, andrographolide analogs with antibacterial activities also possess immunosuppressant activities against the IL-6/STAT3, TLR4/NF- $\mathrm{B}$ and/or TNF- $\alpha / N F-\kappa B$ signaling pathways, enabling us to conclude that dual functional andrographolide analogs can play synergistic roles in IBD treatment.

The results of this study suggest that the development of andrographloide analogs as antibacterial and immunosuppressant agents is possible. Further discovery of more potent

Table $2 \mathrm{EC}_{50}$ (half effective concentration) values of the antibacterially active compounds against the IL- $6 / \mathrm{STAT3}, \mathrm{TLR} 4 / \mathrm{NF}-\kappa \mathrm{B}$, and TNF- $\alpha / \mathrm{NF}-$ $\kappa B$ signaling pathways and cytotoxicities $\left(C_{50}\right.$, half cytotoxic concentration) in AD-293 cells

\begin{tabular}{|c|c|c|c|c|c|}
\hline \multirow[b]{2}{*}{ Entry } & \multirow[b]{2}{*}{ Cmpd } & \multicolumn{3}{|l|}{$\mathrm{EC}_{50}(\mu \mathrm{M})$} & \multirow[b]{2}{*}{$\mathrm{CC}_{50}^{c}(\mu \mathrm{M})$} \\
\hline & & IL-6/STAT3 $^{a}$ & TLR4/NF- $\mathrm{KB}^{a}$ & TNF- $\alpha / \mathrm{NF}-\kappa \mathrm{B}^{b}$ & \\
\hline 1 & 1 & $>10$ & $>10$ & $>10$ & $>10$ \\
\hline 2 & $6 b 3$ (ref. 25) & $>10$ & $3.49 \pm 0.34$ & $8.97 \pm 1.03$ & $>10$ \\
\hline 3 & $5 a 17$ & $4.71 \pm 0.17$ & $>10$ & $>10$ & $>10$ \\
\hline 4 & $5 b 17$ & $6.35 \pm 0.77$ & $2.85 \pm 0.07$ & $2.45 \pm 0.49$ & $>10$ \\
\hline 5 & $6 \mathbf{a 1 7}$ & $5.62 \pm 0.13$ & $>10$ & $>10$ & $>10$ \\
\hline 6 & $6 b 17$ & $2.41 \pm 0.31$ & $2.65 \pm 0.07$ & $2.00 \pm 0.28$ & $>10$ \\
\hline 7 & $7 \mathbf{b} 1$ & $>10$ & $>10$ & $4.91 \pm 0.02$ & $>10$ \\
\hline 8 & $8 b 1$ & $>10$ & $4.84 \pm 0.31$ & $>10$ & $>10$ \\
\hline 9 & $9 b$ & $6.13 \pm 0.39$ & $5.96 \pm 0.03$ & $2.03 \pm 0.01$ & $>10$ \\
\hline 10 & DCB-3503 (ref. 36) & $-^{d}$ & - & - & $1.83 \pm 0.39$ \\
\hline
\end{tabular}

${ }^{a}$ Treated for 16 h. ${ }^{b}$ Treated for 4 h. ${ }^{c}$ Treated for 24 h. ${ }^{d}$ Not applicable. 
structural cores, structural tuning of the 14-aryloxy substitutions and modifications at other positions are underway on the basis of these findings.

\section{Materials and methods}

\subsection{General information for chemistry}

${ }^{1} \mathrm{H}$ and ${ }^{13} \mathrm{C}$ NMR spectra were recorded on a Bruker AV-400 spectrometer at 400 and $100 \mathrm{MHz}$, respectively, in $\mathrm{CD}_{3} \mathrm{Cl}$, $\mathrm{CD}_{3} \mathrm{OD},\left(\mathrm{CD}_{3}\right)_{2} \mathrm{SO}$ and $\mathrm{C}_{6} \mathrm{D}_{6}$ as indicated. Coupling constants $(J)$ are expressed in hertz $(\mathrm{Hz})$. Chemical shifts $(\delta)$ of NMR are reported in parts per million (ppm) units relative to the solvent. High resolution ESI-MS spectra were recorded on an Applied Biosystems Q-STAR Elite ESI-LC-MS/MS mass spectrometer. Unless otherwise noted, materials were obtained from commercial suppliers and were used without further purification. Melting points were measured using a YRT-3 melting point apparatus (Shanghai, China) and were uncorrected.

\subsection{The preparation and characterization of $2,3 \mathrm{a}, 3 \mathrm{~b}, 4$ and $5 \mathrm{a} 1,5 \mathrm{~b} 1,6 \mathrm{a} 1$ and $6 \mathrm{~b} 1$ were modified from our previous papers $^{25,26}$}

\subsubsection{Preparation of compounds $5 a$ and $5 b$}

General method for synthesis of $\mathbf{5 a}$ and $\mathbf{5 b}$. Under $\mathrm{N}_{2}$ atmosphere and at $0{ }^{\circ} \mathrm{C}, 0.5 \mathrm{~g}(1.28 \mathrm{mmol}) 3 \mathbf{a}$ or $3 \mathbf{b}$, assorted phenols (1.92 $\mathrm{mmol})$ and $0.5 \mathrm{~g} \mathrm{PPh}_{3}(1.92 \mathrm{mmol})$ were dissolved in $8.0 \mathrm{~mL}$ anhydrous THF. To the above mixture, a solution of $0.39 \mathrm{~g}$ (1.92 mmol) diisopropyl azodiformate (DIAD) in $2.0 \mathrm{~mL}$ anhydrous THF was added dropwise in $5 \mathrm{~min}$, and the reaction progress was monitored by TLC. After the reaction was complete, the reaction mixture was treated with ethyl acetate and sol. sat. $\mathrm{NaHCO}_{3}$. The organic phase was washed with brine and dried over anhydrous $\mathrm{Na}_{2} \mathrm{SO}_{4}$. The residue was filtered, dried and subjected to silica gel chromatography using petroleum ether and ethyl acetate to yield product $\mathbf{5 b}$ or $\mathbf{5 a}$.

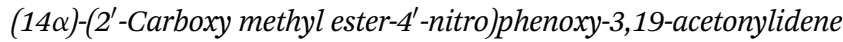
andrographolide (5a1). White solid; $\mathrm{mp} 77.3{ }^{\circ} \mathrm{C}$ to $78.4{ }^{\circ} \mathrm{C} ; 51 \%$ yield; ${ }^{1} \mathrm{H}$ NMR (400 MHz, $\left.\mathrm{C}_{6} \mathrm{D}_{6}\right) \delta 8.52(\mathrm{~d}, J=2.9 \mathrm{~Hz}, 1 \mathrm{H}), 7.75$ (dd, $J=9.1,2.9 \mathrm{~Hz}, 1 \mathrm{H}), 7.27-7.22(\mathrm{~m}, 1 \mathrm{H}), 5.79(\mathrm{~d}, J=9.1 \mathrm{~Hz}, 1 \mathrm{H}), 4.87$ $(\mathrm{s}, 1 \mathrm{H}), 4.81(\mathrm{~d}, J=5.7 \mathrm{~Hz}, 1 \mathrm{H}), 4.61(\mathrm{~s}, 1 \mathrm{H}), 3.79(\mathrm{~d}, J=11.6 \mathrm{~Hz}$, $1 \mathrm{H}), 3.73(\mathrm{dd}, J=10.7,6.1 \mathrm{~Hz}, 1 \mathrm{H}), 3.66(\mathrm{dd}, J=10.7,2.6 \mathrm{~Hz}, 1 \mathrm{H})$, $3.45(\mathrm{dd}, J=7.4,3.3 \mathrm{~Hz}, 1 \mathrm{H}), 3.39(\mathrm{~s}, 3 \mathrm{H}), 3.06(\mathrm{~d}, J=11.6 \mathrm{~Hz}, 1 \mathrm{H})$, $2.51(\mathrm{~m}, 1 \mathrm{H}), 2.27-2.16(\mathrm{~m}, 2 \mathrm{H}), 1.89-1.79$ (m, 1H), 1.79-1.69 (m, $1 \mathrm{H}), 1.62-1.47(\mathrm{~m}, 3 \mathrm{H}), 1.39$ (s, 3H), 1.31 (s, 3H), 1.09 (s, 3H), 1.05$0.96(\mathrm{~m}, 2 \mathrm{H}), 0.94$ (dd, $J=6.4,5.0 \mathrm{~Hz}, 1 \mathrm{H}), 0.89$ (s, 3H), 0.86-0.82 $(\mathrm{m}, 1 \mathrm{H}) ;{ }^{13} \mathrm{C} \mathrm{NMR}\left(101 \mathrm{MHz},\left(\mathrm{CD}_{3}\right)_{2} \mathrm{SO}\right) \delta 169.2,164.5,160.7,151.6$, 148.1, 141.3, 129.3, 127.2, 124.8, 122.1, 116.0, 109.0, 98.6, 76.2, 73.4, 70.9, 63.2, 55.3, 53.0, 51.8, 38.3, 37.6, 37.4, 34.4, 27.9, 26.2, 25.6, 25.2, 25.1, 23.0, 16.0; ESI-HRMS: $m / z 592.2525[\mathrm{M}+\mathrm{Na}]^{+}$, calcd for $\mathrm{C}_{31} \mathrm{H}_{39} \mathrm{NNaO}_{9}, 592.2523$.

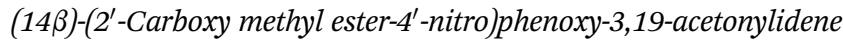
andrographolide (5b1). White solid; mp $104{ }^{\circ} \mathrm{C}$ to $106{ }^{\circ} \mathrm{C} ; 82 \%$ yield; ${ }^{1} \mathrm{H}$ NMR (400 MHz, $\left.\mathrm{C}_{6} \mathrm{D}_{6}\right) \delta 8.57$ (d, $\left.J=2.9 \mathrm{~Hz}, 1 \mathrm{H}\right), 7.74$ (dd, $J=9.1,2.9 \mathrm{~Hz}, 1 \mathrm{H}), 7.25(\mathrm{t}, J=6.2 \mathrm{~Hz}, 1 \mathrm{H}), 5.71(\mathrm{~d}, J=9.1 \mathrm{~Hz}, 1 \mathrm{H})$, $4.86(\mathrm{~s}, 1 \mathrm{H}), 4.80(\mathrm{~s}, 1 \mathrm{H}), 4.42(\mathrm{~s}, 1 \mathrm{H}), 3.78(\mathrm{~d}, J=11.5 \mathrm{~Hz}, 1 \mathrm{H}), 3.62$ (m, 2H), 3.43 (dd, $J=7.1,3.2 \mathrm{~Hz}, 1 \mathrm{H}), 3.35$ (s, 3H), 3.06 (d, $J=$
$11.5 \mathrm{~Hz}, 1 \mathrm{H}), 2.41$ (dd, $J=16.5,5.5 \mathrm{~Hz}, 1 \mathrm{H}), 2.26-2.14(\mathrm{~m}, 2 \mathrm{H})$, 1.78-1.67 (m, 2H), 1.59 (d, $J=10.8 \mathrm{~Hz}, 1 \mathrm{H}), 1.53-1.43(\mathrm{~m}, 2 \mathrm{H}), 1.38$ (s, 3H), 1.33 (s, 3H), 1.08 (s, 3H), $1.00(\mathrm{~m}, 2 \mathrm{H}), 0.94(\mathrm{~d}, J=2.1 \mathrm{~Hz}$, $1 \mathrm{H}), 0.91(\mathrm{~s}, 3 \mathrm{H}), 0.87-0.83(\mathrm{~m}, 1 \mathrm{H}) ;{ }^{13} \mathrm{C} \mathrm{NMR}\left(101 \mathrm{MHz}, \mathrm{C}_{6} \mathrm{D}_{6}\right)$ $\delta 167.90,163.40,160.05,151.64,148.46,141.78,128.31,127.80$, 124.20, 122.34, 114.01, 107.81, 99.48, 74.86, 73.23, 69.52, 64.21, 55.71, 51.99, 50.77, 38.37, 38.25, 37.61, 33.40, 26.17, 26.10, 25.89, 25.06, 24.41, 23.20, 16.70; ESI-HRMS: $m / z$ 592.2523 [M + Na $]^{+}$, calcd for $\mathrm{C}_{31} \mathrm{H}_{39} \mathrm{NNaO}_{9}, 592.2515$.

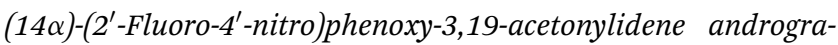
pholide (5a2). White solid; mp $147{ }^{\circ} \mathrm{C}$ to $149{ }^{\circ} \mathrm{C} ; 47 \%$ yield; ${ }^{1} \mathrm{H}$ NMR (400 MHz, $\left.\left(\mathrm{CD}_{3}\right)_{2} \mathrm{SO}\right) \delta 8.26(\mathrm{dd}, J=10.9,2.7 \mathrm{~Hz}, 1 \mathrm{H}), 8.16$ $(\mathrm{m}, 1 \mathrm{H}), 7.48(\mathrm{t}, J=8.8 \mathrm{~Hz}, 1 \mathrm{H}), 6.97(\mathrm{t}, J=6.3 \mathrm{~Hz}, 1 \mathrm{H}), 6.07(\mathrm{~d}, J$ $=5.2 \mathrm{~Hz}, 1 \mathrm{H}), 4.83(\mathrm{~s}, 1 \mathrm{H}), 4.74(\mathrm{dd}, J=11.1,5.5 \mathrm{~Hz}, 1 \mathrm{H}), 4.59(\mathrm{~s}$, $1 \mathrm{H}), 4.45(\mathrm{dd}, J=11.1,1.0 \mathrm{~Hz}, 1 \mathrm{H}), 3.82(\mathrm{~d}, J=11.6 \mathrm{~Hz}, 1 \mathrm{H}), 3.36$ (dd, $J=9.2,4.2 \mathrm{~Hz}, 1 \mathrm{H}), 3.07$ (d, $J=11.6 \mathrm{~Hz}, 1 \mathrm{H}), 2.47-2.36(\mathrm{~m}$, $2 \mathrm{H}), 2.33$ (dd, $J=10.3,2.8 \mathrm{~Hz}, 1 \mathrm{H}), 2.03-1.91$ (m, 2H), 1.89-1.77 (m, 1H), 1.69-1.55 (m, 2H), 1.54-1.45 (m, 1H), 1.28 (s, 3H), 1.25$1.20(\mathrm{~m}, 2 \mathrm{H}), 1.23(\mathrm{~s}, 3 \mathrm{H}), 1.10(\mathrm{~s}, 3 \mathrm{H}), 0.86-0.80(\mathrm{~m}, 1 \mathrm{H}), 0.76(\mathrm{~s}$, $3 \mathrm{H}) ;{ }^{13} \mathrm{C}$ NMR $\left(101 \mathrm{MHz},\left(\mathrm{CD}_{3}\right)_{2} \mathrm{SO}\right) \delta 168.64,152.23,151.34$, $150.40,150.30,149.76,147.60,141.15,141.07,124.19,121.28$, $121.25,115.75,112.68,112.45,108.54,98.15,75.65,73.01$, $70.35,62.74,54.93,51.35,37.85,37.14,36.96,33.83,27.35$, 25.73, 25.13, 24.96, 24.69, 22.59, 15.59; ESI-HRMS: $m / z$ 552.2374 $[\mathrm{M}+\mathrm{Na}]^{+}$, calcd for $\mathrm{C}_{29} \mathrm{H}_{36} \mathrm{FNNaO}_{7}, 552.2368$.

(14ß)-(2'-Fluoro-4'-nitro)phenoxy-3,19-acetonylidene andrographolide (5b2). White solid; mp $114{ }^{\circ} \mathrm{C}$ to $117{ }^{\circ} \mathrm{C} ; 72 \%$ yield; ${ }^{1} \mathrm{H}$ NMR (400 MHz, $\left.\mathrm{C}_{6} \mathrm{D}_{6}\right) \delta 7.57(\mathrm{dd}, J=10.6,2.6 \mathrm{~Hz}, 1 \mathrm{H}), 7.47(\mathrm{~m}$, $1 \mathrm{H}), 7.24-7.19(\mathrm{~m}, 1 \mathrm{H}), 5.76(\mathrm{~m}, 1 \mathrm{H}), 4.84(\mathrm{~d}, J=1.8 \mathrm{~Hz}, 1 \mathrm{H})$, $4.71(\mathrm{~d}, J=5.1 \mathrm{~Hz}, 1 \mathrm{H}), 4.40(\mathrm{~d}, J=1.7 \mathrm{~Hz}, 1 \mathrm{H}), 3.78(\mathrm{~d}, J=$ $11.6 \mathrm{~Hz}, 1 \mathrm{H}), 3.64-3.51$ (m, 2H), $3.44(\mathrm{dd}, J=7.0,3.5 \mathrm{~Hz}, 1 \mathrm{H})$, $3.06(\mathrm{~d}, J=11.5 \mathrm{~Hz}, 1 \mathrm{H}), 2.27-2.09(\mathrm{~m}, 3 \mathrm{H}), 1.80-1.61(\mathrm{~m}, 2 \mathrm{H})$, 1.56-1.44 (m, 2H), 1.40 (s, 3H), 1.34 (s, 3H), 1.27-1.35 (m, 2H), $1.06(\mathrm{~s}, 3 \mathrm{H}), 0.97(\mathrm{td}, J=14.7,13.8,5.4 \mathrm{~Hz}, 2 \mathrm{H}), 0.89(\mathrm{~s}, 3 \mathrm{H})$, 0.87-0.90 (m, 1H); ${ }^{13} \mathrm{C}$ NMR (101 MHz, $\left.\mathrm{C}_{6} \mathrm{D}_{6}\right) \delta 167.99,167.81$, 153.15, 151.64, 151.49, 150.64, 149.80, 149.70, 148.26, 142.41, 142.34, 124.26, 120.68, 115.14, 113.08, 112.85, 107.85, 99.62, $74.78,73.52,69.61,64.32,55.55,50.74,38.40,38.35,37.62$, 33.33, 26.12, 25.93, 25.12, 24.35, 23.24, 16.78; ESI-HRMS: $\mathrm{m} / \mathrm{z}$ $552.2374[\mathrm{M}+\mathrm{Na}]^{+}$, calcd for $\mathrm{C}_{29} \mathrm{H}_{36} \mathrm{FNNaO}_{7}, 552.2418$.

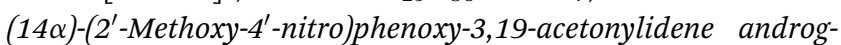
rapholide (5a3). ${ }^{25,26}$ Pale yellow solid; mp $121{ }^{\circ} \mathrm{C}$ to $123{ }^{\circ} \mathrm{C} ; 46 \%$ yield; ${ }^{1} \mathrm{HNMR}\left(400 \mathrm{MHz}, \mathrm{C}_{6} \mathrm{D}_{6}\right) \delta 7.56(\mathrm{dd}, J=8.8,2.4 \mathrm{~Hz}, 1 \mathrm{H})$, $7.45(\mathrm{~d}, J=2.5 \mathrm{~Hz}, 1 \mathrm{H}), 7.14-7.10(\mathrm{~m}, 1 \mathrm{H}), 6.07-5.99(\mathrm{~m}, 1 \mathrm{H})$, 4.90 (s, 1H), $4.82(\mathrm{~s}, 1 \mathrm{H}), 4.61(\mathrm{~s}, 1 \mathrm{H}), 3.85-3.76(\mathrm{~m}, 2 \mathrm{H}), 3.71$ (dd, $J=10.8,5.9 \mathrm{~Hz}, 1 \mathrm{H}), 3.46$ (dd, $J=7.5,3.7 \mathrm{~Hz}, 1 \mathrm{H}$ ), 3.11-3.03 (m, 4H), 2.41-2.24 (m, 1H), 2.22-2.05 (m, 2H), $1.85(\mathrm{~m}, 1 \mathrm{H})$, 1.79-1.67 (m, 1H), 1.62-1.52 (m, 1H), 1.62-1.52 (m, 1H), 1.52$1.46(\mathrm{~m}, 1 \mathrm{H}), 1.41(\mathrm{~s}, 3 \mathrm{H}), 1.36(\mathrm{~s}, 3 \mathrm{H}), 1.32(\mathrm{~m}, 1 \mathrm{H}), 1.08(\mathrm{~s}, 3 \mathrm{H})$, 1.04-0.89 (m, 3H), $0.81(\mathrm{~s}, 3 \mathrm{H}) ;{ }^{13} \mathrm{C}$ NMR (101 MHz, $\left.\mathrm{C}_{6} \mathrm{D}_{6}\right)$ $\delta 168.17,151.11,150.60,147.17,143.51,124.80,116.98,115.61$, 109.33, 107.40, 99.44, 75.17, 73.37, 69.90, 64.12, 55.82, 55.21, 51.25, 38.16, 38.04, 37.64, 34.06, 26.32, 26.01, 25.32, 25.20, 24.69, 23.16, 16.39; ESI-HRMS: $m / z$ 564.2569 [M + Na $]^{+}$, calcd for $\mathrm{C}_{30} \mathrm{H}_{39} \mathrm{NNaO}_{8}, 564.2573$.

(14ß)-(2'-Methoxy-4'-nitro)phenoxy-3,19-acetonylidene andrographolide (5b3). ${ }^{25,26}$ Pale yellow solid; mp $129{ }^{\circ} \mathrm{C}$ to $131{ }^{\circ} \mathrm{C} ; 51 \%$ 
yield; ${ }^{1} \mathrm{H}$ NMR $\left(400 \mathrm{MHz}, \mathrm{C}_{6} \mathrm{D}_{6}\right) \delta 7.56(\mathrm{dd}, J=8.8,2.6 \mathrm{~Hz}, 1 \mathrm{H})$, $7.46(\mathrm{~d}, J=2.6 \mathrm{~Hz}, 1 \mathrm{H}), 7.18(\mathrm{~d}, J=1.5 \mathrm{~Hz}, 1 \mathrm{H}), 5.95(\mathrm{~d}, J=$ $8.8 \mathrm{~Hz}, 1 \mathrm{H}), 4.90-4.86(\mathrm{~m}, 1 \mathrm{H}), 4.85-4.80$ (m, 1H), 4.39 (dd, $J=$ 1.9, $1.0 \mathrm{~Hz}, 1 \mathrm{H}), 3.82-3.74(\mathrm{~m}, 2 \mathrm{H}), 3.63-3.57$ (m, 2H), 3.41 (dd, $J$ $=7.3,3.6 \mathrm{~Hz}, 1 \mathrm{H}), 3.10-3.02(\mathrm{~m}, 1 \mathrm{H}), 3.06(\mathrm{~s}, 3 \mathrm{H}), 2.19-2.10(\mathrm{~m}$, $3 \mathrm{H})$, 1.77-1.60 (m, 2H), 1.52-1.44 (m, 1H), 1.44-1.37 (m, 1H), $1.40(\mathrm{~s}, 3 \mathrm{H}), 1.36(\mathrm{~s}, 3 \mathrm{H}), 1.34-1.25(\mathrm{~m}, 2 \mathrm{H}), 1.06(\mathrm{~s}, 3 \mathrm{H}), 0.99(\mathrm{~m}$, 1H), 0.94-0.80 (m, 3H), 0.85 (s, 3H); ${ }^{13} \mathrm{C} \mathrm{NMR} \mathrm{(101} \mathrm{MHz,} \mathrm{CDCl}_{3}$ ) $\delta 168.12,150.83,150.47,150.31,148.06,143.21,128.02,127.78$, $127.54,124.91,116.92,114.96,107.68,107.11,99.35,74.78$, $72.86,69.71,64.04,55.41,55.12,50.72,38.16,38.06,37.43$, 33.20, 26.08, 25.82, 25.55, 24.99, 24.32, 23.04, 16.44; ESI-HRMS: $m / z 564.2584[\mathrm{M}+\mathrm{Na}]^{+}$, calcd for $\mathrm{C}_{30} \mathrm{H}_{39} \mathrm{NNaO}_{8}, 564.2573$.

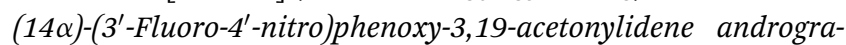
pholide (5a4). White solid; mp $137{ }^{\circ} \mathrm{C}$ to $139{ }^{\circ} \mathrm{C} ; 51 \%$ yield; ${ }^{1} \mathrm{H}$ NMR (400 MHz, $\left.\mathrm{C}_{6} \mathrm{D}_{6}\right) \delta 7.46(\mathrm{~m}, 1 \mathrm{H}), 6.34-6.26(\mathrm{~m}, 1 \mathrm{H}), 6.05(\mathrm{t}$, $J=7.9 \mathrm{~Hz}, 2 \mathrm{H}), 5.42(\mathrm{~s}, 1 \mathrm{H}), 5.12(\mathrm{~m}, 2 \mathrm{H}), 3.86(\mathrm{~d}, J=11.5 \mathrm{~Hz}$, $1 \mathrm{H}), 3.69(\mathrm{~m}, 2 \mathrm{H}), 3.50(\mathrm{dd}, J=7.0,3.2 \mathrm{~Hz}, 1 \mathrm{H}), 3.09$ (d, $J=$ $11.5 \mathrm{~Hz}, 1 \mathrm{H}), 2.32-2.22(\mathrm{~m}, 2 \mathrm{H}), 2.03-1.91$ (m, 2H), 1.86-1.64 (m, 4H), 1.43 (s, 3H), 1.41 (s, 3H), 1.50-1.32 (m, 2H), 1.11-1.06 $(\mathrm{m}, 2 \mathrm{H}), 1.04(\mathrm{~s}, 3 \mathrm{H}), 1.01(\mathrm{~s}, 3 \mathrm{H}) ;{ }^{13} \mathrm{C}$ NMR (101 MHz, $\left.\mathrm{C}_{6} \mathrm{D}_{6}\right)$ $\delta 171.37,163.02,162.91,158.53,155.89,147.16,145.92,133.57$, 131.56, 131.49, 128.03, 127.79, 110.42, 110.39, 109.14, 104.87, 104.63, 99.58, 74.86, 73.48, 69.98, 64.29, 52.30, 51.40, 38.39, $38.28,38.16$, 33.88, 30.73, 26.12, 25.86, 25.14, 24.56, 23.45, 16.99; ESI-HRMS: $m / z$ 552.2365 $[\mathrm{M}+\mathrm{Na}]^{+}$, calcd for $\mathrm{C}_{29} \mathrm{H}_{36}{ }^{-}$ $\mathrm{FNNaO}_{7}, 552.2374$.

(14ß)-(3'-Fluoro-4'-nitro)phenoxy-3,19-acetonylidene andrographolide (5b4). White solid; mp $184{ }^{\circ} \mathrm{C}$ to $187{ }^{\circ} \mathrm{C} ; 52 \%$ yield; ${ }^{1} \mathrm{H}$ NMR (400 MHz, $\left.\mathrm{C}_{6} \mathrm{D}_{6}\right) \delta 7.51(\mathrm{t}, J=8.9 \mathrm{~Hz}, 1 \mathrm{H}), 7.20(\mathrm{~d}, J=$ $1.6 \mathrm{~Hz}, 1 \mathrm{H}), 5.89-5.77(\mathrm{~m}, 2 \mathrm{H}), 4.86(\mathrm{~d}, J=1.1 \mathrm{~Hz}, 1 \mathrm{H}), 4.54-4.48$ $(\mathrm{m}, 1 \mathrm{H}), 4.41$ (d, $J=0.7 \mathrm{~Hz}, 1 \mathrm{H}), 3.76(\mathrm{~d}, J=11.5 \mathrm{~Hz}, 1 \mathrm{H}), 3.50$ (d, $J=3.8 \mathrm{~Hz}, 2 \mathrm{H}), 3.43(\mathrm{dd}, J=6.8,3.5 \mathrm{~Hz}, 1 \mathrm{H}), 3.06$ (d, $J=$ $11.5 \mathrm{~Hz}, 1 \mathrm{H}), 2.23-2.06$ (m, 3H), 1.76-1.63 (m, 2H), 1.48-1.35 $(\mathrm{m}, 2 \mathrm{H}), 1.38(\mathrm{~s}, 3 \mathrm{H}), 1.33(\mathrm{~s}, 3 \mathrm{H}), 1.34-1.27(\mathrm{~m}, 2 \mathrm{H}), 1.05(\mathrm{~d}, J=$ 4.6 Hz, 3H), 1.04-0.95 (m, 1H), 0.95-0.87 (m, 2H), 0.89 (s, 3H); ${ }^{13} \mathrm{C}$ NMR (101 MHz, $\left.\mathrm{C}_{6} \mathrm{D}_{6}\right) \delta 167.85,167.84,161.50,161.50$, $161.40,161.40,158.59$, 158.59, 155.95, 155.95, 151.01, 151.01, $148.11,148.11,132.01,131.94,131.94,124.20,124.20,111.06$, 111.06, 111.03, 111.03, 107.94, 107.94, 104.20, 104.20, 103.96, 103.96, 99.72, 99.72, 74.57, 74.57, 72.19, 72.19, 69.41, 69.41, $64.33,64.33,55.60,55.60,50.79,50.79,38.40,38.40,37.67$, $37.67,33.47$, 33.47, 25.97, 25.97, 25.93, 25.93, 25.07, 25.07, 24.25, 24.25, 23.21, 23.21, 16.82, 16.82; ESI-HRMS: $m / z 552.2415$ $[\mathrm{M}+\mathrm{Na}]^{+}$, calcd for $\mathrm{C}_{29} \mathrm{H}_{36} \mathrm{FNNaO}_{7}, 552.2374$.

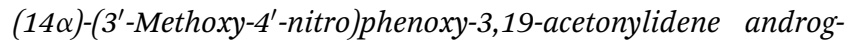
rapholide (5a5). White solid; mp $127{ }^{\circ} \mathrm{C}$ to $129{ }^{\circ} \mathrm{C} ; 41 \%$ yield; ${ }^{1} \mathrm{H}$ NMR $\left(400 \mathrm{MHz},\left(\mathrm{CD}_{3}\right)_{2} \mathrm{SO}\right) \delta 8.00(\mathrm{~d}, J=9.1 \mathrm{~Hz}, 1 \mathrm{H}), 6.98(\mathrm{dd}, J=$ $10.0,3.9 \mathrm{~Hz}, 1 \mathrm{H}), 6.86(\mathrm{~d}, J=2.4 \mathrm{~Hz}, 1 \mathrm{H}), 6.74(\mathrm{dd}, J=9.1$, $2.5 \mathrm{~Hz}, 1 \mathrm{H}), 6.03$ (d, $J=5.2 \mathrm{~Hz}, 1 \mathrm{H}), 4.87$ (s, 1H), 4.71 (dd, $J=$ 11.0, $5.5 \mathrm{~Hz}, 1 \mathrm{H}), 4.61(\mathrm{~s}, 1 \mathrm{H}), 4.36$ (dd, $J=11.0,0.9 \mathrm{~Hz}, 1 \mathrm{H})$, 3.93 (s, 3H), 3.83 (d, $J=11.7 \mathrm{~Hz}, 1 \mathrm{H}), 3.39-3.35(\mathrm{~m}, 1 \mathrm{H}), 3.08$ (d, $J=11.6 \mathrm{~Hz}, 1 \mathrm{H}), 2.47-2.30$ (m, 3H), 2.02-1.92 (m, 2H), 1.88-1.78 (m, 1H), 1.69-1.57 (m, 2H), 1.53-1.44 (m, 1H), 1.29 (s, 3H), 1.23 (s, 3H), 1.21-1.25 (m, 2H), 1.21-1.16 (m, 1H), 1.10 (s, 3H), 0.77 $(\mathrm{s}, 3 \mathrm{H}) ;{ }^{13} \mathrm{C} \mathrm{NMR}\left(101 \mathrm{MHz},\left(\mathrm{CD}_{3}\right)_{2} \mathrm{SO}\right) \delta 168.84,161.72,154.94$, 150.46 , 147.60, 133.08, 127.88, 124.70, 108.46, 106.86, 101.33,
98.16, 75.67, 71.68, 70.69, 62.73, 56.88, 54.95, 51.35, 37.92, $37.14,36.96,33.87,27.38,25.73,25.14,24.97,24.72$, 22.58, 15.60; ESI-HRMS: $\mathrm{m} / z \quad 564.2569[\mathrm{M}+\mathrm{Na}]^{+}$, calcd for $\mathrm{C}_{30} \mathrm{H}_{39} \mathrm{NNaO}_{8}, 564.2573$.

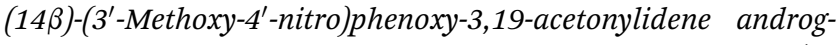
rapholide (5b5). White solid; $\mathrm{mp} 169{ }^{\circ} \mathrm{C}$ to $171{ }^{\circ} \mathrm{C} ; 75 \%$ yield; ${ }^{1} \mathrm{H}$ NMR (400 MHz, $\left.\mathrm{C}_{6} \mathrm{D}_{6}\right) \delta 7.60(\mathrm{~d}, J=9.0 \mathrm{~Hz}, 1 \mathrm{H}), 7.22(\mathrm{~m}, 1 \mathrm{H})$, $5.98(\mathrm{~d}, J=2.4 \mathrm{~Hz}, 1 \mathrm{H}), 5.54(\mathrm{dd}, J=9.0,2.5 \mathrm{~Hz}, 1 \mathrm{H}), 4.87$ (d, $J=$ $0.9 \mathrm{~Hz}, 1 \mathrm{H}), 4.76$ (d, J = 5.4 Hz, 1H), 4.45 (s, 1H), 3.80-3.69 (m, $2 \mathrm{H}), 3.63(\mathrm{~m}, 1 \mathrm{H}), 3.41(\mathrm{~m}, 1 \mathrm{H}), 3.09$ (s, 3H), $3.06(\mathrm{~m}, 1 \mathrm{H}), 2.30-$ $2.13(\mathrm{~m}, 3 \mathrm{H}), 1.70(\mathrm{~m}, 2 \mathrm{H}), 1.52(\mathrm{t}, J=8.6 \mathrm{~Hz}, 1 \mathrm{H}), 1.45-1.36(\mathrm{~m}$, $1 \mathrm{H}), 1.38(\mathrm{~s}, 3 \mathrm{H}), 1.35-1.28(\mathrm{~m}, 2 \mathrm{H}), 1.32(\mathrm{~s}, 3 \mathrm{H}), 1.06(\mathrm{~s}, 3 \mathrm{H})$, 1.04-0.96 (m, 1H), 0.95-0.90 (m, 1H), 0.98-0.82 (m, 1H), 0.87 (s, $3 \mathrm{H}) ;{ }^{13} \mathrm{C}$ NMR $\left(101 \mathrm{MHz}, \mathrm{C}_{6} \mathrm{D}_{6}\right) \delta 168.23,160.90,155.43,150.53$, 148.07, 134.84, 127.80, 124.84, 107.95, 104.43, 101.58, 99.50, $74.86,71.75,69.87,64.15,55.72,55.64,51.01,38.39,38.21$, $37.65,33.57,26.20,25.92,25.80,25.08,24.45,23.16$, 16.60; ESIHRMS: $m / z$ 564.2569 $[\mathrm{M}+\mathrm{Na}]^{+}$, calcd for $\mathrm{C}_{30} \mathrm{H}_{39} \mathrm{NNaO}_{8}$, 564.2573 .

(14ß)-(2'-Nitro)phenoxy-3,19-acetonylidene andrographolide (5b6). White solid; mp $146{ }^{\circ} \mathrm{C}$ to $148{ }^{\circ} \mathrm{C} ; 72 \%$ yield; ${ }^{1} \mathrm{H}$ NMR $(400 \mathrm{MHz}$, $\left.\mathrm{C}_{6} \mathrm{D}_{6}\right) \delta$ 7.32-7.25 (m, 1H), 7.24-7.18 (m, 2H), 6.77-6.65 (m, 1H), 6.42-6.30 (m, 1H), 6.06-5.92 (m, 1H), 4.93-4.80 (m, 2H), 4.42-4.35 $(\mathrm{m}, 1 \mathrm{H}), 3.82(\mathrm{~d}, J=11.5 \mathrm{~Hz}, 1 \mathrm{H}), 3.71-3.55(\mathrm{~m}, 2 \mathrm{H}), 3.45$ (dd, $J=$ 7.7, 3.3 Hz, 1H), 3.08 (d, $J=11.5 \mathrm{~Hz}, 1 \mathrm{H}), 2.40-2.29$ (m, 1H), 2.26$2.11(\mathrm{~m}, 2 \mathrm{H}), 1.86-1.67(\mathrm{~m}, 2 \mathrm{H}), 1.62-1.47(\mathrm{~m}, 3 \mathrm{H}), 1.42(\mathrm{~s}, 3 \mathrm{H})$, $1.36(\mathrm{~s}, 3 \mathrm{H}), 1.39-1.31(\mathrm{~m}, 1 \mathrm{H}), 1.12(\mathrm{~s}, 3 \mathrm{H}), 1.05-0.91(\mathrm{~m}, 3 \mathrm{H}), 0.87$ $(\mathrm{s}, 3 \mathrm{H}) ;{ }^{13} \mathrm{C} \mathrm{NMR}\left(101 \mathrm{MHz}, \mathrm{C}_{6} \mathrm{D}_{6}\right) \delta 168.02,168.02,161.21,151.64$, 149.29 , 149.29, 148.41, 141.55, 141.55, 133.24, 133.24, 128.28, 128.22 , 128.16, 128.04, 127.92, 127.80, 127.68, 125.77, 124.31, 121.71, 121.71, 115.78, 107.77, 99.27, 99.26, 99.26, 75.38, 73.27, 69.64, 64.11, 59.13, 55.72, 51.04, 38.39, 38.11, 37.63, 37.57, 33.61, 26.66, 25.93, 25.22, 24.72, 23.19, 16.49; ESI-HRMS: $m / z 534.2467$ $[\mathrm{M}+\mathrm{Na}]^{+}$, calcd for $\mathrm{C}_{29} \mathrm{H}_{37} \mathrm{NNaO}_{7}, 534.2468$.

(14ß)-(3'-Nitro)phenoxy-3,19-acetonylidene andrographolide (5b7). White solid; mp $163{ }^{\circ} \mathrm{C}$ to $165{ }^{\circ} \mathrm{C}$; $32 \%$ yield; ${ }^{1} \mathrm{H}$ NMR $(400 \mathrm{MHz}$, $\left.\mathrm{C}_{6} \mathrm{D}_{6}\right) \delta 7.51(\mathrm{~d}, J=7.1 \mathrm{~Hz}, 1 \mathrm{H}), 7.31(\mathrm{~d}, J=2.1 \mathrm{~Hz}, 1 \mathrm{H}), 7.20(\mathrm{~d}, J=$ $6.8 \mathrm{~Hz}, 2 \mathrm{H}), 6.62(\mathrm{t}, J=8.2 \mathrm{~Hz}, 1 \mathrm{H}), 6.52(\mathrm{dd}, J=8.3,1.8 \mathrm{~Hz}, 1 \mathrm{H})$, $4.85(\mathrm{~s}, 1 \mathrm{H}), 4.62(\mathrm{~d}, J=5.1 \mathrm{~Hz}, 1 \mathrm{H}), 4.43(\mathrm{~s}, 1 \mathrm{H}), 3.77$ (d, $J=$ $11.6 \mathrm{~Hz}, 1 \mathrm{H}$ ), 3.64 (dd, $J=10.8,1.8 \mathrm{~Hz}, 1 \mathrm{H}), 3.58$ (dd, $J=10.8$, $5.5 \mathrm{~Hz}, 1 \mathrm{H}), 3.41$ (dd, $J=7.1,3.5 \mathrm{~Hz}, 1 \mathrm{H}), 3.06(\mathrm{~d}, J=11.5 \mathrm{~Hz}, 1 \mathrm{H})$, 2.24-2.05 (m, 3H), 1.68 (m, 2H), 1.52-1.41 (m, 2H), 1.39 (s, 3H), $1.34(\mathrm{~s}, 3 \mathrm{H}), 1.30(\mathrm{~m}, 2 \mathrm{H}), 1.07$ (s, 3H), 1.04-0.94 (m, 1H), 0.94-0.89 $(\mathrm{m}, 1 \mathrm{H}), 0.87(\mathrm{~d}, J=5.9 \mathrm{~Hz}, 1 \mathrm{H}), 0.84(\mathrm{~s}, 3 \mathrm{H}) ;{ }^{13} \mathrm{C}$ NMR $(101 \mathrm{MHz}$, $\left.\mathrm{C}_{6} \mathrm{D}_{6}\right) \delta 168.13,157.06,150.18,149.49,147.85,130.36,128.16$, 127.92, 127.80, 127.68, 124.91, 122.22, 116.85, 109.17, 107.97, 99.46, 74.86, 71.83, 69.76, 64.15, 55.58, 50.96, 38.36, 38.22, 37.61, 33.51, 26.20, 25.90, 25.79, 25.07, 24.38, 23.14, 16.58; ESI-HRMS: $m$ / $z 534.2463[\mathrm{M}+\mathrm{Na}]^{+}$, calcd for $\mathrm{C}_{29} \mathrm{H}_{37} \mathrm{NNaO}_{7}, 534.2468$.

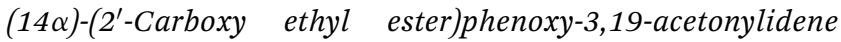
andrographolide (5as). White solid; mp $122{ }^{\circ} \mathrm{C}$ to $124{ }^{\circ} \mathrm{C} ; 60 \%$ yield; ${ }^{1} \mathrm{H}$ NMR (400 MHz, $\left.\mathrm{C}_{6} \mathrm{D}_{6}\right) \delta 7.78(\mathrm{dd}, J=7.7,1.8 \mathrm{~Hz}, 1 \mathrm{H})$, $7.21(\mathrm{t}, J=6.0 \mathrm{~Hz}, 1 \mathrm{H}), 6.98-6.92(\mathrm{~m}, 1 \mathrm{H}), 6.71(\mathrm{t}, J=7.6 \mathrm{~Hz}, 1 \mathrm{H})$, $6.38(\mathrm{~d}, J=8.2 \mathrm{~Hz}, 1 \mathrm{H}), 5.11(\mathrm{~s}, 1 \mathrm{H}), 4.84(\mathrm{~s}, 1 \mathrm{H}), 4.57(\mathrm{~s}, 1 \mathrm{H})$, 4.19-4.11 (m, 2H), 4.10-4.06 (m, 1H), 3.83-3.75 (m, 2H), 3.44 (dd, $J=7.9,3.7 \mathrm{~Hz}, 1 \mathrm{H}), 3.07$ (d, $J=11.5 \mathrm{~Hz}, 1 \mathrm{H}), 2.22-2.13$ (m, 3H), $1.84(\mathrm{~m}, 1 \mathrm{H}), 1.78-1.67(\mathrm{~m}, 1 \mathrm{H}), 1.60-1.51(\mathrm{~m}, 1 \mathrm{H})$, 
1.51-1.43 (m, 2H), $1.42(\mathrm{~s}, 3 \mathrm{H}), 1.35$ (s, 3H), 1.31 (d, $J=2.5 \mathrm{~Hz}$, 1H), 1.09 (s, 3H), 1.06 (t, $J=7.1 \mathrm{~Hz}, 3 \mathrm{H}), 0.99-0.88(\mathrm{~m}, 3 \mathrm{H}), 0.80$ $(\mathrm{s}, 3 \mathrm{H}) ;{ }^{13} \mathrm{C}$ NMR $\left(101 \mathrm{MHz}, \mathrm{C}_{6} \mathrm{D}_{6}\right) \delta 168.70,165.60,156.04$, 149.51, 147.00, 132.85, 132.04, 125.51, 124.38, 122.50, 117.83, 109.13, 99.26, 75.48, 73.78, 70.37, 64.02, 60.96, 55.62, 51.54, 38.23 , 38.07, 37.66, 34.21, 26.70, 26.05, 25.29, 25.24, 24.89, 23.15, 16.22, 14.10; ESI-HRMS: $m / z 561.2824[\mathrm{M}+\mathrm{Na}]^{+}$calcd for $\mathrm{C}_{32} \mathrm{H}_{42} \mathrm{NaO}_{7}, 561.2828$.

(14ß)-(2'-Carboxy ethyl ester)phenoxy-3,19-acetonylidene andrographolide (5b8). White solid; $\mathrm{mp} 168{ }^{\circ} \mathrm{C}$ to $170{ }^{\circ} \mathrm{C} ; 78 \%$ yield; ${ }^{1} \mathrm{H}$ NMR (400 MHz, $\mathrm{C}_{6} \mathrm{D}_{6}$ ) $\delta 7.80(\mathrm{dd}, J=7.7,1.8 \mathrm{~Hz}, 1 \mathrm{H}), 7.24-7.18$ $(\mathrm{m}, 1 \mathrm{H}), 6.98-6.92(\mathrm{~m}, 1 \mathrm{H}), 6.69(\mathrm{~m}, 1 \mathrm{H}), 6.28(\mathrm{~d}, J=8.2 \mathrm{~Hz}, 1 \mathrm{H})$, $5.04(\mathrm{~d}, J=5.4 \mathrm{~Hz}, 1 \mathrm{H}), 4.84(\mathrm{~d}, J=1.1 \mathrm{~Hz}, 1 \mathrm{H}), 4.44(\mathrm{~s}, 1 \mathrm{H})$, 4.19-4.04 (m, 2H), 4.01 (dd, $J=10.6,1.4 \mathrm{~Hz}, 1 \mathrm{H}), 3.82$ (d, $J=$ $11.5 \mathrm{~Hz}, 1 \mathrm{H}), 3.68(\mathrm{dd}, J=10.6,5.5 \mathrm{~Hz}, 1 \mathrm{H}), 3.42(\mathrm{dd}, J=7.6$, $3.7 \mathrm{~Hz}, 1 \mathrm{H}), 3.08$ (d, $J=11.5 \mathrm{~Hz}, 1 \mathrm{H}), 2.24-2.05$ (m, 3H), 1.80$1.65(\mathrm{~m}, 2 \mathrm{H}), 1.59$ (d, $J=8.3 \mathrm{~Hz}, 1 \mathrm{H}), 1.53-1.43(\mathrm{~m}, 1 \mathrm{H}), 1.41(\mathrm{~s}$, $3 \mathrm{H}), 1.40-1.31(\mathrm{~m}, 2 \mathrm{H}), 1.37(\mathrm{~s}, 3 \mathrm{H}), 1.11(\mathrm{~s}, 3 \mathrm{H}), 1.04(\mathrm{t}, 3 \mathrm{H})$, 1.00-0.88 (m, 3H), $0.85(\mathrm{~s}, 3 \mathrm{H}) ;{ }^{13} \mathrm{C}$ NMR (101 MHz, $\left.\mathrm{C}_{6} \mathrm{D}_{6}\right)$ $\delta 168.70,165.65,155.99,149.74,148.21,132.91,132.15,128.16$, 127.92, 127.80, 127.68, 125.81, 123.92, 122.16, 116.61, 107.89, $99.29,75.26,73.23,70.29,64.14,60.97,55.83,50.97,38.39$, 38.15 , 37.64, 33.49, 26.55, 25.91, 25.87, 25.20, 24.64, 23.22, 16.51, 14.12; ESI-HRMS: $m / z$ 561.2829 $[\mathrm{M}+\mathrm{Na}]^{+}$, calcd for $\mathrm{C}_{32} \mathrm{H}_{42} \mathrm{NaO}_{7}, 561.2828$.

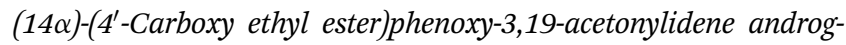
rapholide (5a9). White solid; $\mathrm{mp} 67.8^{\circ} \mathrm{C}$ to $73.7{ }^{\circ} \mathrm{C} ; 30 \%$ yield; ${ }^{1} \mathrm{H}$ NMR (400 MHz, $\left.\mathrm{C}_{6} \mathrm{D}_{6}\right) \delta 8.15-8.08(\mathrm{~m}, 2 \mathrm{H}), 6.49(\mathrm{~d}, J=8.7 \mathrm{~Hz}$, $2 \mathrm{H}), 4.85(\mathrm{~s}, 2 \mathrm{H}), 4.65(\mathrm{~s}, 1 \mathrm{H}), 4.16(\mathrm{q}, J=7.1 \mathrm{~Hz}, 2 \mathrm{H}), 3.82-3.72$ $(\mathrm{m}, 3 \mathrm{H}), 3.44(\mathrm{dd}, J=7.8,3.8 \mathrm{~Hz}, 1 \mathrm{H}), 3.06$ (d, $J=11.6 \mathrm{~Hz}, 1 \mathrm{H})$, 2.39-2.28 (m, 1H), 2.21-2.12 (m, 2H), 1.86-1.69 (m, 2H), $1.54(\mathrm{t}, J$ $=10.1 \mathrm{~Hz}, 2 \mathrm{H}), 1.43-1.38(\mathrm{~m}, 1 \mathrm{H}), 1.42(\mathrm{~s}, 3 \mathrm{H}), 1.34(\mathrm{~s}, 3 \mathrm{H})$, $1.33-1.29(\mathrm{~m}, 1 \mathrm{H}), 1.09$ (s, 3H), 1.05 (t, $J=7.1 \mathrm{~Hz}, 3 \mathrm{H}), 1.00-0.93$ $(\mathrm{m}, 2 \mathrm{H}), 0.85(\mathrm{t}, J=6.1 \mathrm{~Hz}, 2 \mathrm{H}), 0.75(\mathrm{~s}, 3 \mathrm{H}) ;{ }^{13} \mathrm{C} \mathrm{NMR}(101 \mathrm{MHz}$, $\left.\left(\mathrm{CD}_{3}\right)_{2} \mathrm{SO}\right) \delta 169.4,165.7,161.0,150.8,148.1,131.9,125.3,123.7$, 115.8, 109.0, 98.6, 76.1, 71.8, 71.3, 63.2, 60.9, 55.4, 51.8, 38.3, 37.6, 37.4, 34.3, 27.8, 26.2, 25.6, 25.4, 25.2, 23.1, 16.1, 14.7; ESIHRMS: $m / z 561.2822[\mathrm{M}+\mathrm{Na}]^{+}$, calcd for $\mathrm{C}_{32} \mathrm{H}_{42} \mathrm{NaO}_{7}, 561.2828$.

(14ß)-(4'-Carboxy ethyl ester)phenoxy-3,19-acetonylidene andrographolide (5b9). White solid; mp $122{ }^{\circ} \mathrm{C}$ to $125{ }^{\circ} \mathrm{C} ; 45 \%$ yield; ${ }^{1} \mathrm{H}$ NMR (400 MHz, $\mathrm{C}_{6} \mathrm{D}_{6}$ ) $\delta$ 8.14-8.09 (m, 2H), 7.23-7.18 $(\mathrm{m}, 1 \mathrm{H}), 6.45(\mathrm{~d}, J=8.8 \mathrm{~Hz}, 2 \mathrm{H}), 4.86-4.78(\mathrm{~m}, 2 \mathrm{H}), 4.44(\mathrm{~s}, 1 \mathrm{H})$, $4.16(\mathrm{q}, J=7.1 \mathrm{~Hz}, 2 \mathrm{H}), 3.80-3.71(\mathrm{~m}, 2 \mathrm{H}), 3.68(\mathrm{t}, J=7.2 \mathrm{~Hz}$, $1 \mathrm{H}), 3.38(\mathrm{dd}, J=7.4,3.6 \mathrm{~Hz}, 1 \mathrm{H}), 3.05$ (d, $J=11.5 \mathrm{~Hz}, 1 \mathrm{H}), 2.16$ (m, 3H), 1.75-1.63 (m, 2H), 1.52 (d, $J=10.2 \mathrm{~Hz}, 1 \mathrm{H}), 1.46-1.36$ $(\mathrm{m}, 1 \mathrm{H}), 1.37(\mathrm{~s}, 3 \mathrm{H}), 1.35-1.26(\mathrm{~m}, 2 \mathrm{H}), 1.33(\mathrm{~s}, 3 \mathrm{H}), 1.06(\mathrm{~s}, 3 \mathrm{H})$, 1.07-1.01 (m, 3H), 1.01-0.83 (m, 3H), 0.81 (s, 3H); ${ }^{13} \mathrm{C}$ NMR (101 $\left.\mathrm{MHz}, \mathrm{C}_{6} \mathrm{D}_{6}\right) \delta 168.29,165.52,160.29,149.91,147.98,132.07$ (2C), 125.26, 124.92, 115.12 (2C), 107.85, 75.00, 71.48, 70.01, 64.14, $60.70,55.66,51.07,38.37,38.18,37.64,33.49$, 26.32, 25.91, 25.68, 25.11, 24.47, 23.17, 16.49, 14.21; ESI-HRMS: $m / z 561.2825$ $[\mathrm{M}+\mathrm{Na}]^{+}$, calcd for $\mathrm{C}_{32} \mathrm{H}_{42} \mathrm{NaO}_{7}, 561.2828$.

(14ß)-(4'-Cyano)phenoxy-3,19-acetonylidene andrographolide (5b10). White solid; mp $177{ }^{\circ} \mathrm{C}$ to $179{ }^{\circ} \mathrm{C} ; 42 \%$ yield; ${ }^{1} \mathrm{H}$ NMR $\left(400 \mathrm{MHz}, \mathrm{C}_{6} \mathrm{D}_{6}\right) \delta 7.22-7.18(\mathrm{~m}, 1 \mathrm{H}), 6.97-6.91(\mathrm{~m}, 2 \mathrm{H}), 6.12-$ $6.07(\mathrm{~m}, 2 \mathrm{H}), 4.85(\mathrm{~d}, J=1.1 \mathrm{~Hz}, 1 \mathrm{H}), 4.66(\mathrm{~s}, 1 \mathrm{H}), 4.42(\mathrm{~s}, 1 \mathrm{H})$, 3.77 (d, $J=11.5 \mathrm{~Hz}, 1 \mathrm{H}), 3.63-3.56(\mathrm{~m}, 2 \mathrm{H}), 3.43$ (dd, $J=7.1$,
$3.6 \mathrm{~Hz}, 1 \mathrm{H}), 3.06$ (d, $J=11.5 \mathrm{~Hz}, 1 \mathrm{H}), 2.23-2.04(\mathrm{~m}, 3 \mathrm{H}), 1.74-$ $1.64(\mathrm{~m}, 2 \mathrm{H}), 1.51-1.38(\mathrm{~m}, 2 \mathrm{H}), 1.41(\mathrm{~s}, 3 \mathrm{H}), 1.35(\mathrm{~s}, 3 \mathrm{H}), 1.34-$ $1.24(\mathrm{~m}, 2 \mathrm{H}), 1.07$ (s, 1H), $0.98(\mathrm{~m}, 1 \mathrm{H}), 0.97(\mathrm{~m}, 1 \mathrm{H}), 0.92-0.84$ $(\mathrm{m}, 2 \mathrm{H}), 0.83(\mathrm{~s}, 3 \mathrm{H}) ;{ }^{13} \mathrm{C} \mathrm{NMR}\left(101 \mathrm{MHz}, \mathrm{C}_{6} \mathrm{D}_{6}\right) \delta 168.06,159.36$, 150.35, 148.00, 134.09, 124.74, 118.44, 115.68, 107.84, 106.04, $99.53,74.78,71.45,69.64,64.18,55.54,50.88,38.31,38.25$, 37.60, 33.44, 26.12, 25.91, 25.72, 25.08, 24.33, 23.13, 16.59; ESIHRMS: $m / z$ 514.2566 $[\mathrm{M}+\mathrm{Na}]^{+}$calcd for $\mathrm{C}_{30} \mathrm{H}_{37} \mathrm{NNaO}_{5}$, 514.2569 .

(14ß)-(4'-Methoxy)phenoxy-3,19-acetonylidene andrographolide (5b11). White solid; mp $149{ }^{\circ} \mathrm{C}$ to $151{ }^{\circ} \mathrm{C} ; 48 \%$ yield; ${ }^{1} \mathrm{H}$ NMR (400 MHz, $\left.\mathrm{C}_{6} \mathrm{D}_{6}\right) \delta$ 7.20-7.17 (m, 1H), 6.69-6.62 (m, 2H), 6.57$6.51(\mathrm{~m}, 2 \mathrm{H}), 4.86-4.78(\mathrm{~m}, 2 \mathrm{H}), 4.43(\mathrm{q}, J=1.4 \mathrm{~Hz}, 1 \mathrm{H}), 4.01$ (dd, $J=10.5,1.8 \mathrm{~Hz}, 1 \mathrm{H}), 3.82(\mathrm{~d}, J=11.5 \mathrm{~Hz}, 1 \mathrm{H}), 3.75-3.68(\mathrm{~m}$, $1 \mathrm{H}), 3.41(\mathrm{~m}, 1 \mathrm{H}), 3.30(\mathrm{~s}, 3 \mathrm{H}), 3.08$ (d, $J=11.5 \mathrm{~Hz}, 1 \mathrm{H}), 2.21-$ $2.05(\mathrm{~m}, 3 \mathrm{H}), 1.82-1.64(\mathrm{~m}, 2 \mathrm{H}), 1.55-1.43(\mathrm{~m}, 2 \mathrm{H}), 1.41(\mathrm{~s}, 3 \mathrm{H})$, 1.38-1.29 (m, 2H), 1.37 (s, 3H), 1.08 (s, 3H), 1.02-0.90 (m, 2H), 0.89-0.79 (m, 1H), $0.83(\mathrm{~s}, 3 \mathrm{H}) ;{ }^{13} \mathrm{C} \mathrm{NMR}\left(101 \mathrm{MHz}, \mathrm{C}_{6} \mathrm{D}_{6}\right)$ $\delta 168.82,155.47,150.74,149.23,148.08,126.05,117.95,117.95$, 115.12, 115.12, 107.93, 99.28, 75.34, 72.90, 70.43, 64.10, 55.63, 55.06, 51.21, 38.34, 38.11, 37.64, 33.66, 26.57, 25.98, 25.63, 25.24, 24.72, 23.18, 16.43; ESI-HRMS: $m / z 519.2725[\mathrm{M}+\mathrm{Na}]^{+}$, calcd for $\mathrm{C}_{30} \mathrm{H}_{40} \mathrm{NaO}_{6}, 519.2723$.

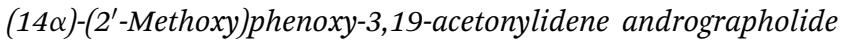
(5a12). White solid; mp $48.7{ }^{\circ} \mathrm{C}$ to $52.6{ }^{\circ} \mathrm{C} ; 57 \%$ yield; ${ }^{1} \mathrm{H}$ NMR $\left(400 \mathrm{MHz}, \mathrm{C}_{6} \mathrm{D}_{6}\right) \delta 6.81$ (ddd, $J=8.1,6.9,2.3 \mathrm{~Hz}, 1 \mathrm{H}$ ), 6.69-6.61 $(\mathrm{m}, 2 \mathrm{H}), 6.48(\mathrm{~d}, J=8.2 \mathrm{~Hz}, 1 \mathrm{H}), 5.15(\mathrm{~d}, J=5.2 \mathrm{~Hz}, 1 \mathrm{H}), 4.82(\mathrm{~s}$, $1 \mathrm{H}), 4.62$ (s, 1H), 4.21 (dd, $J=10.6,1.6 \mathrm{~Hz}, 1 \mathrm{H}), 3.82$ (d, $J=$ $11.5 \mathrm{~Hz}, 1 \mathrm{H}), 3.75(\mathrm{dd}, J=10.6,5.6 \mathrm{~Hz}, 1 \mathrm{H}), 3.46(\mathrm{dd}, J=7.7$, $3.7 \mathrm{~Hz}, 1 \mathrm{H}), 3.28$ (s, 3H), 3.08 (d, $J=11.5 \mathrm{~Hz}, 1 \mathrm{H}), 2.25-2.12(\mathrm{~m}$, $3 \mathrm{H}), 1.87$ (m, 1H), 1.77-1.66 (m, 1H), 1.61-1.52 (m, 1H), 1.50$1.41(\mathrm{~m}, 2 \mathrm{H}), 1.43(\mathrm{~s}, 3 \mathrm{H}), 1.39(\mathrm{~s}, 3 \mathrm{H}), 1.36-1.27(\mathrm{~m}, 2 \mathrm{H}), 1.09(\mathrm{~s}$, $3 \mathrm{H}), 1.02-0.87(\mathrm{~m}, 4 \mathrm{H}), 0.82(\mathrm{~s}, 3 \mathrm{H}) ;{ }^{13} \mathrm{C} \mathrm{NMR}(101 \mathrm{MHz}$, $\left.\left(\mathrm{CD}_{3}\right)_{2} \mathrm{SO}\right) \delta 169.8,151.3,149.8,147.9,145.9,126.1,124.1,121.2$, 119.2, 113.1, 109.1, 98.6, 76.2, 73.3, 71.7, 63.2, 56.0, 55.3, 51.8, 38.4, 37.6, 37.5, 34.4, 27.9, 26.2, 25.7, 25.2, 25.0, 23.1, 16.0; ESIHRMS: $m / z 519.2719[\mathrm{M}+\mathrm{Na}]^{+}$, calcd for $\mathrm{C}_{30} \mathrm{H}_{40} \mathrm{NaO}_{6}, 519.2723$.

(14ß)-(2'-Methoxy)phenoxy-3,19-acetonylidene andrographolide (5b12). White solid; mp $130{ }^{\circ} \mathrm{C}$ to $131{ }^{\circ} \mathrm{C} ; 60 \%$ yield; ${ }^{1} \mathrm{H}$ NMR $\left(400 \mathrm{MHz}, \mathrm{C}_{6} \mathrm{D}_{6}\right) \delta 7.13-7.10(\mathrm{~m}, 1 \mathrm{H}), 6.80(\mathrm{~m}, 1 \mathrm{H}), 6.65(\mathrm{~m}, 1 \mathrm{H})$, $6.58(\mathrm{dd}, J=7.9,1.6 \mathrm{~Hz}, 1 \mathrm{H}), 6.47(\mathrm{dd}, J=8.1,1.3 \mathrm{~Hz}, 1 \mathrm{H}), 5.18$ $(\mathrm{d}, J=5.4 \mathrm{~Hz}, 1 \mathrm{H}), 4.82(\mathrm{~d}, J=1.2 \mathrm{~Hz}, 1 \mathrm{H}), 4.42(\mathrm{~s}, 1 \mathrm{H}), 4.15$ (dd, $J=10.6,1.5 \mathrm{~Hz}, 1 \mathrm{H}), 3.83(\mathrm{~d}, J=11.5 \mathrm{~Hz}, 1 \mathrm{H}), 3.65(\mathrm{dd}, J=10.6$, $5.5 \mathrm{~Hz}, 1 \mathrm{H}), 3.41$ (dd, $J=7.7,3.7 \mathrm{~Hz}, 1 \mathrm{H}), 3.29$ (s, 3H), 3.09 (d, $J$ $=11.5 \mathrm{~Hz}, 1 \mathrm{H}), 2.26-2.04(\mathrm{~m}, 3 \mathrm{H}), 1.83-1.62(\mathrm{~m}, 2 \mathrm{H}), 1.55-1.44$ $(\mathrm{m}, 2 \mathrm{H}), 1.42(\mathrm{~s}, 3 \mathrm{H}), 1.39(\mathrm{~s}, 3 \mathrm{H}), 1.38-1.28(\mathrm{~m}, 2 \mathrm{H}), 1.08(\mathrm{~s}, 3 \mathrm{H})$, 1.05-0.94 (m, 1H), 0.94-0.88 (m, 1H), 0.88-0.83 (m, 1H), 0.85 (s, $3 \mathrm{H}) ;{ }^{13} \mathrm{C}$ NMR $\left(101 \mathrm{MHz}, \mathrm{C}_{6} \mathrm{D}_{6}\right) \delta 169.08,151.78,149.42,148.27$, 145.92, 128.15, 128.03, 127.91, 127.79, 127.67, 126.39, 124.00, 121.11, 120.16, 112.54, 107.85, 99.30, 75.39, 73.44, 70.56, 64.14, 55.72, 55.11, 51.10, 38.34, 38.12, 37.66, 33.56, 26.57, 26.00, 25.64, 25.29, 24.74, 23.24, 16.46; ESI-HRMS: $m / z$ 519.2715 [M + $\mathrm{Na}]^{+}$, calcd for $\mathrm{C}_{30} \mathrm{H}_{40} \mathrm{NaO}_{6}, 519.2723$.

(14ß)-(3'-Methoxy)phenoxy-3,19-acetonylidene andrographolide (2b13). White solid; mp $168{ }^{\circ} \mathrm{C}$ to $170{ }^{\circ} \mathrm{C}$; $58 \%$ yield; ${ }^{1} \mathrm{H}$ NMR $\left(400 \mathrm{MHz}, \mathrm{C}_{6} \mathrm{D}_{6}\right) \delta 7.25-7.19(\mathrm{~m}, 1 \mathrm{H}), 6.97(\mathrm{t}, J=8.2 \mathrm{~Hz}, 1 \mathrm{H})$, 6.43 (dd, $J=8.2,2.0 \mathrm{~Hz}, 1 \mathrm{H}), 6.38$ (t, $J=2.2 \mathrm{~Hz}, 1 \mathrm{H}), 6.19$ (d, 
$J=8.2 \mathrm{~Hz}, 1 \mathrm{H}), 4.90(\mathrm{~s}, 1 \mathrm{H}), 4.84(\mathrm{~d}, J=0.9 \mathrm{~Hz}, 1 \mathrm{H}), 4.46(\mathrm{~s}, 1 \mathrm{H})$, $3.93(\mathrm{~d}, J=10.6 \mathrm{~Hz}, 1 \mathrm{H}), 3.81$ (d, $J=11.5 \mathrm{~Hz}, 1 \mathrm{H}), 3.76-3.68(\mathrm{~m}$, $1 \mathrm{H}), 3.40(\mathrm{dd}, J=7.7,3.7 \mathrm{~Hz}, 1 \mathrm{H}), 3.30(\mathrm{~s}, 3 \mathrm{H}), 3.07$ (d, $J=$ $11.5 \mathrm{~Hz}, 1 \mathrm{H}), 2.34-2.25(\mathrm{~m}, 1 \mathrm{H}), 2.15(\mathrm{~m}, 2 \mathrm{H}), 1.79-1.65(\mathrm{~m}, 2 \mathrm{H})$, $1.58(\mathrm{~d}, J=10.4 \mathrm{~Hz}, 1 \mathrm{H}), 1.51-1.42(\mathrm{~m}, 1 \mathrm{H}), 1.41(\mathrm{~s}, 3 \mathrm{H}), 1.40-$ 1.37 (m, 1H), 1.37-1.30 (m, 2H), 1.36 (s, 3H), 1.09 (s, 3H), 1.02$0.92(\mathrm{~m}, 2 \mathrm{H}), 0.88$ (dd, $J=12.9,2.1 \mathrm{~Hz}, 1 \mathrm{H}), 0.81(\mathrm{~s}, 3 \mathrm{H}) ;{ }^{13} \mathrm{C}$ NMR $\left(101 \mathrm{MHz}, \mathrm{C}_{6} \mathrm{D}_{6}\right) \delta 168.61,161.60,158.18,149.42,147.97$, 130.45 , 125.84, 107.90, 107.58, 107.42, 102.64, 99.25, 75.36, $71.37,70.39,64.06,55.70,54.79,51.24,38.40,38.10,37.66$, 33.61, 26.66, 25.95, 25.59, 25.20, 24.72, 23.16, 16.40; ESI-HRMS: $m / z 519.2717[\mathrm{M}+\mathrm{Na}]^{+}$calcd for $\mathrm{C}_{30} \mathrm{H}_{40} \mathrm{NaO}_{6}, 519.2723$.

(14ß)-(Naphthyl-1'-oxy)-3,19-acetonylidene andrographolide (5b14). White solid; mp $158{ }^{\circ} \mathrm{C}$ to $161{ }^{\circ} \mathrm{C} ; 46 \%$ yield; ${ }^{1} \mathrm{H}$ NMR $\left(400 \mathrm{MHz}, \mathrm{C}_{6} \mathrm{D}_{6}\right) \delta 8.16(\mathrm{dd}, J=6.2,3.5 \mathrm{~Hz}, 1 \mathrm{H}), 7.59-7.54(\mathrm{~m}$, $1 \mathrm{H}), 7.39$ (dd, $J=11.0,4.2 \mathrm{~Hz}, 1 \mathrm{H}), 7.30$ (d, $J=8.3 \mathrm{~Hz}, 1 \mathrm{H}), 7.26-$ $7.21(\mathrm{~m}, 2 \mathrm{H}), 7.11-7.06(\mathrm{~m}, 1 \mathrm{H}), 6.02(\mathrm{~d}, J=7.6 \mathrm{~Hz}, 1 \mathrm{H}), 4.96(\mathrm{~d}, J$ $=5.6 \mathrm{~Hz}, 1 \mathrm{H}), 4.85(\mathrm{~s}, 1 \mathrm{H}), 4.51(\mathrm{~s}, 1 \mathrm{H}), 3.88(\mathrm{~d}, J=7.2 \mathrm{~Hz}, 1 \mathrm{H})$, $3.78(\mathrm{dd}, J=10.7,5.6 \mathrm{~Hz}, 1 \mathrm{H}), 3.70$ (d, $J=11.5 \mathrm{~Hz}, 1 \mathrm{H}), 3.06$ (dd, $J=7.6,3.7 \mathrm{~Hz}, 1 \mathrm{H}), 2.98$ (d, $J=11.5 \mathrm{~Hz}, 1 \mathrm{H}), 2.24-2.03(\mathrm{~m}, 3 \mathrm{H})$, 1.74 (dd, $J=20.3,8.7 \mathrm{~Hz}, 2 \mathrm{H}), 1.40-1.33(\mathrm{~m}, 1 \mathrm{H}), 1.32(\mathrm{~s}, 3 \mathrm{H})$, 1.31-1.24 (m, 1H), $1.28(\mathrm{~s}, 3 \mathrm{H}), 1.12(\mathrm{~m}, 1 \mathrm{H}), 0.98-0.85(\mathrm{~m}, 1 \mathrm{H})$, $0.92(\mathrm{~s}, 3 \mathrm{H}), 0.84-0.73(\mathrm{~m}, 1 \mathrm{H}), 0.71(\mathrm{~s}, 3 \mathrm{H}), 0.70-0.60(\mathrm{~m}, 2 \mathrm{H})$; ${ }^{13} \mathrm{C}$ NMR $\left(101 \mathrm{MHz}, \mathrm{C}_{6} \mathrm{D}_{6}\right) \delta 168.55,152.54,149.60,147.88$, 135.21, 127.02, 126.27, 126.02, 125.83, 125.54, 122.47, 121.65, 107.86, 105.47, 99.17, 74.98, 71.22, 70.42, 64.02, 56.55, 50.80, $38.39,37.95,37.74,33.27,26.47,25.68,25.07,24.08,23.17$, 16.35, 14.06; ESI-HRMS: $m / z$ 539.2768 $[\mathrm{M}+\mathrm{Na}]^{+}$, calcd for $\mathrm{C}_{33} \mathrm{H}_{40} \mathrm{NaO}_{5}, 539.2773$.

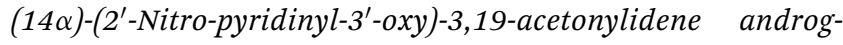
rapholide (5a15). White solid; mp $174{ }^{\circ} \mathrm{C}$ to $176{ }^{\circ} \mathrm{C} ; 53 \%$ yield; ${ }^{1} \mathrm{H}$ NMR $\left(400 \mathrm{MHz},\left(\mathrm{CD}_{3}\right)_{2} \mathrm{SO}\right) \delta 8.21(\mathrm{dd}, J=4.5,1.0 \mathrm{~Hz}, 1 \mathrm{H})$, 8.05-8.00 (m, 1H), $7.84(\mathrm{~m}, 4.6 \mathrm{~Hz}, 1 \mathrm{H}), 6.94(\mathrm{t}, J=6.1 \mathrm{~Hz}, 1 \mathrm{H})$, $6.07(\mathrm{~d}, J=5.2 \mathrm{~Hz}, 1 \mathrm{H}), 4.81(\mathrm{~s}, 1 \mathrm{H}), 4.73(\mathrm{~m}, 1 \mathrm{H}), 4.50-4.43(\mathrm{~m}$, $2 \mathrm{H}), 3.83(\mathrm{~d}, J=11.7 \mathrm{~Hz}, 1 \mathrm{H}), 3.38-3.34(\mathrm{~m}, 1 \mathrm{H}), 3.08(\mathrm{~d}, J=$ $11.6 \mathrm{~Hz}, 1 \mathrm{H}), 2.48-2.41(\mathrm{~m}, 1 \mathrm{H}), 2.40-2.29(\mathrm{~m}, 2 \mathrm{H}), 1.96(\mathrm{~m}, 2 \mathrm{H})$, $1.81(\mathrm{~m}, 1 \mathrm{H}), 1.68-1.55(\mathrm{~m}, 2 \mathrm{H}), 1.52-1.43(\mathrm{~m}, 1 \mathrm{H}), 1.28(\mathrm{~m}, 3 \mathrm{H})$, $1.23(\mathrm{~s}, 3 \mathrm{H}), 1.21-1.25(\mathrm{~m}, 1 \mathrm{H}), 1.21-1.13(\mathrm{~m}, 2 \mathrm{H}), 1.11(\mathrm{~s}, 3 \mathrm{H})$, $0.77(\mathrm{~s}, 3 \mathrm{H}) ;{ }^{13} \mathrm{C}$ NMR $\left(101 \mathrm{MHz},\left(\mathrm{CD}_{3}\right)_{2} \mathrm{SO}\right) \delta 168.57,151.44$, 149.03, 147.50, 144.23, 140.41, 129.46, 126.43, 124.08, 108.52, $98.14,75.70,73.14,70.22,62.73,54.90,51.35,37.86,37.13$, $36.90,33.88,27.41,25.75,25.15,24.74,24.72$, 22.57, 15.57; ESIHRMS: $m / z 535.2415[\mathrm{M}+\mathrm{Na}]^{+}$, calcd for $\mathrm{C}_{28} \mathrm{H}_{36} \mathrm{~N}_{2} \mathrm{NaO}_{7}$, 535.2420 .

(14ß)-(2'-Nitro-pyridinyl-3'-oxy)-3,19-acetonylidene andrographolide (5b15). White solid; mp $104{ }^{\circ} \mathrm{C}$ to $107{ }^{\circ} \mathrm{C} ; 42 \%$ yield; ${ }^{1} \mathrm{H} \mathrm{NMR}\left(400 \mathrm{MHz}, \mathrm{C}_{6} \mathrm{D}_{6}\right) \delta 7.53(\mathrm{~d}, J=4.6 \mathrm{~Hz}, 1 \mathrm{H}), 6.32(\mathrm{~m}, 1 \mathrm{H})$, $6.10(\mathrm{~m}, 1 \mathrm{H}), 4.82(\mathrm{~s}, 1 \mathrm{H}), 4.76(\mathrm{~s}, 1 \mathrm{H}), 4.33(\mathrm{~s}, 1 \mathrm{H}), 3.82(\mathrm{~d}, J=$ $11.5 \mathrm{~Hz}, 1 \mathrm{H}), 3.51(\mathrm{~m}, 2 \mathrm{H}), 3.44(\mathrm{~m}, 1 \mathrm{H}), 3.07$ (d, $J=11.5 \mathrm{~Hz}$, $1 \mathrm{H}), 2.30-2.12(\mathrm{~m}, 3 \mathrm{H}), 1.87-1.66(\mathrm{~m}, 2 \mathrm{H}), 1.63-1.47(\mathrm{~m}, 3 \mathrm{H})$, $1.42(\mathrm{~s}, 3 \mathrm{H}), 1.39-1.31(\mathrm{~m}, 1 \mathrm{H}), 1.36(\mathrm{~s}, 3 \mathrm{H}), 1.10(\mathrm{~s}, 3 \mathrm{H}), 1.04-$ $0.88(\mathrm{~m}, 3 \mathrm{H}), 0.90(\mathrm{~s}, 3 \mathrm{H}) ;{ }^{13} \mathrm{C}$ NMR $\left(101 \mathrm{MHz}, \mathrm{C}_{6} \mathrm{D}_{6}\right) \delta 167.65$, 152.42, 151.04, 148.50, 143.65, 140.77, 127.47, 124.75, 123.67, 107.70, 99.31, 75.29, 73.91, 69.17, 64.12, 55.77, 51.06, 38.40, $38.13,37.58,33.67,26.56,26.05,25.93,25.21,24.63,23.19$, 16.51; ESI-HRMS: $\mathrm{m} / \mathrm{z} 535.2415[\mathrm{M}+\mathrm{Na}]^{+}$, calcd for $\mathrm{C}_{28} \mathrm{H}_{36} \mathrm{~N}_{2} \mathrm{NaO}_{7}, 535.2420$.

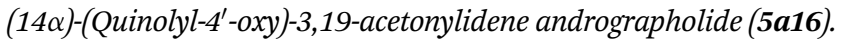
White solid; mp $97.8{ }^{\circ} \mathrm{C}$ to $102.9{ }^{\circ} \mathrm{C}$; $40 \%$ yield; ${ }^{1} \mathrm{H}$ NMR (400 $\left.\mathrm{MHz},\left(\mathrm{CD}_{3}\right)_{2} \mathrm{SO}\right) \delta 8.79(\mathrm{~d}, J=5.2 \mathrm{~Hz}, 1 \mathrm{H}), 8.07(\mathrm{~d}, J=8.3 \mathrm{~Hz}$, $1 \mathrm{H}), 7.99(\mathrm{~d}, J=8.4 \mathrm{~Hz}, 1 \mathrm{H}), 7.79-7.74(\mathrm{~m}, 1 \mathrm{H}), 7.57(\mathrm{t}, J=$ $7.6 \mathrm{~Hz}, 1 \mathrm{H}), 7.11-7.04(\mathrm{~m}, 2 \mathrm{H}), 6.12(\mathrm{~d}, J=6.9 \mathrm{~Hz}, 1 \mathrm{H}), 4.88-4.81$ $(\mathrm{m}, 2 \mathrm{H}), 4.63(\mathrm{~s}, 1 \mathrm{H}), 4.47-4.42(\mathrm{~m}, 1 \mathrm{H}), 3.76(\mathrm{~d}, J=11.7 \mathrm{~Hz}, 1 \mathrm{H})$, $3.27(\mathrm{dd}, J=9.2,3.9 \mathrm{~Hz}, 1 \mathrm{H}), 3.02(\mathrm{~d}, J=11.5 \mathrm{~Hz}, 1 \mathrm{H}), 2.31(\mathrm{~d}, J$ $=11.7 \mathrm{~Hz}, 1 \mathrm{H}), 2.02(\mathrm{~s}, 1 \mathrm{H}), 1.92(\mathrm{~s}, 1 \mathrm{H}), 1.76-1.57(\mathrm{~m}, 3 \mathrm{H})$, 1.53-1.43 (m, 1H), 1.42-1.30 (m, 2H), $1.23(\mathrm{~s}, 3 \mathrm{H}), 1.20(\mathrm{~s}, 3 \mathrm{H})$, 1.15-1.12 (m, 2H), $1.10(\mathrm{~s}, 1 \mathrm{H}), 1.06-1.04(\mathrm{~m}, 3 \mathrm{H}), 0.66(\mathrm{~d}, J=$ $9.5 \mathrm{~Hz}, 3 \mathrm{H}), 0.65(\mathrm{~s}, 3 \mathrm{H}) ;{ }^{13} \mathrm{C}$ NMR $\left(101 \mathrm{MHz},\left(\mathrm{CD}_{3}\right)_{2} \mathrm{SO}\right) \delta 169.4$, $159.3,151.9,151.5,149.5,148.2$, 132.1, 130.5, 129.2, 126.5, 124.9, 121.8, 109.0, 103.0, 98.6, 76.1, 72.1, 71.1, 63.1, 55.2, 51.8, 38.3, 37.5, 37.3, 34.3, 27.9, 26.2, 25.6, 25.5, 25.1, 23.0, 16.0; ESIHRMS: $m / z 518.2902[\mathrm{M}+\mathrm{H}]^{+}$, calcd for $\mathrm{C}_{32} \mathrm{H}_{40} \mathrm{NO}_{5}, 518.2906$.

(14ß)-(Quinolyl-4'-oxy)-3,19-acetonylidene andrographolide (5b16). White solid; mp $122{ }^{\circ} \mathrm{C}$ to $124{ }^{\circ} \mathrm{C}$; 53\% yield; ${ }^{1} \mathrm{H}$ NMR $\left(400 \mathrm{MHz}, \mathrm{C}_{6} \mathrm{D}_{6}\right) \delta 8.63(\mathrm{~d}, J=5.1 \mathrm{~Hz}, 1 \mathrm{H}), 8.31-8.25(\mathrm{~m}, 1 \mathrm{H})$, $7.98(\mathrm{dd}, J=8.4,1.4 \mathrm{~Hz}, 1 \mathrm{H}), 7.42(\mathrm{~m}, 1 \mathrm{H}), 7.37-7.30(\mathrm{~m}, 1 \mathrm{H})$, 5.66-5.62 (m, 1H), 4.89-4.82 (m, 2H), 4.51 (d, $J=1.7 \mathrm{~Hz}, 1 \mathrm{H})$, 3.76-3.65 (m, 3H), 3.10 (dd, $J=7.1,3.5 \mathrm{~Hz}, 1 \mathrm{H}), 2.98$ (d, $J=$ $11.5 \mathrm{~Hz}, 1 \mathrm{H}), 2.23-2.05$ (m, 3H), 1.80-1.63 (m, 2H), 1.34-1.24 $(\mathrm{m}, 2 \mathrm{H}), 1.30(\mathrm{~s}, 3 \mathrm{H}), 1.28(\mathrm{~s}, 3 \mathrm{H}), 1.14(\mathrm{~m}, 1 \mathrm{H}), 1.00-0.91(\mathrm{~m}$, $1 \mathrm{H}), 0.90(\mathrm{~s}, 3 \mathrm{H}), 0.76$ (s, 3H), 0.74-0.59 (m, 3H); ${ }^{13} \mathrm{C}$ NMR (101 $\left.\mathrm{MHz}, \mathrm{C}_{6} \mathrm{D}_{6}\right) \delta 168.22,158.91,151.10,150.54,150.43,147.82$, 130.19, 129.97, 128.15, 127.91, 127.79, 127.67, 126.07, 125.40, 121.97, 121.27, 107.91, 100.92, 99.36, 74.50, 71.28, 69.95, 64.12, $56.67,50.62,38.42,38.08,37.75,33.15,26.10,25.73,25.63$, 24.94, 23.67, 23.18, 16.53; ESI-HRMS: $m / z$ 518.2900 $[\mathrm{M}+\mathrm{H}]^{+}$, calcd for $\mathrm{C}_{32} \mathrm{H}_{40} \mathrm{NaO}_{5}, 518.2906$.

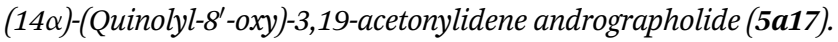
White solid; mp $143{ }^{\circ} \mathrm{C}$ to $146{ }^{\circ} \mathrm{C} ; 42 \%$ yield; ${ }^{1} \mathrm{H}$ NMR $(400 \mathrm{MHz}$, $\left.\mathrm{C}_{6} \mathrm{D}_{6}\right) \delta 8.64(\mathrm{dd}, J=4.1,1.7 \mathrm{~Hz}, 1 \mathrm{H}), 7.46(\mathrm{dd}, J=8.4,1.7 \mathrm{~Hz}$, $1 \mathrm{H}), 7.27-7.22(\mathrm{~m}, 1 \mathrm{H}), 7.08(\mathrm{dd}, J=8.2,1.3 \mathrm{~Hz}, 1 \mathrm{H}), 6.99(\mathrm{t}, J=$ $7.8 \mathrm{~Hz}, 1 \mathrm{H}), 6.88(\mathrm{~m}, 1 \mathrm{H}), 6.74(\mathrm{dd}, J=8.3,4.1 \mathrm{~Hz}, 1 \mathrm{H}), 6.08(\mathrm{~d}, J$ $=5.6 \mathrm{~Hz}, 1 \mathrm{H}), 4.82(\mathrm{~s}, 1 \mathrm{H}), 4.69(\mathrm{~s}, 1 \mathrm{H}), 4.39(\mathrm{dd}, J=10.8,1.6 \mathrm{~Hz}$, $1 \mathrm{H}), 3.88(\mathrm{dd}, J=10.8,5.6 \mathrm{~Hz}, 1 \mathrm{H}), 3.79(\mathrm{~d}, J=11.5 \mathrm{~Hz}, 1 \mathrm{H}), 3.41$ (dd, $J=8.1,3.9 \mathrm{~Hz}, 1 \mathrm{H}), 3.06$ (d, $J=11.5 \mathrm{~Hz}, 1 \mathrm{H}), 2.35(\mathrm{~m}, 1 \mathrm{H})$, 2.25-2.11 (m, 2H), 1.81 (m, 1H), 1.74-1.64 (m, 1H), 1.55-1.48 (m, 1H), 1.48-1.40 (m, 1H), $1.42(\mathrm{~s}, 3 \mathrm{H}), 1.36(\mathrm{~s}, 3 \mathrm{H}), 1.32-1.23$ $(\mathrm{m}, 2 \mathrm{H}), 1.08(\mathrm{~s}, 3 \mathrm{H}), 0.99-0.78(\mathrm{~m}, 3 \mathrm{H}), 0.71(\mathrm{~s}, 3 \mathrm{H}) ;{ }^{13} \mathrm{C}$ NMR $\left(101 \mathrm{MHz}, \mathrm{C}_{6} \mathrm{D}_{6}\right) \delta 169.33,153.10,149.55,149.07,147.00$, $142.46,135.98,130.11,126.78,126.52$, 123.22, 121.41, 119.68, 109.42, 99.18, 75.65, 75.33, 70.92, 64.00, 55.65, 51.54, 38.19, 38.00, 37.68, 34.09, 26.83, 26.09, 25.63, 25.39, 25.04, 23.18, 16.12; ESI-HRMS: $m / z 518.2901[\mathrm{M}+\mathrm{H}]^{+}$, calcd for $\mathrm{C}_{32} \mathrm{H}_{40} \mathrm{NO}_{5}$, 518.2906 .

(14ß)-(Quinolyl-8'-oxy)-3,19-acetonylidene andrographolide (5b17). White solid; mp $146{ }^{\circ} \mathrm{C}$ to $148{ }^{\circ} \mathrm{C} ; 87 \%$ yield; ${ }^{1} \mathrm{H}$ NMR $(400 \mathrm{MHz}$, $\left.\mathrm{C}_{6} \mathrm{D}_{6}\right) \delta 8.67(\mathrm{dd}, J=4.1,1.7 \mathrm{~Hz}, 1 \mathrm{H}), 7.49(\mathrm{dd}, J=8.3,1.7 \mathrm{~Hz}$, 1H), 7.30-7.24 (m, 1H), $7.08(\mathrm{~m}, 1 \mathrm{H}), 7.01(\mathrm{~m}, 1 \mathrm{H}), 6.75(\mathrm{~m}, 2 \mathrm{H})$, $5.97(\mathrm{~d}, J=5.5 \mathrm{~Hz}, 1 \mathrm{H}), 4.84(\mathrm{~d}, J=1.2 \mathrm{~Hz}, 1 \mathrm{H}), 4.54(\mathrm{~s}, 1 \mathrm{H}), 4.25$ (dd, $J=10.7,1.6 \mathrm{~Hz}, 1 \mathrm{H}), 3.84-3.75(\mathrm{~m}, 2 \mathrm{H}), 3.28$ (m, 1H), 3.06 (d, $J=11.5 \mathrm{~Hz}, 1 \mathrm{H}), 2.37$ (m, 1H), 2.30-2.21 (m, 1H), 2.21-2.13 (m, 1H), $1.74(\mathrm{~m}, 1 \mathrm{H}), 1.69-1.58(\mathrm{~m}, 2 \mathrm{H}), 1.39$ (s, 3H), 1.36-1.30 (m, 1H), 1.34 (s, 3H), 1.29-1.19 (m, 2H), 1.04 (m, 3H), 1.01-0.92 
(m, 1H), $0.84(\mathrm{~m}, 2 \mathrm{H}), 0.75(\mathrm{~s}, 3 \mathrm{H}) ;{ }^{13} \mathrm{C} \mathrm{NMR}\left(101 \mathrm{MHz}, \mathrm{C}_{6} \mathrm{D}_{6}\right)$ $\delta$ 169.13, 153.03, 149.84, 149.10, 148.26, 142.17, 135.83, 130.10, 126.66, 126.65, 122.68, 121.51, 117.63, 107.87, 99.13, 75.55, $74.63,70.62,64.03,55.77,51.17,38.37,37.99,37.69,33.57$, 26.74, 25.99, 25.99, 25.31, 24.74, 23.30, 16.25; ESI-HRMS: $m / z$ $518.2880[\mathrm{M}+\mathrm{H}]^{+}$, calcd for $\mathrm{C}_{32} \mathrm{H}_{40} \mathrm{NO}_{5}, 518.2906$.

\subsubsection{Preparation of compounds $6 \mathbf{a}$ and $6 \mathbf{b}$}

General method for synthesis of $\mathbf{6} \boldsymbol{a}$ and $\mathbf{6} \boldsymbol{b}$. At room temperature, $1.0 \mathrm{mmol} \mathbf{5 a}$ or $\mathbf{5 b}$ were dissolved in $15 \mathrm{~mL}$ methanol, and $0.1 \mathrm{mmol} \mathrm{TsOH} \cdot \mathrm{H}_{2} \mathrm{O}$ was added. The reaction was stirred at $\mathrm{rt}$ and was generally complete in $5 \mathrm{~min}$. After the reaction was complete, the reaction mixture was treated with sol. sat. $\mathrm{NaHCO}_{3}$ and extracted with ethyl acetate. The organic phase was washed with brine and dried over anhydrous $\mathrm{Na}_{2} \mathrm{SO}_{4}$. The solvent was removed in vacuo, and the residue was further purified using flash column chromatography eluting with petroleum ether and ethyl acetate to afford $\mathbf{6 a}$ or $\mathbf{6 b}$.

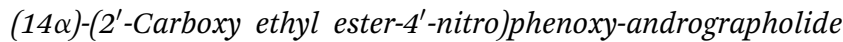
(6a1). White solid; mp $82.6{ }^{\circ} \mathrm{C}$ to $92.7{ }^{\circ} \mathrm{C}$; $97 \%$ yield; ${ }^{1} \mathrm{H}$ NMR $\left(400 \mathrm{MHz},\left(\mathrm{CD}_{3}\right)_{2} \mathrm{SO}\right) \delta 8.51(\mathrm{~d}, J=2.9 \mathrm{~Hz}, 1 \mathrm{H}), 8.44(\mathrm{dd}, J=9.2$, $3.0 \mathrm{~Hz}, 1 \mathrm{H}), 7.40$ (d, $J=9.3 \mathrm{~Hz}, 1 \mathrm{H}), 6.99-6.93(\mathrm{~m}, 1 \mathrm{H}), 6.05$ (d, $J$ $=5.4 \mathrm{~Hz}, 1 \mathrm{H}), 5.00(\mathrm{~d}, J=4.9 \mathrm{~Hz}, 1 \mathrm{H}), 4.81-4.74(\mathrm{~m}, 2 \mathrm{H}), 4.47(\mathrm{~s}$, $1 \mathrm{H}), 4.39(\mathrm{dd}, J=11.0,1.5 \mathrm{~Hz}, 1 \mathrm{H}), 4.09(\mathrm{dd}, J=7.5,2.9 \mathrm{~Hz}, 1 \mathrm{H})$, $3.79(\mathrm{~s}, 3 \mathrm{H}), 3.79-3.74(\mathrm{~m}, 1 \mathrm{H}), 3.24-3.11(\mathrm{~m}, 2 \mathrm{H}), 2.48-2.44(\mathrm{~m}$, $1 \mathrm{H}), 2.38-2.27$ (m, 2H), 1.96-1.86 (m, 2H), 1.70 (d, $J=13.2 \mathrm{~Hz}$, $1 \mathrm{H}), 1.57-1.43(\mathrm{~m}, 3 \mathrm{H}), 1.31(\mathrm{~m}, 1 \mathrm{H}), 1.17-1.10(\mathrm{~m}, 1 \mathrm{H}), 1.08-$ $1.01(\mathrm{~m}, 1 \mathrm{H}), 1.04(\mathrm{~s}, 3 \mathrm{H}), 0.52(\mathrm{~s}, 3 \mathrm{H}) ;{ }^{13} \mathrm{C}$ NMR $(101 \mathrm{MHz}$, $\left.\left(\mathrm{CD}_{3}\right)_{2} \mathrm{SO}\right) \delta 169.2,164.5,160.7,151.7,148.2,141.3,129.2,127.2$, 124.6, 122.1, 116.0, 108.5, 78.8, 73.4, 70.9, 63.0, 55.5, 54.8, 53.1, 42.7, 38.9, 37.8, 36.9, 28.2 , 24.9, 24.3, 23.5, 14.9; ESI-HRMS: $m / z$ $552.2203[\mathrm{M}+\mathrm{Na}]^{+}$, calcd for $\mathrm{C}_{28} \mathrm{H}_{35} \mathrm{NNaO}_{9}, 552.2210$.

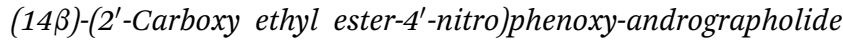
(6b1). White solid; mp $190{ }^{\circ} \mathrm{C}$ to $192{ }^{\circ} \mathrm{C}$; $78 \%$ yield; ${ }^{1} \mathrm{H}$ NMR $\left(400 \mathrm{MHz},\left(\mathrm{CD}_{3}\right)_{2} \mathrm{SO}\right) \delta 8.58(\mathrm{~d}, J=2.9 \mathrm{~Hz}, 1 \mathrm{H}), 8.49(\mathrm{dd}, J=9.2$, $3.0 \mathrm{~Hz}, 1 \mathrm{H}), 7.44(\mathrm{~d}, J=9.3 \mathrm{~Hz}, 1 \mathrm{H}), 7.02(\mathrm{t}, J=6.9 \mathrm{~Hz}, 1 \mathrm{H}), 6.15$ $(\mathrm{d}, J=5.2 \mathrm{~Hz}, 1 \mathrm{H}), 4.99$ (d, $J=4.8 \mathrm{~Hz}, 1 \mathrm{H}), 4.83(\mathrm{~s}, 1 \mathrm{H}), 4.77$ (dd, $J=11.1,5.5 \mathrm{~Hz}, 1 \mathrm{H}), 4.55$ (s, 1H), 4.41 (d, $J=11.0 \mathrm{~Hz}, 1 \mathrm{H}), 4.07$ (dd, $J=7.5,2.8 \mathrm{~Hz}, 1 \mathrm{H}), 3.82(\mathrm{~s}, 3 \mathrm{H}), 3.75(\mathrm{dd}, J=11.0,2.8 \mathrm{~Hz}$, $1 \mathrm{H}), 3.20(\mathrm{~m}, 1 \mathrm{H}), 3.02-2.95(\mathrm{~m}, 1 \mathrm{H}), 2.44(\mathrm{~m}, 1 \mathrm{H}), 2.46-2.30(\mathrm{~m}$, $2 \mathrm{H}), 1.90(\mathrm{~m}, 2 \mathrm{H}), 1.71(\mathrm{~m}, 1 \mathrm{H}), 1.55-1.38(\mathrm{~m}, 2 \mathrm{H}), 1.38-1.24(\mathrm{~m}$, 2H), 1.10-1.00 (m, 1H), 1.04 (s, 3H), $0.86(\mathrm{~m}, 1 \mathrm{H}), 0.54(\mathrm{~s}, 3 \mathrm{H})$; ${ }^{13} \mathrm{C}$ NMR $\left(101 \mathrm{MHz},\left(\mathrm{CD}_{3}\right)_{2} \mathrm{SO}\right) \delta 168.69,163.67,160.48,151.11$, 147.59, 140.66, 129.03, 126.96, 124.68, 120.98, 115.50, 107.80, $78.25,72.78,70.46,62.47,55.62,54.18,52.51,42.12,38.67$, $37.35,36.04,27.71,25.03,23.86,22.95,14.54$; ESI-HRMS: $m / z$ 552.2204 $[\mathrm{M}+\mathrm{Na}]^{+}$, calcd for $\mathrm{C}_{28} \mathrm{H}_{35} \mathrm{NNaO}_{9}, 552.2210$.

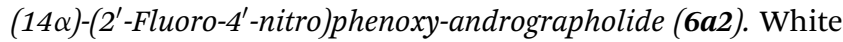
solid; mp $172{ }^{\circ} \mathrm{C}$ to $175{ }^{\circ} \mathrm{C}$; $87 \%$ yield; ${ }^{1} \mathrm{H}$ NMR $(400 \mathrm{MHz}$, $\left.\left(\mathrm{CD}_{3}\right)_{2} \mathrm{SO}\right) \delta 8.25(\mathrm{dd}, J=10.9,2.7 \mathrm{~Hz}, 1 \mathrm{H}), 8.18-8.13(\mathrm{~m}, 1 \mathrm{H})$, $7.48(\mathrm{t}, J=8.7 \mathrm{~Hz}, 1 \mathrm{H}), 6.96(\mathrm{t}, J=6.3 \mathrm{~Hz}, 1 \mathrm{H}), 6.05(\mathrm{~d}, J=5.3 \mathrm{~Hz}$, $1 \mathrm{H}), 5.03(\mathrm{~d}, J=4.9 \mathrm{~Hz}, 1 \mathrm{H}), 4.79(\mathrm{~s}, 1 \mathrm{H}), 4.74(\mathrm{~m}, 1 \mathrm{H}), 4.54(\mathrm{~s}$, $1 \mathrm{H}), 4.44(\mathrm{~d}, J=12.2 \mathrm{~Hz}, 1 \mathrm{H}), 4.11(\mathrm{~m}, 1 \mathrm{H}), 3.78(\mathrm{dd}, J=11.0$, $2.9 \mathrm{~Hz}, 1 \mathrm{H}), 3.19$ (m, 2H), 2.45 (s, 1H), 2.42-2.26 (m, 2H), 1.98$1.87(\mathrm{~m}, 2 \mathrm{H}), 1.71(\mathrm{~m}, 1 \mathrm{H}), 1.54(\mathrm{~m}, 3 \mathrm{H}), 1.38-1.25(\mathrm{~m}, 1 \mathrm{H}), 1.18-$ $1.10(\mathrm{~m}, 2 \mathrm{H}), 1.06(\mathrm{~s}, 3 \mathrm{H}), 0.54(\mathrm{~s}, 3 \mathrm{H}) ;{ }^{13} \mathrm{C}$ NMR $(101 \mathrm{MHz}$, $\left.\left(\mathrm{CD}_{3}\right)_{2} \mathrm{SO}\right) \delta 168.64,152.22,151.45,150.42,150.32,149.74$, $147.67,141.12$, 141.04, 124.11, 121.27, 121.23, 115.72, 112.68,
112.45, 108.05, 78.36, 73.02, 70.34, 62.53, 55.12, 54.30, 42.18, 38.43, 37.36, 36.35, 27.77, 24.80, 23.84, 23.01, 14.52; ESI-HRMS: $m / z 512.2054[\mathrm{M}+\mathrm{Na}]^{+}$, calcd for $\mathrm{C}_{26} \mathrm{H}_{32} \mathrm{FNNaO}_{7}$, 512.2061.

(14ß)-(2'-Fluoro-4'-nitro)phenoxy-andrographolide (6b2). White solid; mp $162{ }^{\circ} \mathrm{C}$ to $165{ }^{\circ} \mathrm{C}$; $84 \%$ yield; ${ }^{1} \mathrm{H}$ NMR $(400 \mathrm{MHz}$, $\left.\mathrm{CD}_{3} \mathrm{OD}\right) \delta 8.19-8.11(\mathrm{~m}, 2 \mathrm{H}), 7.34(\mathrm{t}, J=8.4 \mathrm{~Hz}, 1 \mathrm{H}), 7.13-7.04$ (m, 1H), 6.03-5.97 (m, 1H), $4.72(\mathrm{dd}, J=11.2,5.5 \mathrm{~Hz}, 1 \mathrm{H}), 4.56$ $(\mathrm{s}, 1 \mathrm{H}), 4.45(\mathrm{dd}, J=11.2,1.4 \mathrm{~Hz}, 1 \mathrm{H}), 4.02(\mathrm{~d}, J=11.1 \mathrm{~Hz}, 1 \mathrm{H})$, 3.32 (m, 1H), 3.21 (dd, $J=11.8,4.1 \mathrm{~Hz}, 1 \mathrm{H}), 2.52$ (m, 1H), 2.452.34 (m, 2H), 2.07-1.92 (m, 2H), 1.87-1.78 (m, 1H), 1.73-1.46 (m, 3H), 1.41-1.28 (m, 1H), $1.22(\mathrm{~m}, 1 \mathrm{H}), 1.17(\mathrm{~s}, 3 \mathrm{H}), 1.10-0.98$ $(\mathrm{m}, 1 \mathrm{H}), 0.64(\mathrm{~s}, 3 \mathrm{H}) ;{ }^{13} \mathrm{C} \mathrm{NMR}\left(101 \mathrm{MHz}, \mathrm{CD}_{3} \mathrm{OD}\right) \delta 171.05$, $154.37,152.98,151.89,151.83$, 151.73, 148.94, 143.42, 143.34, $126.12,122.24,122.20,116.71,113.79,113.56,108.54,80.83$, $74.64,72.22,64.88,57.72,56.33,43.63,40.24,38.93,37.90$, 28.89, 26.76, 25.19, 23.39, 15.42; ESI-HRMS: $m / z$ 512.2099 [M + $\mathrm{Na}]^{+}$, calcd for $\mathrm{C}_{26} \mathrm{H}_{32} \mathrm{FNNaO}_{7}, 512.2061$.

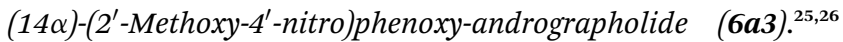
Yellow solid; mp $155^{\circ} \mathrm{C}$ to $159{ }^{\circ} \mathrm{C}$; $87 \%$ yield; ${ }^{1} \mathrm{H}$ NMR $(400 \mathrm{MHz}$, $\left.\mathrm{CD}_{3} \mathrm{OD}\right) \delta 7.95(\mathrm{dd}, J=8.8,2.6 \mathrm{~Hz}, 1 \mathrm{H}), 7.92(\mathrm{~d}, J=2.6 \mathrm{~Hz}, 1 \mathrm{H})$, $7.16(\mathrm{~d}, J=8.8 \mathrm{~Hz}, 1 \mathrm{H}), 7.12-7.03(\mathrm{~m}, 1 \mathrm{H}), 5.87$ (d, $J=5.7 \mathrm{~Hz}$, $1 \mathrm{H}), 4.91(\mathrm{~s}, 1 \mathrm{H}), 4.73(\mathrm{dd}, J=10.9,5.8 \mathrm{~Hz}, 1 \mathrm{H}), 4.67(\mathrm{~s}, 1 \mathrm{H}), 4.46$ (dd, $J=10.9,1.8 \mathrm{~Hz}, 1 \mathrm{H}), 4.10$ (d, $J=11.1 \mathrm{~Hz}, 1 \mathrm{H}), 3.98(\mathrm{~s}, 3 \mathrm{H})$, $3.38(\mathrm{t}, J=5.4 \mathrm{~Hz}, 1 \mathrm{H}), 2.58-2.40(\mathrm{~m}, 3 \mathrm{H}), 2.09-1.95(\mathrm{~m}, 2 \mathrm{H})$, 1.90-1.83 (m, 1H), 1.80-1.60 (m, 3H), 1.44-1.32 (m, 1H), 1.32$1.17(\mathrm{~m}, 2 \mathrm{H}), 1.22(\mathrm{~s}, 3 \mathrm{H}), 0.66(\mathrm{~s}, 3 \mathrm{H}) ;{ }^{13} \mathrm{C}$ NMR $(101 \mathrm{MHz}$, $\left.\mathrm{CD}_{3} \mathrm{OD}\right) \delta 171.44,153.11,152.54,151.94,148.72,144.43,126.17$, 118.27, 116.57, 109.47, 108.44, 80.88, 74.75, 72.58, 64.91, 57.17, 56.86, 56.29, 43.65, 39.84, 38.87, 38.15, 28.96, 26.36, 25.17, 23.35, 15.43; ESI-HRMS: $m / z$ 524.2253 $[\mathrm{M}+\mathrm{Na}]^{+}$, calcd for $\mathrm{C}_{27} \mathrm{H}_{35} \mathrm{NNaO}_{8}, 524.2260$.

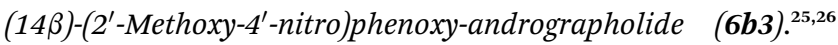
Yellow solid; mp $151{ }^{\circ} \mathrm{C}$ to $153{ }^{\circ} \mathrm{C}$; $90 \%$ yield; ${ }^{1} \mathrm{H}$ NMR $(400 \mathrm{MHz}$, $\left.\mathrm{CDCl}_{3}\right) \delta 7.89(\mathrm{~m}, 1 \mathrm{H}), 7.84-7.79(\mathrm{~m}, 1 \mathrm{H}), 7.13-7.05(\mathrm{~m}, 1 \mathrm{H}), 6.88$ (dd, $J=9.2,4.2 \mathrm{~Hz}, 1 \mathrm{H}), 5.71-5.65(\mathrm{~m}, 1 \mathrm{H}), 4.83(\mathrm{~d}, J=1.9 \mathrm{~Hz}$, $1 \mathrm{H}), 4.58(\mathrm{dd}, J=11.0,5.8 \mathrm{~Hz}, 1 \mathrm{H}), 4.42(\mathrm{dd}, J=11.0,1.8 \mathrm{~Hz}$, $1 \mathrm{H}), 4.34(\mathrm{~s}, 1 \mathrm{H}), 4.16-4.08(\mathrm{~m}, 1 \mathrm{H}), 3.96(\mathrm{~s}, 3 \mathrm{H}), 3.38(\mathrm{dd}, J=$ 11.6, $3.5 \mathrm{~Hz}, 1 \mathrm{H}), 3.28$ (d, $J=11.1 \mathrm{~Hz}, 1 \mathrm{H}), 2.58(\mathrm{~d}, J=52.7 \mathrm{~Hz}$, $2 \mathrm{H}), 2.44-2.36(\mathrm{~m}, 2 \mathrm{H}), 2.32-2.21(\mathrm{~m}, 1 \mathrm{H}), 1.97(\mathrm{~m}, 1 \mathrm{H}), 1.89$ (dd, $J=9.3,2.7 \mathrm{~Hz}, 1 \mathrm{H}), 1.85-1.78(\mathrm{~m}, 1 \mathrm{H}), 1.78-1.60(\mathrm{~m}, 2 \mathrm{H})$, $1.52(\mathrm{~m}, 1 \mathrm{H}), 1.26-1.16(\mathrm{~m}, 2 \mathrm{H}), 1.22(\mathrm{~s}, 3 \mathrm{H}), 1.14-1.03(\mathrm{~m}, 1 \mathrm{H})$, $0.61(\mathrm{~s}, 3 \mathrm{H}) ;{ }^{13} \mathrm{C}$ NMR $\left(101 \mathrm{MHz}, \mathrm{CDCl}_{3}\right) \delta$ 168.99, 151.84, 151.03 , 150.56, 147.09, 143.34, 124.42, 117.39, 116.00, 108.22, $107.50,80.35,77.37,77.26,77.05,76.73,73.32,70.60,64.04$, 56.36, 55.75, 55.06, 42.82, 38.93, 37.65, 36.64, 28.16, 25.71, 23.70, 22.77, 15.12; ESI-HRMS: $m / z 524.2253[\mathrm{M}+\mathrm{Na}]^{+}$, calcd for $\mathrm{C}_{27} \mathrm{H}_{35} \mathrm{NNaO}_{8}, 524.2260$.

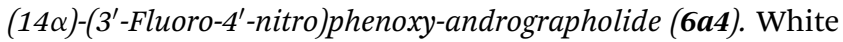
solid; mp $191{ }^{\circ} \mathrm{C}$ to $194{ }^{\circ} \mathrm{C}$; 86\% yield; ${ }^{1} \mathrm{H}$ NMR $(400 \mathrm{MHz}$, $\left.\left(\mathrm{CD}_{3}\right)_{2} \mathrm{SO}\right) \delta 8.10(\mathrm{t}, J=9.1 \mathrm{~Hz}, 1 \mathrm{H}), 7.65(\mathrm{~s}, 1 \mathrm{H}), 7.13(\mathrm{dd}, J=$ 13.4, $2.6 \mathrm{~Hz}, 1 \mathrm{H}), 6.90(\mathrm{dd}, J=9.3,2.3 \mathrm{~Hz}, 1 \mathrm{H}), 5.11(\mathrm{~s}, 1 \mathrm{H}), 5.04$ $(\mathrm{d}, J=4.9 \mathrm{~Hz}, 1 \mathrm{H}), 4.93-4.86(\mathrm{~m}, 1 \mathrm{H}), 4.89(\mathrm{~s}, 3 \mathrm{H}), 4.11(\mathrm{~m}, 1 \mathrm{H})$, $3.82(\mathrm{~m}, 1 \mathrm{H}), 3.24(\mathrm{~m}, 2 \mathrm{H}), 2.31$ (m, 1H), 2.03-1.91 (m, 2H), 1.89$1.59(\mathrm{~m}, 6 \mathrm{H}), 1.40-1.27$ (m, 1H), 1.26-1.11 (m, 2H), $1.05(\mathrm{~m}, 3 \mathrm{H})$, $0.62(\mathrm{~s}, 3 \mathrm{H}) ;{ }^{13} \mathrm{C} \mathrm{NMR}\left(101 \mathrm{MHz},\left(\mathrm{CD}_{3}\right)_{2} \mathrm{SO}\right) \delta 172.00,163.60$, 163.49, 157.78, 155.17, 149.66, 146.99, 131.27, 130.46, 130.40, $128.16,111.88,111.86,107.72$, 105.08, 104.84, 78.29, 72.99, 
$71.10,62.58,54.48,51.23,42.27,38.45,37.77,36.50,29.11$, 27.80, 23.99, 22.95, 14.77; ESI-HRMS: $m / z 512.2055[\mathrm{M}+\mathrm{Na}]^{+}$, calcd for $\mathrm{C}_{26} \mathrm{H}_{32} \mathrm{FNNaO}_{7}, 512.2061$.

(14ß)-(3'-Fluoro-4'-nitro)phenoxy-andrographolide (6b4). Yellow solid; mp $163{ }^{\circ} \mathrm{C}$ to $166{ }^{\circ} \mathrm{C}$; 90\% yield; ${ }^{1} \mathrm{H}$ NMR $(400 \mathrm{MHz}$, $\left.\mathrm{CD}_{3} \mathrm{OD}\right) \delta 8.20(\mathrm{t}, J=9.0 \mathrm{~Hz}, 1 \mathrm{H}), 7.18-7.06(\mathrm{~m}, 2 \mathrm{H}), 6.99(\mathrm{~m}, 1 \mathrm{H})$, $5.97(\mathrm{~d}, J=5.3 \mathrm{~Hz}, 1 \mathrm{H}), 4.70(\mathrm{dd}, J=11.1,5.5 \mathrm{~Hz}, 1 \mathrm{H}), 4.57$ (s, $1 \mathrm{H}), 4.40(\mathrm{dd}, J=11.1,1.3 \mathrm{~Hz}, 1 \mathrm{H}), 4.04(\mathrm{~d}, J=11.1 \mathrm{~Hz}, 1 \mathrm{H}), 3.61$ $(\mathrm{q}, J=7.0 \mathrm{~Hz}, 3 \mathrm{H}), 3.33(\mathrm{~s}, 1 \mathrm{H}), 3.24(\mathrm{~m}, 1 \mathrm{H}), 2.56(\mathrm{~m}, 1 \mathrm{H}), 2.47-$ $2.36(\mathrm{~m}, 2 \mathrm{H}), 2.02(\mathrm{~m}, 1 \mathrm{H}), 1.98-1.91(\mathrm{~m}, 1 \mathrm{H}), 1.89-1.79(\mathrm{~m}, 1 \mathrm{H})$, $1.63(\mathrm{~m}, 3 \mathrm{H}), 1.42-1.20(\mathrm{~m}, 2 \mathrm{H}), 1.18(\mathrm{~s}, 3 \mathrm{H}), 1.13-1.01(\mathrm{~m}, 1 \mathrm{H})$, $0.66(\mathrm{~s}, 3 \mathrm{H}) ;{ }^{13} \mathrm{C}$ NMR (101 MHz, CD $\left.\mathrm{OD}\right) \delta$ 171.07, 163.94, 163.83 , 159.93, 157.31, 152.70, 148.90, 132.84, 132.77, 129.41, $126.15,113.08,113.05,108.63,106.14,105.90,80.82,73.80,72.22$, 64.90, 57.52, 56.34, 43.65, 40.25, 38.95, 38.09, 28.91, 26.76, 25.20, 23.39, 15.44; ESI-HRMS: $m / z 512.2093[\mathrm{M}+\mathrm{Na}]^{+}$, calcd for $\mathrm{C}_{26^{-}}$ $\mathrm{H}_{32} \mathrm{FNNaO}_{7}, 512.2061$.

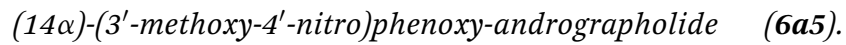
White solid; mp $131{ }^{\circ} \mathrm{C}$ to $133{ }^{\circ} \mathrm{C}$; $81 \%$ yield; ${ }^{1} \mathrm{H}$ NMR $(400 \mathrm{MHz}$, $\left.\left(\mathrm{CD}_{3}\right)_{2} \mathrm{SO}\right) \delta 7.99(\mathrm{~d}, J=9.1 \mathrm{~Hz}, 1 \mathrm{H}), 6.96(\mathrm{t}, J=6.8 \mathrm{~Hz}, 1 \mathrm{H}), 6.85$ $(\mathrm{d}, J=2.4 \mathrm{~Hz}, 1 \mathrm{H}), 6.73(\mathrm{dd}, J=9.1,2.4 \mathrm{~Hz}, 1 \mathrm{H}), 6.01(\mathrm{~d}, J=$ $5.0 \mathrm{~Hz}, 1 \mathrm{H}), 5.04$ (d, $J=4.9 \mathrm{~Hz}, 1 \mathrm{H}), 4.83$ (s, 1H), 4.71 (dd, $J=$ 11.0, $5.4 \mathrm{~Hz}, 1 \mathrm{H}), 4.56(\mathrm{~s}, 1 \mathrm{H}), 4.39-4.33(\mathrm{~m}, 1 \mathrm{H}), 4.12$ (dd, $J=$ $7.4,2.9 \mathrm{~Hz}, 1 \mathrm{H}), 3.78$ (dd, $J=11.0,2.8 \mathrm{~Hz}, 1 \mathrm{H}), 3.26-3.14(\mathrm{~m}$, $2 \mathrm{H}), 2.44(\mathrm{dd}, J=5.8,3.0 \mathrm{~Hz}, 1 \mathrm{H}), 2.36-2.28(\mathrm{~m}, 2 \mathrm{H}), 1.97-1.87$ (m, 2H), 1.76-1.68 (m, 1H), 1.60-1.48 (m, 3H), 1.36-1.22 (m, $2 \mathrm{H}), 1.18-1.13(\mathrm{~m}, 3 \mathrm{H}), 1.06(\mathrm{~s}, 3 \mathrm{H}), 0.90-0.76(\mathrm{~m}, 1 \mathrm{H}), 0.55(\mathrm{~s}$, $3 \mathrm{H}) ;{ }^{13} \mathrm{C}$ NMR $\left(101 \mathrm{MHz}, \mathrm{CDCl}_{3}\right.$ ) $\delta$ 168.7, 161.5, 155.8, 151.9, 146.6, 134.2, 128.7, 123.8, 109.1, 104.6, 101.7, 80.4, 71.8, 70.4, 64.1, 56.7, 55.8, 55.2, 42.8, 38.8, 37.7, 37.0, 28.1, 25.4, 23.6, 22.7, 15.2; ESI-HRMS: $\mathrm{m} / \mathrm{z} 524.2252[\mathrm{M}+\mathrm{Na}]^{+}$, calcd for $\mathrm{C}_{27} \mathrm{H}_{35} \mathrm{NNaO}_{8}, 524.2260$.

(14ß)-(3'-Methoxy-4'-nitro)phenoxy-andrographolide (6b5). Yellow solid; mp $126{ }^{\circ} \mathrm{C}$ to $129^{\circ} \mathrm{C}$; $85 \%$ yield; ${ }^{1} \mathrm{H}$ NMR $(400 \mathrm{MHz}$, $\left.\mathrm{CD}_{3} \mathrm{OD}\right) \delta 8.02(\mathrm{~d}, J=9.1 \mathrm{~Hz}, 1 \mathrm{H}), 7.15(\mathrm{t}, J=6.6 \mathrm{~Hz}, 1 \mathrm{H}), 6.85(\mathrm{~d}$, $J=2.5 \mathrm{~Hz}, 1 \mathrm{H}), 6.71(\mathrm{dd}, J=9.1,2.5 \mathrm{~Hz}, 1 \mathrm{H}), 5.98(\mathrm{~d}, J=5.4 \mathrm{~Hz}$, $1 \mathrm{H}), 4.72(\mathrm{dd}, J=11.0,5.5 \mathrm{~Hz}, 1 \mathrm{H}), 4.60$ (s, 1H), 4.42 (dd, $J=$ 11.0, $1.3 \mathrm{~Hz}, 1 \mathrm{H}), 4.06$ (d, $J=11.1 \mathrm{~Hz}, 1 \mathrm{H}), 3.99$ (s, 3H), 3.35 (d, $J$ $=4.2 \mathrm{~Hz}, 1 \mathrm{H}), 3.25(\mathrm{dd}, J=11.8,4.1 \mathrm{~Hz}, 1 \mathrm{H}), 2.60-2.52(\mathrm{~m}, 1 \mathrm{H})$, $2.42(\mathrm{~m}, 2 \mathrm{H}), 2.10-2.00(\mathrm{~m}, 1 \mathrm{H}), 1.97(\mathrm{~m}, 1 \mathrm{H}), 1.90-1.81(\mathrm{~m}, 1 \mathrm{H})$, 1.76-1.64 (m, 1H), 1.64-1.54 (m, 2H), 1.42-1.30 (m, 1H), 1.24 $(\mathrm{m}, 1 \mathrm{H}), 1.20(\mathrm{~s}, 3 \mathrm{H}), 1.15-1.05(\mathrm{~m}, 1 \mathrm{H}), 0.68(\mathrm{~s}, 3 \mathrm{H}) ;{ }^{13} \mathrm{C} \mathrm{NMR}$ (101 MHz, CD $3 \mathrm{OD}) \delta 171.33,163.25,156.92,152.16,148.93$, 135.26, 129.27, 126.63, 108.56, 107.53, 102.64, 80.83, 73.31, $72.52,64.88,57.55,57.34,56.33,43.65,40.24,38.95,38.03$, 28.91, 26.71, 25.20, 23.38, 15.41; ESI-HRMS: $m / z$ 524.2254 [M + $\mathrm{Na}]^{+}$, calcd for $\mathrm{C}_{27} \mathrm{H}_{35} \mathrm{NNaO}_{8}, 524.2260$.

(14ß)-(2'-Nitro)phenoxy-andrographolide (6b6). Yellow solid; mp $167{ }^{\circ} \mathrm{C}$ to $168{ }^{\circ} \mathrm{C}$; 89\% yield; ${ }^{1} \mathrm{H}$ NMR (400 $\mathrm{MHz}, \mathrm{CDCl}_{3}$ ) $\delta 7.89(\mathrm{dd}, J=8.1,1.6 \mathrm{~Hz}, 1 \mathrm{H}), 7.62-7.55(\mathrm{~m}, 1 \mathrm{H}), 7.18(\mathrm{t}, J=$ $7.7 \mathrm{~Hz}, 1 \mathrm{H}), 7.13(\mathrm{dd}, J=10.1,3.9 \mathrm{~Hz}, 1 \mathrm{H}), 6.92(\mathrm{~d}, J=8.3 \mathrm{~Hz}$, $1 \mathrm{H}), 5.64(\mathrm{~d}, J=5.6 \mathrm{~Hz}, 1 \mathrm{H}), 4.84(\mathrm{~d}, J=15.2 \mathrm{~Hz}, 1 \mathrm{H}), 4.66(\mathrm{dd}, J$ $=10.9,6.0 \mathrm{~Hz}, 1 \mathrm{H}), 4.44(\mathrm{dd}, J=10.9,2.0 \mathrm{~Hz}, 1 \mathrm{H}), 4.31(\mathrm{~s}, 1 \mathrm{H})$, 4.16-4.09 (m, 1H), 3.43 (dd, $J=11.5,4.6 \mathrm{~Hz}, 1 \mathrm{H}), 3.28$ (d, $J=$ $11.1 \mathrm{~Hz}, 1 \mathrm{H}), 2.56-2.45(\mathrm{~m}, 1 \mathrm{H}), 2.38(\mathrm{dd}, J=13.2,3.5 \mathrm{~Hz}, 1 \mathrm{H})$, $2.26(\mathrm{~m}, 1 \mathrm{H}), 2.09(\mathrm{~s}, 3 \mathrm{H}), 1.98(\mathrm{t}, J=12.3 \mathrm{~Hz}, 1 \mathrm{H}), 1.89(\mathrm{~d}, J=$ $10.4 \mathrm{~Hz}, 1 \mathrm{H}), 1.85-1.78$ (m, 1H), 1.78-1.63 (m, 2H), 1.59 (m, 1H),
1.31-1.18 (m, 2H), 1.24 (s, 3H), $1.10(\mathrm{~m}, 1 \mathrm{H}), 0.58(\mathrm{~s}, 3 \mathrm{H}) ;{ }^{13} \mathrm{C}$ NMR (101 MHz, $\left.\mathrm{CDCl}_{3}\right) \delta 168.74,152.64,149.38,147.27,141.14$, $134.14,126.28,123.69,122.33$, 115.90, 108.07, 80.31, 77.37, $77.25,77.05,76.73,73.14,70.30,64.10,55.80,54.86,42.80$, 38.89, 37.63, 36.54, 28.12, 25.81, 23.69, 22.63, 15.12; ESI-HRMS: $m / z 494.2158[\mathrm{M}+\mathrm{Na}]^{+}$, calcd for $\mathrm{C}_{26} \mathrm{H}_{33} \mathrm{NNaO}_{7}, 494.2155$.

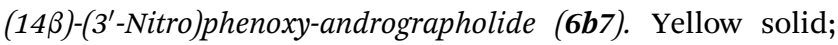
mp $144{ }^{\circ} \mathrm{C}$ to $146{ }^{\circ} \mathrm{C}$; $93 \%$ yield; ${ }^{1} \mathrm{H}$ NMR (400 $\mathrm{MHz}, \mathrm{CDCl}_{3}$ ) $\delta 7.94(\mathrm{~m}, 1 \mathrm{H}), 7.69(\mathrm{t}, J=2.3 \mathrm{~Hz}, 1 \mathrm{H}), 7.58-7.49(\mathrm{~m}, 1 \mathrm{H}), 7.20$ $(\mathrm{m}, 1 \mathrm{H}), 7.17-7.11(\mathrm{~m}, 1 \mathrm{H}), 5.62(\mathrm{~m}, 1 \mathrm{H}), 4.87(\mathrm{dd}, J=2.5$, $1.3 \mathrm{~Hz}, 1 \mathrm{H}), 4.72-4.63(\mathrm{~m}, 1 \mathrm{H}), 4.45-4.35(\mathrm{~m}, 2 \mathrm{H}), 4.16-4.08$ (m, $1 \mathrm{H}), 3.41(\mathrm{~m}, 1 \mathrm{H}), 3.33-3.25(\mathrm{~m}, 1 \mathrm{H}), 2.51(\mathrm{~m}, 1 \mathrm{H}), 2.46-2.38(\mathrm{~m}$, $1 \mathrm{H}), 2.37-2.23(\mathrm{~m}, 1 \mathrm{H}), 2.29(\mathrm{~s}, 3 \mathrm{H}), 2.01-1.93(\mathrm{~m}, 1 \mathrm{H}), 1.93-1.87$ $(\mathrm{m}, 1 \mathrm{H}), 1.83(\mathrm{~m}, 1 \mathrm{H}), 1.74(\mathrm{~m}, 1 \mathrm{H}), 1.62(\mathrm{~m}, 2 \mathrm{H}), 1.34-1.18(\mathrm{~m}$, $2 \mathrm{H}), 1.24$ (s, 3H), 1.18-1.06 (m, 1H), $0.60(\mathrm{~s}, 3 \mathrm{H}) ;{ }^{13} \mathrm{C}$ NMR (101 $\left.\mathrm{MHz}, \mathrm{CDCl}_{3}\right) \delta 168.90,156.99,151.67,149.36,146.91,130.85$, $124.19,122.41,117.26,109.70,108.28,80.29$, 77.38, 77.06, $76.74,71.95,70.39,64.05,55.77,55.15,42.80,39.00,37.68$, 36.91, 28.05, 25.74, 23.68, 22.72, 15.10; ESI-HRMS: $m / z 494.2156$ $[\mathrm{M}+\mathrm{Na}]^{+}$, calcd for $\mathrm{C}_{26} \mathrm{H}_{33} \mathrm{NNaO}_{7}, 494.2155$.

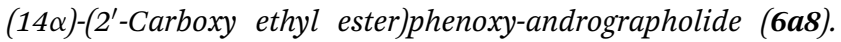
White solid; mp $157{ }^{\circ} \mathrm{C}$ to $159{ }^{\circ} \mathrm{C}$; $96 \%$ yield; ${ }^{1} \mathrm{H}$ NMR $(400 \mathrm{MHz}$, $\left.\mathrm{C}_{6} \mathrm{D}_{6}\right) \delta 7.78(\mathrm{dd}, J=7.7,1.8 \mathrm{~Hz}, 1 \mathrm{H}), 7.21(\mathrm{t}, J=6.0 \mathrm{~Hz}, 1 \mathrm{H})$, 6.98-6.92 (m, 1H), $6.71(\mathrm{t}, J=7.6 \mathrm{~Hz}, 1 \mathrm{H}), 6.38(\mathrm{~d}, J=8.2 \mathrm{~Hz}$, $1 \mathrm{H}), 5.11(\mathrm{~s}, 1 \mathrm{H}), 4.84(\mathrm{~s}, 1 \mathrm{H}), 4.57(\mathrm{~s}, 1 \mathrm{H}), 4.19-4.11(\mathrm{~m}, 2 \mathrm{H})$, $4.09(\mathrm{dd}, J=8.8,4.0 \mathrm{~Hz}, 1 \mathrm{H}), 3.78(\mathrm{dd}, J=17.5,8.6 \mathrm{~Hz}, 2 \mathrm{H}), 3.44$ $(\mathrm{dd}, J=7.9,3.7 \mathrm{~Hz}, 1 \mathrm{H}), 3.07$ (d, $J=11.5 \mathrm{~Hz}, 1 \mathrm{H}), 2.22-2.13(\mathrm{~m}$, $3 \mathrm{H}), 1.89-1.80(\mathrm{~m}, 1 \mathrm{H}), 1.78-1.67(\mathrm{~m}, 1 \mathrm{H}), 1.60-1.51(\mathrm{~m}, 1 \mathrm{H})$, 1.51-1.43 (m, 2H), $1.42(\mathrm{~s}, 3 \mathrm{H}), 1.35$ (s, 3H), 1.31 (d, $J=2.5 \mathrm{~Hz}$, $1 \mathrm{H}), 1.09(\mathrm{~s}, 3 \mathrm{H}), 1.06(\mathrm{t}, J=7.1 \mathrm{~Hz}, 3 \mathrm{H}), 0.99-0.88(\mathrm{~m}, 3 \mathrm{H}), 0.80$ $(\mathrm{s}, 3 \mathrm{H}) ;{ }^{13} \mathrm{C}$ NMR $\left(101 \mathrm{MHz}, \mathrm{C}_{6} \mathrm{D}_{6}\right) \delta 168.70,165.60,156.04$, 149.51, 147.00, 132.85, 132.04, 125.51, 124.38, 122.50, 117.83, 109.13, 99.26, 75.48, 73.78, 70.37, 64.02, 60.96, 55.62, 51.54, $38.23,38.07,37.66,34.21,26.70,26.05,25.29,25.24,24.89$, 23.15, 16.22, 14.10; ESI-HRMS: $m / z: 521.2509[\mathrm{M}+\mathrm{Na}]^{+}$, calcd for $\mathrm{C}_{29} \mathrm{H}_{38} \mathrm{NaO}_{7}, 521.2515$.

(14ß)-(2'-Carboxy ethyl ester)phenoxy-andrographolide (6b8). White solid; mp $181{ }^{\circ} \mathrm{C}$ to $182{ }^{\circ} \mathrm{C} ; 88 \%$ yield; ${ }^{1} \mathrm{H}$ NMR $(400 \mathrm{MHz}$, $\left.\mathrm{CDCl}_{3}\right) \delta 7.88(\mathrm{dd}, J=7.8,1.7 \mathrm{~Hz}, 1 \mathrm{H}), 7.54-7.48(\mathrm{~m}, 1 \mathrm{H}), 7.15(\mathrm{t}$, $J=7.6 \mathrm{~Hz}, 1 \mathrm{H}), 7.04(\mathrm{t}, J=7.0 \mathrm{~Hz}, 1 \mathrm{H}), 6.91(\mathrm{~d}, J=8.3 \mathrm{~Hz}, 1 \mathrm{H})$, $5.61(\mathrm{~d}, J=5.3 \mathrm{~Hz}, 1 \mathrm{H}), 4.83(\mathrm{~d}, J=1.9 \mathrm{~Hz}, 1 \mathrm{H}), 4.58(\mathrm{dd}, J=$ 10.7, $5.4 \mathrm{~Hz}, 1 \mathrm{H}), 4.52(\mathrm{dd}, J=10.7,1.7 \mathrm{~Hz}, 1 \mathrm{H}), 4.34(\mathrm{dd}, J=$ 14.7, 7.6 Hz, 3H), 4.14 (d, $J=11.1 \mathrm{~Hz}, 1 \mathrm{H}), 3.46-3.36(\mathrm{~m}, 1 \mathrm{H})$, 3.33-3.25 (m, 1H), 2.47-2.25 (m, 4H), 2.22-2.21 (m, 1H), 2.02$1.90(\mathrm{~m}, 1 \mathrm{H}), 1.88-1.78(\mathrm{~m}, 2 \mathrm{H}), 1.78-1.61$ (m, 2H), 1.53-1.46 $(\mathrm{m}, 1 \mathrm{H}), 1.36(\mathrm{t}, 3 \mathrm{H}), 1.32-1.16(\mathrm{~m}, 2 \mathrm{H}), 1.24(\mathrm{~s}, 3 \mathrm{H}), 1.10-0.99$ $(\mathrm{m}, 1 \mathrm{H}), 0.56(\mathrm{~s}, 3 \mathrm{H}) ;{ }^{13} \mathrm{C}$ NMR $\left(101 \mathrm{MHz}, \mathrm{CDCl}_{3}\right) \delta$ 169.45, 165.73 , 155.78, 150.94, 147.11, 133.38, 132.26, 124.95, 123.22, 122.60, 117.01, 108.19, 80.33, 77.36, 77.25, 77.04, 76.73, 73.39, $70.98,64.09,61.16,55.76,54.90,42.81,38.81,37.63,36.55$, 28.12, 25.64, 23.68, 22.64, 15.07, 14.29 ESI-HRMS: $\mathrm{m} / z$ 521.2517 $[\mathrm{M}+\mathrm{Na}]^{+}$, calcd for $\mathrm{C}_{29} \mathrm{H}_{39} \mathrm{NaO}_{7}, 521.2515$.

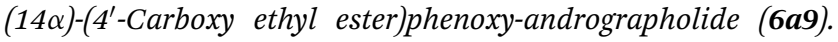
White solid; mp $183{ }^{\circ} \mathrm{C}$ to $185{ }^{\circ} \mathrm{C} ; 84 \%$ yield; ${ }^{1} \mathrm{H}$ NMR $(400 \mathrm{MHz}$, $\left.\left(\mathrm{CD}_{3}\right)_{2} \mathrm{SO}\right) \delta 8.00-7.91(\mathrm{~m}, 2 \mathrm{H}), 7.09(\mathrm{~d}, J=8.9 \mathrm{~Hz}, 2 \mathrm{H}), 6.93(\mathrm{t}, J$ $=6.2 \mathrm{~Hz}, 1 \mathrm{H}), 5.88(\mathrm{~d}, J=5.5 \mathrm{~Hz}, 1 \mathrm{H}), 5.01(\mathrm{~d}, J=4.7 \mathrm{~Hz}, 1 \mathrm{H})$, $4.82(\mathrm{~s}, 1 \mathrm{H}), 4.73(\mathrm{dd}, J=10.9,5.6 \mathrm{~Hz}, 1 \mathrm{H}), 4.58$ (s, 1H), 4.33- 
$4.26(\mathrm{~m}, 3 \mathrm{H}), 4.10(\mathrm{~d}, J=5.1 \mathrm{~Hz}, 1 \mathrm{H}), 3.77(\mathrm{~d}, J=10.8 \mathrm{~Hz}, 1 \mathrm{H})$, 3.24-3.13 (m, 2H), 2.43 (s, 1H), 2.37-2.27 (m, 2H), 1.96-1.87 (m, $2 \mathrm{H}), 1.71(\mathrm{~d}, J=13.1 \mathrm{~Hz}, 1 \mathrm{H}), 1.58-1.45(\mathrm{~m}, 3 \mathrm{H}), 1.38-1.24(\mathrm{~m}$, $1 \mathrm{H}), 1.31(\mathrm{t}, J=7.1 \mathrm{~Hz}, 3 \mathrm{H}), 1.12(\mathrm{dd}, J=15.9,12.0 \mathrm{~Hz}, 2 \mathrm{H}), 1.05$ $(\mathrm{s}, 3 \mathrm{H}), 0.52(\mathrm{~s}, 3 \mathrm{H}) ;{ }^{13} \mathrm{C} \mathrm{NMR}\left(101 \mathrm{MHz},\left(\mathrm{CD}_{3}\right)_{2} \mathrm{SO}\right) \delta 169.4$, 165.7, 161.0, 150.9, 148.2, 131.9, 125.3, 123.7, 115.8, 108.5, 78.8, 71.8, 71.2, 63.0, 60.9, 55.6, 54.8, 42.7, 38.9, 37.9, 36.9, 28.3, 25.2, 24.3, 23.5, 21.2, 15.0, 14.7, 14.5; ESI-HRMS: $m / z$ 521.2507 [M + $\mathrm{Na}]^{+}$, calcd for $\mathrm{C}_{29} \mathrm{H}_{38} \mathrm{NaO}_{7}, 521.2515$.

(14ß)-(4'-Carboxy ethyl ester)phenoxy-andrographolide (6b9). White solid; mp $136{ }^{\circ} \mathrm{C}$ to $139{ }^{\circ} \mathrm{C}$; $95 \%$ yield; ${ }^{1} \mathrm{H}$ NMR $(400 \mathrm{MHz}$, $\left.\mathrm{CD}_{3} \mathrm{OD}\right) \delta 8.07-8.01(\mathrm{~m}, 2 \mathrm{H}), 7.12(\mathrm{t}, J=7.3 \mathrm{~Hz}, 1 \mathrm{H}), 7.09-7.04$ $(\mathrm{m}, 2 \mathrm{H}), 5.88(\mathrm{~d}, J=5.4 \mathrm{~Hz}, 1 \mathrm{H}), 4.70(\mathrm{dd}, J=10.9,5.5 \mathrm{~Hz}, 1 \mathrm{H})$, 4.56 (s, 1H), 4.40-4.31 (m, 3H), 4.03 (d, J=11.1 Hz, 1H), 3.29 (s, $1 \mathrm{H}), 3.20(\mathrm{dd}, J=11.9,4.1 \mathrm{~Hz}, 1 \mathrm{H}), 2.55-2.47(\mathrm{~m}, 1 \mathrm{H}), 2.45-2.30$ (m, 2H), 2.08-1.91 (m, 2H), 1.86-1.79 (m, 1H), 1.71-1.58 (m, $1 \mathrm{H}), 1.58-1.48(\mathrm{~m}, 2 \mathrm{H}), 1.42-1.27(\mathrm{~m}, 4 \mathrm{H}), 1.24-1.14(\mathrm{~m}, 1 \mathrm{H})$, $1.17(\mathrm{~s}, 3 \mathrm{H}), 1.09-0.96(\mathrm{~m}, 1 \mathrm{H}), 0.63(\mathrm{~s}, 3 \mathrm{H}) ;{ }^{13} \mathrm{C} \mathrm{NMR}(101 \mathrm{MHz}$, $\left.\mathrm{CD}_{3} \mathrm{OD}\right) \delta 171.50,167.59,162.09,151.93,148.95,132.93,126.89$, 125.30, 116.59, 108.53, 80.79, 72.88, 72.66, 64.90, 62.07, 57.61, 56.29, 43.62, 40.21, 38.95, 37.99, 28.87, 26.65, 25.18, 23.36, 15.43, 14.68; ESI-HRMS: $m / z$ 521.2509 $[\mathrm{M}+\mathrm{Na}]^{+}$, calcd for $\mathrm{C}_{29} \mathrm{H}_{38} \mathrm{NaO}_{7}, 521.2515$.

(14ß)-(4'-Cyano)phenoxy-andrographolide (6b10). White solid; mp $182{ }^{\circ} \mathrm{C}$ to $184{ }^{\circ} \mathrm{C} ; 76 \%$ yield; ${ }^{1} \mathrm{H}$ NMR (400 $\mathrm{MHz}, \mathrm{CD}_{3} \mathrm{OD}$ ) $\delta$ 7.73-7.68 (m, 2H), 7.13-7.06 (m, 3H), $5.86(\mathrm{~d}, J=5.5 \mathrm{~Hz}, 1 \mathrm{H})$, 4.85 (s, 1H), 4.65 (dd, $J=11.0,5.5 \mathrm{~Hz}, 1 \mathrm{H}), 4.52$ (s, 1H), 4.31 (dd, $J=10.9,1.4 \mathrm{~Hz}, 1 \mathrm{H}), 3.99$ (d, $J=11.1 \mathrm{~Hz}, 1 \mathrm{H}), 3.30-3.35(\mathrm{~m}, 1 \mathrm{H})$, $3.18(\mathrm{dd}, J=11.8,4.2 \mathrm{~Hz}, 1 \mathrm{H}), 2.53-2.45(\mathrm{~m}, 1 \mathrm{H}), 2.41-2.28(\mathrm{~m}$, 2H), 2.02-1.89 (m, 2H), 1.82-1.76 (m, 1H), $1.63(\mathrm{~m}, 1 \mathrm{H}), 1.51(\mathrm{~m}$, 2H), 1.36-1.24 (m, 1H), 1.20-1.15 (m, 1H), 1.14 (s, 3H), 1.06-0.97 $(\mathrm{m}, 1 \mathrm{H}), 0.60(\mathrm{~s}, 3 \mathrm{H}) ;{ }^{13} \mathrm{C} \mathrm{NMR}\left(101 \mathrm{MHz}, \mathrm{CD}_{3} \mathrm{OD}\right) \delta$ 171.30, $161.67,152.20$, 148.92, 135.62, 126.56, 119.68, 117.60, 108.51, $106.25,80.79,72.91,72.40,64.87,57.60,56.33,43.62,40.21$, 38.93, 38.04, 28.86, 26.67, 25.17, 23.35, 15.40; ESI-HRMS: $\mathrm{m} / \mathrm{z}$ $474.2252[\mathrm{M}+\mathrm{Na}]^{+}$calcd for $\mathrm{C}_{27} \mathrm{H}_{33} \mathrm{NNaO}_{5}, 474.2256$.

(14ß)-(4'-Methoxy)phenoxy-andrographolide (6b11). White solid; mp $178{ }^{\circ} \mathrm{C}$ to $180{ }^{\circ} \mathrm{C}$; $75 \%$ yield; ${ }^{1} \mathrm{H}$ NMR $(400 \mathrm{MHz}$, $\left.\left(\mathrm{CD}_{3}\right)_{2} \mathrm{SO}\right) \delta$ 6.97-6.88 (m, 4H), 6.87-6.82 (m, 1H), $5.66(\mathrm{~d}, J=$ $5.4 \mathrm{~Hz}, 1 \mathrm{H}), 4.83-4.77(\mathrm{~m}, 1 \mathrm{H}), 4.60(\mathrm{dd}, J=10.7,5.4 \mathrm{~Hz}, 1 \mathrm{H})$, 4.46-4.40 (m, 1H), 4.33 (dd, $J=10.7,1.4 \mathrm{~Hz}, 1 \mathrm{H}), 3.78(\mathrm{~d}, J=$ $10.9 \mathrm{~Hz}, 1 \mathrm{H}), 3.72(\mathrm{~s}, 3 \mathrm{H}), 3.21$ (d, $J=10.8 \mathrm{~Hz}, 1 \mathrm{H}), 3.09(\mathrm{dd}, J=$ 11.2, $4.5 \mathrm{~Hz}, 1 \mathrm{H}), 2.30(\mathrm{~m}, 1 \mathrm{H}), 2.21-2.12(\mathrm{~m}, 2 \mathrm{H}), 1.97-1.83(\mathrm{~m}$, $2 \mathrm{H}), 1.71(\mathrm{~m}, 1 \mathrm{H}), 1.61-1.22(\mathrm{~m}, 4 \mathrm{H}), 1.14-0.91(\mathrm{~m}, 2 \mathrm{H}), 1.05(\mathrm{~s}$, $3 \mathrm{H}), 0.55(\mathrm{~s}, 3 \mathrm{H}) ;{ }^{13} \mathrm{C} \mathrm{NMR}\left(101 \mathrm{MHz},\left(\mathrm{CD}_{3}\right)_{2} \mathrm{SO}\right) \delta$ 169.24, 154.49, 150.27, 149.39, 147.73, 125.79, 117.95, 117.95, 114.82, 114.82 , 107.75, 78.30, 72.48, 71.16, 62.55, 55.38, 55.36, 54.22, 42.16, 38.59, 37.38, 36.24, 27.74, 24.95, 23.87, 22.96, 14.58; ESIHRMS: $m / z$ 479.2417 [M Na $]^{+}$, calcd for $\mathrm{C}_{27} \mathrm{H}_{36} \mathrm{NaO}_{6}, 479.2410$.

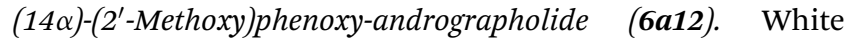
solid; mp $155.2{ }^{\circ} \mathrm{C}$ to $161.6{ }^{\circ} \mathrm{C}$; $92 \%$ yield; ${ }^{1} \mathrm{H}$ NMR $(400 \mathrm{MHz}$, $\left.\left(\mathrm{CD}_{3}\right)_{2} \mathrm{SO}\right) \delta 7.07-7.03(\mathrm{~m}, 2 \mathrm{H}), 6.97(\mathrm{~d}, J=7.5 \mathrm{~Hz}, 1 \mathrm{H}), 6.93-6.87$ $(\mathrm{m}, 1 \mathrm{H}), 6.82(\mathrm{dd}, J=6.8,5.7 \mathrm{~Hz}, 1 \mathrm{H}), 5.58(\mathrm{~d}, J=5.3 \mathrm{~Hz}, 1 \mathrm{H})$, $5.04(\mathrm{~d}, J=4.8 \mathrm{~Hz}, 1 \mathrm{H}), 4.79(\mathrm{~s}, 1 \mathrm{H}), 4.57$ (dd, $J=10.7,5.4 \mathrm{~Hz}$, $1 \mathrm{H}), 4.52(\mathrm{~s}, 1 \mathrm{H}), 4.36(\mathrm{dd}, J=10.7,1.2 \mathrm{~Hz}, 1 \mathrm{H}), 4.12(\mathrm{dd}, J=7.4$, $2.7 \mathrm{~Hz}, 1 \mathrm{H}), 3.81-3.74(\mathrm{~m}, 1 \mathrm{H}), 3.76(\mathrm{~s}, 3 \mathrm{H}), 3.22(\mathrm{dd}, J=10.9$, $7.7 \mathrm{~Hz}, 1 \mathrm{H}), 3.16$ (dd, $J=10.4,5.0 \mathrm{~Hz}, 1 \mathrm{H}), 2.36-2.26(\mathrm{~m}, 2 \mathrm{H})$,
2.21-2.11 (m, $1 \mathrm{H}), 1.94-1.81(\mathrm{~m}, 2 \mathrm{H}), 1.70(\mathrm{~d}, J=12.9 \mathrm{~Hz}, 1 \mathrm{H})$, 1.62-1.51 (m, 2H), 1.50-1.43 (m, 1H), 1.30 (m, 1H), 1.15-1.07 $(\mathrm{m}, 2 \mathrm{H}), 1.05(\mathrm{~s}, 3 \mathrm{H}), 0.53(\mathrm{~s}, 3 \mathrm{H}) ;{ }^{13} \mathrm{C} \mathrm{NMR}\left(101 \mathrm{MHz},\left(\mathrm{CD}_{3}\right)_{2} \mathrm{SO}\right)$ $\delta 169.8,151.2,149.9,148.0,145.9,126.0,124.0,121.2,118.9$, 113.1, 108.6, 78.8, 73.3, 71.7, 63.0, 56.0, 55.5, 54.8, 42.7, 38.9, 37.9, 36.9, 28.3, 24.9, 24.4, 23.5, 15.0; ESI-HRMS: $m / z$ 479.2406 $[\mathrm{M}+\mathrm{Na}]^{+}$, calcd for $\mathrm{C}_{27} \mathrm{H}_{36} \mathrm{NaO}_{6}, 479.2410$.

(14ß)-(2'-Methoxy)phenoxy-andrographolide (6b12). White solid; mp $175{ }^{\circ} \mathrm{C}$ to $178{ }^{\circ} \mathrm{C}$; $88 \%$ yield; ${ }^{1} \mathrm{H}$ NMR $(400 \mathrm{MHz}$, $\left.\mathrm{CDCl}_{3}\right) \delta 7.13-7.02(\mathrm{~m}, 1 \mathrm{H}), 7.01-6.83(\mathrm{~m}, 4 \mathrm{H}), 5.56(\mathrm{~d}, J=$ $5.4 \mathrm{~Hz}, 1 \mathrm{H}), 4.81(\mathrm{~d}, J=1.8 \mathrm{~Hz}, 1 \mathrm{H}), 4.55-4.40(\mathrm{~m}, 2 \mathrm{H}), 4.32(\mathrm{~s}$, $1 \mathrm{H}), 4.13(\mathrm{t}, J=8.9 \mathrm{~Hz}, 1 \mathrm{H}), 3.92-3.81(\mathrm{~m}, 3 \mathrm{H}), 3.47-3.35(\mathrm{~m}$, $1 \mathrm{H}), 3.30(\mathrm{~d}, J=11.1 \mathrm{~Hz}, 1 \mathrm{H}), 2.42-2.33(\mathrm{~m}, 1 \mathrm{H}), 2.32-2.21(\mathrm{~m}$, $2 \mathrm{H}), 2.02-1.90(\mathrm{~m}, 1 \mathrm{H}), 1.88-1.73(\mathrm{~m}, 3 \mathrm{H}), 1.73-1.65(\mathrm{~m}, 1 \mathrm{H})$, 1.60-1.52 (m, 1H), 1.32-1.24 (m, 1H), $1.23(\mathrm{~s}, 3 \mathrm{H}), 1.22-1.16(\mathrm{~m}$, $1 \mathrm{H}), 1.10(\mathrm{td}, J=13.2,4.2 \mathrm{~Hz}, 1 \mathrm{H}), 0.59(\mathrm{~s}, 1 \mathrm{H}) ;{ }^{13} \mathrm{C} \mathrm{NMR}(101$ $\left.\mathrm{MHz}, \mathrm{CDCl}_{3}\right) \delta 169.77,151.35,150.68,147.23,145.29,125.46$, $124.33,121.09,119.97,112.35,108.12,80.45,73.42,71.20$, $64.14,55.80,55.69,55.03,42.87,38.88,37.69,36.64,28.22$, 25.55, 23.73, 22.70, 15.10; ESI-HRMS: $m / z 479.2400[\mathrm{M}+\mathrm{Na}]^{+}$, calcd for $\mathrm{C}_{27} \mathrm{H}_{36} \mathrm{NaO}_{6}, 479.2410$.

(14ß)-(3'-Methoxy)phenoxy-andrographolide (6b13). White solid; mp $156{ }^{\circ} \mathrm{C}$ to $158{ }^{\circ} \mathrm{C}$; $92 \%$ yield; ${ }^{1} \mathrm{H}$ NMR $(400 \mathrm{MHz}$, $\left.\left(\mathrm{CD}_{3}\right)_{2} \mathrm{SO}\right) \delta 7.29-7.16(\mathrm{~m}, 1 \mathrm{H}), 6.94(\mathrm{dd}, J=7.2,6.0 \mathrm{~Hz}, 1 \mathrm{H})$, 6.64-6.49 (m, 3H), $5.79(\mathrm{~d}, J=5.3 \mathrm{~Hz}, 1 \mathrm{H}), 4.99(\mathrm{~d}, J=4.9 \mathrm{~Hz}$, $1 \mathrm{H}), 4.81(\mathrm{~s}, 1 \mathrm{H}), 4.66(\mathrm{dd}, J=10.7,5.4 \mathrm{~Hz}, 1 \mathrm{H}), 4.52(\mathrm{~s}, 1 \mathrm{H}), 4.28$ (dd, $J=10.7,1.1 \mathrm{~Hz}, 1 \mathrm{H}), 4.10(\mathrm{dd}, J=7.5,2.8 \mathrm{~Hz}, 1 \mathrm{H}), 3.79-3.37$ (m, 1H), 3.74 (s, 3H), 3.19 (dd, $J=10.8,7.7 \mathrm{~Hz}, 1 \mathrm{H}), 3.05-2.98$ $(\mathrm{m}, 1 \mathrm{H}), 2.43-2.35(\mathrm{~m}, 1 \mathrm{H}), 2.33-2.22(\mathrm{~m}, 2 \mathrm{H}), 1.92(\mathrm{t}, J=$ $10.2 \mathrm{~Hz}, 2 \mathrm{H}), 1.70$ (d, $J=13.2 \mathrm{~Hz}, 1 \mathrm{H}), 1.47$ (m, 3H), 1.36-1.21 (m, 1H), 1.11-1.05 (m, 1H), $1.02(\mathrm{~s}, 3 \mathrm{H}), 0.94(\mathrm{~m}, 1 \mathrm{H}), 0.55$ (s, $3 \mathrm{H}) ;{ }^{13} \mathrm{C}$ NMR $\left(101 \mathrm{MHz},\left(\mathrm{CD}_{3}\right)_{2} \mathrm{SO}\right) \delta 169.09,160.65,157.69$, 149.66, 147.70, 130.25, 125.73, 107.71, 107.55, 107.35, 102.01, $78.24,71.14,71.04,62.52,55.66,55.16,54.21,42.13,38.68$, $37.41,36.17,27.75,24.91,23.88,22.93,14.56$; ESI-HRMS: $\mathrm{m} / \mathrm{z}$ $479.2400[\mathrm{M}+\mathrm{Na}]^{+}$, calcd for $\mathrm{C}_{27} \mathrm{H}_{36} \mathrm{NaO}_{6}, 479.2410$.

(14ß)-(Naphthyl-1'-oxy)andrographolide (6b14). White solid; mp $172{ }^{\circ} \mathrm{C}$ to $175{ }^{\circ} \mathrm{C} ; 88 \%$ yield; ${ }^{1} \mathrm{H}$ NMR $\left(400 \mathrm{MHz},\left(\mathrm{CD}_{3}\right)_{2} \mathrm{SO}\right)$ $\delta 8.07(\mathrm{~d}, J=8.1 \mathrm{~Hz}, 1 \mathrm{H}), 7.92(\mathrm{~d}, J=7.7 \mathrm{~Hz}, 1 \mathrm{H}), 7.62-7.41(\mathrm{~m}$, $4 \mathrm{H}), 7.14(\mathrm{t}, J=7.2 \mathrm{~Hz}, 1 \mathrm{H}), 7.01(\mathrm{~d}, J=7.5 \mathrm{~Hz}, 1 \mathrm{H}), 5.99(\mathrm{~d}, J=$ $5.2 \mathrm{~Hz}, 1 \mathrm{H}), 4.84(\mathrm{~s}, 1 \mathrm{H}), 4.83-4.79(\mathrm{~m}, 1 \mathrm{H}), 4.76(\mathrm{~d}, J=4.9 \mathrm{~Hz}$, $1 \mathrm{H}), 4.62(\mathrm{~s}, 1 \mathrm{H}), 4.44(\mathrm{dd}, J=10.8,1.0 \mathrm{~Hz}, 1 \mathrm{H}), 4.05-4.00(\mathrm{~m}$, $1 \mathrm{H}), 3.63(\mathrm{dd}, J=11.0,2.8 \mathrm{~Hz}, 1 \mathrm{H}), 3.07(\mathrm{dd}, J=10.8,7.6 \mathrm{~Hz}$, $1 \mathrm{H}), 2.45-2.33(\mathrm{~m}, 2 \mathrm{H}), 2.33-2.22(\mathrm{~m}, 2 \mathrm{H}), 1.96-1.86(\mathrm{~m}, 2 \mathrm{H})$, 1.63-1.54 (m, 1H), $1.24(\mathrm{~m}, 3 \mathrm{H}), 1.06(\mathrm{~m}, 1 \mathrm{H}), 0.80(\mathrm{~s}, 3 \mathrm{H}), 0.69$ (dd, $J=12.6,2.2 \mathrm{~Hz}, 1 \mathrm{H}), 0.58-0.47(\mathrm{~m}, 1 \mathrm{H}), 0.43(\mathrm{~s}, 3 \mathrm{H}) ;{ }^{13} \mathrm{C}$ NMR (101 MHz, $\left.\left(\mathrm{CD}_{3}\right)_{2} \mathrm{SO}\right) \delta 169.13,168.88,151.95,150.00$, $147.65,134.31$, 127.60, 126.69, 126.08, 125.97, 125.58, 124.93, $121.86,121.66,121.00,107.65,106.45,99.49,77.83,71.21$, $62.40,56.28,53.62,48.13,41.83,38.72,38.61,37.39,35.72$, 27.56, 24.92, 23.78, 22.59, 20.75, 20.75, 14.45; ESI-HRMS: $\mathrm{m} / \mathrm{z}$ 499.2462 [M+Na $]^{+}$, calcd for $\mathrm{C}_{30} \mathrm{H}_{36} \mathrm{NaO}_{5}, 499.2460$.

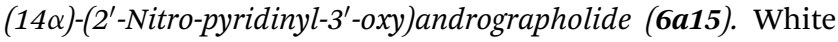
solid; mp $140{ }^{\circ} \mathrm{C}$ to $142{ }^{\circ} \mathrm{C}$; $83 \%$ yield; ${ }^{1} \mathrm{H}$ NMR $(400 \mathrm{MHz}$, $\left.\left(\mathrm{CD}_{3}\right)_{2} \mathrm{SO}\right) \delta 8.21(\mathrm{dd}, J=4.5,1.1 \mathrm{~Hz}, 1 \mathrm{H}), 8.02(\mathrm{dd}, J=8.5$, $1.0 \mathrm{~Hz}, 1 \mathrm{H}), 7.83(\mathrm{dd}, J=8.5,4.6 \mathrm{~Hz}, 1 \mathrm{H}), 6.93(\mathrm{t}, J=6.0 \mathrm{~Hz}, 1 \mathrm{H})$, $6.06(\mathrm{~d}, J=5.4 \mathrm{~Hz}, 1 \mathrm{H}), 5.02(\mathrm{~d}, J=4.9 \mathrm{~Hz}, 1 \mathrm{H}), 4.77(\mathrm{~s}, 1 \mathrm{H}), 4.72$ 
(dd, $J=11.2,5.6 \mathrm{~Hz}, 1 \mathrm{H}), 4.46(\mathrm{dd}, J=11.1,1.3 \mathrm{~Hz}, 1 \mathrm{H}), 4.40$ (s, $1 \mathrm{H}), 4.12(\mathrm{dd}, J=7.4,2.9 \mathrm{~Hz}, 1 \mathrm{H}), 3.79(\mathrm{dd}, J=11.0,2.8 \mathrm{~Hz}, 1 \mathrm{H})$, 3.26-3.13 (m, 2H), 2.47-2.41 (m, 1H), 2.36-2.25 (m, 2H), 1.91 $(\mathrm{m}, 2 \mathrm{H}), 1.71(\mathrm{~m}, 1 \mathrm{H}), 1.63-1.44(\mathrm{~m}, 3 \mathrm{H}), 1.32(\mathrm{~m}, 1 \mathrm{H}), 1.19-1.11$ (m, 1H), 1.10-1.02 (m, 1H), 1.06 (s, 3H), 0.55 (s, 3H); ${ }^{13} \mathrm{C}$ NMR $\left(101 \mathrm{MHz},\left(\mathrm{CD}_{3}\right)_{2} \mathrm{SO}\right) \delta 168.58,151.60,149.00,147.58,144.24$, $140.35,129.44,126.35,123.96,108.04,78.36,73.08,70.19$, $62.54,55.07,54.28,42.19,38.44,37.30,36.38,27.77,24.62$, 23.82, 23.02, 14.51; ESI-HRMS: $m / z$ 495.2102 [M + Na $]^{+}$, calcd for $\mathrm{C}_{25} \mathrm{H}_{32} \mathrm{~N}_{2} \mathrm{NaO}_{7}, 495.2107$.

(14ß)-(2'-Nitro-pyridinyl-3'-oxy)andrographolide (6b15). White solid; mp $146{ }^{\circ} \mathrm{C}$ to $149{ }^{\circ} \mathrm{C}$; 90\% yield; ${ }^{1} \mathrm{H}$ NMR $(400 \mathrm{MHz}$, $\left.\mathrm{CD}_{3} \mathrm{OD}\right) \delta 8.18(\mathrm{dd}, J=4.6,1.2 \mathrm{~Hz}, 1 \mathrm{H}), 7.90(\mathrm{dd}, J=8.5,1.1 \mathrm{~Hz}$, $1 \mathrm{H}), 7.75(\mathrm{dd}, J=8.5,4.6 \mathrm{~Hz}, 1 \mathrm{H}), 7.16(\mathrm{td}, J=7.3,1.5 \mathrm{~Hz}, 1 \mathrm{H})$, $6.05(\mathrm{~d}, J=5.5 \mathrm{~Hz}, 1 \mathrm{H}), 4.90(\mathrm{~s}, 1 \mathrm{H}), 4.73(\mathrm{dd}, J=11.2,5.6 \mathrm{~Hz}$, $1 \mathrm{H}), 4.54(\mathrm{~s}, 1 \mathrm{H}), 4.47$ (dd, $J=11.2,1.4 \mathrm{~Hz}, 1 \mathrm{H}), 4.07$ (d, $J=$ $11.1 \mathrm{~Hz}, 1 \mathrm{H}), 3.34(\mathrm{~d}, J=2.9 \mathrm{~Hz}, 1 \mathrm{H}), 3.28(\mathrm{dd}, J=11.9,4.1 \mathrm{~Hz}$, $1 \mathrm{H}), 2.54(\mathrm{~m}, 1 \mathrm{H}), 2.47-2.33(\mathrm{~m}, 2 \mathrm{H}), 2.04(\mathrm{~m}, 1 \mathrm{H}), 1.95(\mathrm{~m}, 1 \mathrm{H})$, 1.90-1.82 (m, 1H), 1.77-1.53 (m, 3H), 1.41-1.26 (m, 2H), 1.21 (s, $3 \mathrm{H}), 1.09-0.99(\mathrm{~m}, 1 \mathrm{H}), 0.66(\mathrm{~s}, 3 \mathrm{H}) ;{ }^{13} \mathrm{C} \mathrm{NMR}\left(101 \mathrm{MHz}, \mathrm{CD}_{3} \mathrm{OD}\right)$ $\delta 170.88,153.35,151.17,149.05,145.93,141.67,130.25,126.69$, 125.80, 108.52, 80.74, 74.60, 72.00, 64.95, 57.59, 56.03, 43.64, 40.20, 38.89, 37.88, 28.93, 26.91, 25.20, 23.29, 15.47; ESI-HRMS: $m / z 495.2101[\mathrm{M}+\mathrm{Na}]^{+}$, calcd for $\mathrm{C}_{25} \mathrm{H}_{32} \mathrm{~N}_{2} \mathrm{NaO}_{7}, 495.2107$.

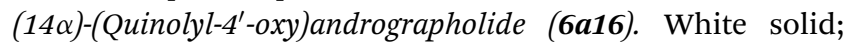
$\mathrm{mp} 102.6{ }^{\circ} \mathrm{C}$ to $104.8{ }^{\circ} \mathrm{C}$; $83 \%$ yield; ${ }^{1} \mathrm{H}$ NMR $(400 \mathrm{MHz}$, $\left.\left(\mathrm{CD}_{3}\right)_{2} \mathrm{SO}\right) \delta 8.75(\mathrm{~d}, J=5.2 \mathrm{~Hz}, 1 \mathrm{H}), 8.03(\mathrm{~d}, J=7.5 \mathrm{~Hz}, 1 \mathrm{H}), 7.95$ $(\mathrm{d}, J=8.3 \mathrm{~Hz}, 1 \mathrm{H}), 7.77-7.71(\mathrm{~m}, 1 \mathrm{H}), 7.53(\mathrm{t}, J=7.6 \mathrm{~Hz}, 1 \mathrm{H})$, $7.05(\mathrm{~d}, J=5.3 \mathrm{~Hz}, 1 \mathrm{H}), 7.01(\mathrm{t}, J=6.8 \mathrm{~Hz}, 1 \mathrm{H}), 6.08(\mathrm{~d}, J=$ $5.3 \mathrm{~Hz}, 1 \mathrm{H}), 4.96(\mathrm{~d}, J=4.9 \mathrm{~Hz}, 1 \mathrm{H}), 4.84-4.76(\mathrm{~m}, 2 \mathrm{H}), 4.55(\mathrm{~s}$, $1 \mathrm{H}), 4.41(\mathrm{~d}, J=11.0 \mathrm{~Hz}, 1 \mathrm{H}), 4.05(\mathrm{dd}, J=7.4,2.8 \mathrm{~Hz}, 1 \mathrm{H}), 3.68$ (dd, $J=11.0,2.8 \mathrm{~Hz}, 1 \mathrm{H}), 3.13(\mathrm{dd}, J=11.1,7.6 \mathrm{~Hz}, 1 \mathrm{H}), 3.10-$ $3.02(\mathrm{~m}, 1 \mathrm{H}), 2.43-2.34(\mathrm{~m}, 1 \mathrm{H}), 2.25(\mathrm{~d}, J=11.9 \mathrm{~Hz}, 1 \mathrm{H}), 1.94(\mathrm{~d}$, $J=11.4 \mathrm{~Hz}, 1 \mathrm{H}), 1.89-1.83(\mathrm{~m}, 1 \mathrm{H}), 1.63(\mathrm{~d}, J=13.6 \mathrm{~Hz}, 1 \mathrm{H})$, 1.49-1.41 (m, 1H), 1.40-1.35 (m, 2H), 0.98 (s, 3H), 0.85-0.67 (m, $3 \mathrm{H}), 0.64-0.56(\mathrm{~m}, 1 \mathrm{H}), 0.40(\mathrm{~s}, 3 \mathrm{H}) ;{ }^{13} \mathrm{C} \mathrm{NMR}(101 \mathrm{MHz}$, $\left.\left(\mathrm{CD}_{3}\right)_{2} \mathrm{SO}\right) \delta 169.4,159.3,151.8,151.6,149.4,148.3,130.5,129.2$, 126.5, 124.9, 121.8, 121.1, 108.5, 103.0, 78.8, 72.1, 71.1, 63.0, 55.5, 54.7, 42.6, 38.9, 37.7, 36.8, 28.2, 25.3, 24.2, 23.5, 14.9; ESIHRMS: $m / z$ 478.2587 $[\mathrm{M}+\mathrm{H}]^{+}$, calcd for $\mathrm{C}_{29} \mathrm{H}_{36} \mathrm{NO}_{5}, 478.2593$.

(14ß)-(Quinolyl-4'-oxy)andrographolide (6b16). White solid; $\mathrm{mp} 175{ }^{\circ} \mathrm{C}$ to $177{ }^{\circ} \mathrm{C}$; $88 \%$ yield; ${ }^{1} \mathrm{H}$ NMR (400 MHz, $\left.\left(\mathrm{CD}_{3}\right)_{2} \mathrm{SO}\right)$ $\delta 8.78(\mathrm{~d}, J=5.2 \mathrm{~Hz}, 1 \mathrm{H}), 8.07(\mathrm{~d}, J=7.6 \mathrm{~Hz}, 1 \mathrm{H}), 7.99(\mathrm{~d}, J=$ $8.1 \mathrm{~Hz}, 1 \mathrm{H}), 7.81-7.74(\mathrm{~m}, 1 \mathrm{H}), 7.21(\mathrm{t}, J=7.2 \mathrm{~Hz}, 1 \mathrm{H}), 7.07$ (d, $J$ $=5.3 \mathrm{~Hz}, 1 \mathrm{H}), 6.13(\mathrm{~d}, J=5.2 \mathrm{~Hz}, 1 \mathrm{H}), 4.84(\mathrm{~s}, 1 \mathrm{H}), 4.78(\mathrm{~d}, J=$ $4.8 \mathrm{~Hz}, 1 \mathrm{H}), 4.66(\mathrm{~s}, 1 \mathrm{H}), 4.48(\mathrm{~d}, J=11.1 \mathrm{~Hz}, 1 \mathrm{H}), 4.04-3.97(\mathrm{~m}$, $1 \mathrm{H}), 3.61(\mathrm{dd}, J=11.0,2.9 \mathrm{~Hz}, 1 \mathrm{H}), 3.06(\mathrm{dd}, J=10.9,7.6 \mathrm{~Hz}$, $1 \mathrm{H}), 2.44(\mathrm{~d}, J=8.6 \mathrm{~Hz}, 1 \mathrm{H}), 2.31-2.24(\mathrm{~m}, 3 \mathrm{H}), 1.89$ (d, $J=$ $9.3 \mathrm{~Hz}, 2 \mathrm{H}), 1.65-1.52(\mathrm{~m}, 2 \mathrm{H}), 1.31-1.24(\mathrm{~m}, 2 \mathrm{H}), 1.24-1.13(\mathrm{~m}$, $2 \mathrm{H}), 1.05-0.94(\mathrm{~m}, 1 \mathrm{H}), 0.78(\mathrm{~s}, 3 \mathrm{H}), 0.71-0.59(\mathrm{~m}, 2 \mathrm{H}), 0.44(\mathrm{~s}$, $3 \mathrm{H}) ;{ }^{13} \mathrm{C}$ NMR $\left(101 \mathrm{MHz},\left(\mathrm{CD}_{3}\right)_{2} \mathrm{SO}\right) \delta 169.0,166.5,153.0,147.9$, $147.7,145.9$, 135.4, 129.6, 124.5, 123.8, 121.2, 120.7, 108.4, 104.2, 78.6, 74.8, 70.6, 62.8, 56.7, 54.6, 42.5, 39.3, 37.9, 36.6, 28.0, 25.7, 24.3, 23.3, 15.0; ESI-HRMS: $m / z 478.2588[\mathrm{M}+\mathrm{H}]^{+}$, calcd for $\mathrm{C}_{29} \mathrm{H}_{36} \mathrm{NO}_{5}, 478.2593$.

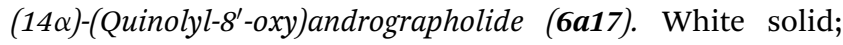
mp $151{ }^{\circ} \mathrm{C}$ to $153{ }^{\circ} \mathrm{C} ; 79 \%$ yield; ${ }^{1} \mathrm{H}$ NMR (400 MHz, $\left.\left(\mathrm{CD}_{3}\right)_{2} \mathrm{SO}\right)$ $\delta 8.89(\mathrm{dd}, J=4.1,1.7 \mathrm{~Hz}, 1 \mathrm{H}), 8.39(\mathrm{dd}, J=8.4,1.7 \mathrm{~Hz}, 1 \mathrm{H}), 7.69$ (dd, $J=8.2,0.9 \mathrm{~Hz}, 1 \mathrm{H}), 7.62-7.51(\mathrm{~m}, 2 \mathrm{H}), 7.28$ (dd, $J=7.6$, $1.0 \mathrm{~Hz}, 1 \mathrm{H}), 6.90(\mathrm{t}, J=6.3 \mathrm{~Hz}, 1 \mathrm{H}), 6.06(\mathrm{~d}, J=5.3 \mathrm{~Hz}, 1 \mathrm{H}), 5.00$ $(\mathrm{d}, J=4.9 \mathrm{~Hz}, 1 \mathrm{H}), 4.76-4.68(\mathrm{~m}, 2 \mathrm{H}), 4.56-4.49(\mathrm{~m}, 2 \mathrm{H}), 4.09$ (dd, $J=7.5,2.8 \mathrm{~Hz}, 1 \mathrm{H}), 3.71(\mathrm{dd}, J=11.0,2.7 \mathrm{~Hz}, 1 \mathrm{H}$ ), 3.19-3.00 (m, 2H), 2.27-2.18 (m, 2H), 2.17-2.07 (m, 1H), $1.81(\mathrm{~m}, 2 \mathrm{H}), 1.64$ $(\mathrm{m}, 1 \mathrm{H}), 1.40(\mathrm{~m}, 2 \mathrm{H}), 1.26-1.20(\mathrm{~m}, 2 \mathrm{H}), 1.15(\mathrm{~m}, 1 \mathrm{H}), 1.03(\mathrm{~m}$, $1 \mathrm{H}), 1.00(\mathrm{~s}, 3 \mathrm{H}), 0.36(\mathrm{~s}, 3 \mathrm{H}) ;{ }^{13} \mathrm{C} \mathrm{NMR}\left(101 \mathrm{MHz},\left(\mathrm{CD}_{3}\right)_{2} \mathrm{SO}\right)$ $\delta 169.9,152.7,150.1,149.9,147.8,141.3,136.7,130.0,127.2$, 126.1, 122.9, 122.5, 116.3, 108.6, 78.7, 74.0, 71.8, 63.0, 55.4, 54.6, 42.6, 38.8, 37.8, 36.6, 28.2, 25.1, 24.3, 23.4, 14.8; ESI-HRMS: $\mathrm{m} / \mathrm{z}$ $478.2588[\mathrm{M}+\mathrm{H}]^{+}$, calcd for $\mathrm{C}_{29} \mathrm{H}_{36} \mathrm{NO}_{5}, 478.2593$.

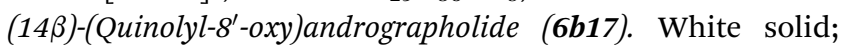
$\mathrm{mp} 134{ }^{\circ} \mathrm{C}$ to $136{ }^{\circ} \mathrm{C}$; $76 \%$ yield; ${ }^{1} \mathrm{H}$ NMR (400 MHz, $\left.\mathrm{CD}_{3} \mathrm{OD}\right)$ $\delta 8.88(\mathrm{dd}, J=4.3,1.7 \mathrm{~Hz}, 1 \mathrm{H}), 8.40(\mathrm{dd}, J=8.3,1.7 \mathrm{~Hz}, 1 \mathrm{H})$, 7.67-7.58 (m, 3H), 7.31-7.22 (m, 2H), 6.09 (d, $J=5.5 \mathrm{~Hz}, 1 \mathrm{H})$, $4.89(\mathrm{~d}, J=1.0 \mathrm{~Hz}, 1 \mathrm{H}), 4.83-4.79(\mathrm{~m}, 1 \mathrm{H}), 4.62-4.55(\mathrm{~m}, 2 \mathrm{H})$, $3.91(\mathrm{~d}, J=11.1 \mathrm{~Hz}, 1 \mathrm{H}), 3.63(\mathrm{q}, J=7.0 \mathrm{~Hz}, 1 \mathrm{H}), 3.21$ (d, $J=$ $10.3 \mathrm{~Hz}, 1 \mathrm{H}), 2.52$ (dd, $J=11.9,4.2 \mathrm{~Hz}, 1 \mathrm{H}), 2.48-2.34(\mathrm{~m}, 2 \mathrm{H})$, 2.32-2.21 (m, 1H), 2.06 (m, 2H), 1.77-1.68 (m, 1H), 1.48-1.34 (m, 1H), 1.30-1.24 (m, 1H), $1.20(\mathrm{~m}, 2 \mathrm{H}), 1.09(\mathrm{~m}, 1 \mathrm{H}), 0.99$ (s, 3H), $0.84(\mathrm{~m}, 1 \mathrm{H}), 0.58(\mathrm{~m}, 1 \mathrm{H}), 0.49(\mathrm{~s}, 3 \mathrm{H}) ;{ }^{13} \mathrm{C}$ NMR (101 $\left.\mathrm{MHz}, \mathrm{CD}_{3} \mathrm{OD}\right) \delta 171.84,153.59,151.90,150.48,149.14,141.29$, 138.32 , 131.55, 128.29, 127.54, 123.50, 122.60, 112.92, 108.19, $80.50,73.65,73.10,64.79,57.59,55.73,43.35,40.01,38.80$, 37.39, 28.65, 26.58, 25.10, 23.18, 15.28; ESI-HRMS: $m / z$ 500.2407 $[\mathrm{M}+\mathrm{Na}]^{+}$, calcd for $\mathrm{C}_{29} \mathrm{H}_{35} \mathrm{NNaO}_{5}, 500.2413$.

4.2.3. Preparation of compound $7 \mathrm{~b} 1$. To a solution of $0.48 \mathrm{~g}$ of $6 \mathrm{~b} 17(1.0 \mathrm{mmol})$ in $15 \mathrm{~mL}$ of dichloromethane, $0.15 \mathrm{~g}$ of trimethylamine $(1.5 \mathrm{mmol})$ in $2 \mathrm{~mL}$ of dichloromethane was added; the mixture was then treated with $0.094 \mathrm{~g}$ of acetyl chloride $(1.2 \mathrm{mmol})$ in $2 \mathrm{~mL}$ of dichloromethane at $0{ }^{\circ} \mathrm{C}$ for $30 \mathrm{~min}$. After removing the volatile solvents by distillation, the residue was dissolved in ethyl acetate and washed with saturated $\mathrm{NaHCO}_{3}$ solution and brine. The organic phase was dried over anhydrous $\mathrm{Na}_{2} \mathrm{SO}_{4}$, filtered, and evaporated to dryness; the residue was purified by silica gel column chromatography (petroleum ether/ethyl acetate $1 / 1$ ) to afford $0.47 \mathrm{~g}$ of $(14 \beta)$ (quinolyl-8'-oxy)-19-acetoxy andrographolide (7b1). 7b1: white solid; mp $74{ }^{\circ} \mathrm{C}$ to $77{ }^{\circ} \mathrm{C}$; $90 \%$ yield; ${ }^{1} \mathrm{H}$ NMR $\left(400 \mathrm{MHz}, \mathrm{CD}_{3} \mathrm{Cl}\right)$ $\delta 9.11(\mathrm{~s}, 1 \mathrm{H}), 8.42(\mathrm{~d}, J=7.9 \mathrm{~Hz}, 1 \mathrm{H}), 7.64(\mathrm{dd}, J=23.1,7.8 \mathrm{~Hz}$, $3 \mathrm{H}), 7.16$ (q, $J=7.0 \mathrm{~Hz}, 2 \mathrm{H}), 6.08(\mathrm{~s}, 1 \mathrm{H}), 4.83$ (s, 1H), 4.76-4.60 $(\mathrm{m}, 2 \mathrm{H}), 4.38(\mathrm{~s}, 1 \mathrm{H}), 4.22(\mathrm{~d}, J=11.6 \mathrm{~Hz}, 1 \mathrm{H}), 4.02(\mathrm{~d}, J=$ $11.7 \mathrm{~Hz}, 1 \mathrm{H}), 3.00(\mathrm{t}, J=8.0 \mathrm{~Hz}, 1 \mathrm{H}), 2.48-2.33(\mathrm{~m}, 2 \mathrm{H}), 2.28-$ $2.17(\mathrm{~m}, 1 \mathrm{H}), 2.03(\mathrm{~s}, 3 \mathrm{H}), 1.99-1.89(\mathrm{~m}, 2 \mathrm{H}), 1.82(\mathrm{~s}, 1 \mathrm{H}), 1.47-$ $1.20(\mathrm{~m}, 5 \mathrm{H}), 1.15(\mathrm{dd}, J=12.6,2.7 \mathrm{~Hz}, 1 \mathrm{H}), 1.08$ (s, 3H), 0.94 (q, $J=11.7,11.2 \mathrm{~Hz}, 1 \mathrm{H}), 0.47(\mathrm{~s}, 3 \mathrm{H}) ;{ }^{13} \mathrm{C} \mathrm{NMR}(101 \mathrm{MHz}$, $\left.\left(\mathrm{CD}_{3}\right)_{2} \mathrm{SO}\right) \delta 170.8,169.8,152.7,150.5,149.9,148.4,140.7,136.6$, 129.9, 127.2, 126.7, 122.6, 122.0, 113.3, 108.0, 76.6, 72.8, 71.7, 65.4, 56.2, 53.68, 4.76, 39.2, 37.9, 36.3, 27.7, 25.35, 25.1, 23.0, 21.4, 14.2; ESI-HRMS: $m / z$ 520.2691 $[\mathrm{M}+\mathrm{H}]^{+}$, calcd for $\mathrm{C}_{31} \mathrm{H}_{38} \mathrm{NO}_{6}, 520.2699$.

4.2.4. Preparation of compound $7 \mathbf{b 2}$. At room temperature, to a solution of $0.4 \mathrm{~g}(0.84 \mathrm{mmol}) 6 \mathrm{b17}$ in $18.0 \mathrm{~mL}$ dry dichloromethane (DCM), $0.66 \mathrm{~mL}(5.0 \mathrm{mmol})$ triethylamine (TEA) and then $0.64 \mathrm{~g}(4.2 \mathrm{mmol}) \mathrm{TBSCl}$ in $2.0 \mathrm{~mL}$ dry DCM were added carefully. After the reaction was complete in $40 \mathrm{~min}$, the 
reaction mixture was treated with sol. sat. $\mathrm{NH}_{4} \mathrm{Cl}$. The organic phase was extracted with ethyl acetate and washed with sol. sat. $\mathrm{NaHCO}_{3}$ and brine, then dried over anhydrous $\mathrm{Na}_{2} \mathrm{SO}_{4}$. The residue was filtered and chromatographed on silica gel (petro-

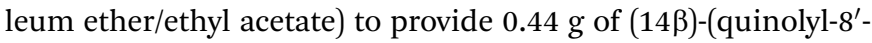
oxy)-19-( $t$-butyldimethylsilyloxy)andrographolide (7b2). 7b2: white solid; mp $149{ }^{\circ} \mathrm{C}$ to $151{ }^{\circ} \mathrm{C} ; 89 \%$ yield; ${ }^{1} \mathrm{H}$ NMR $(400 \mathrm{MHz}$, $\left.\left(\mathrm{CD}_{3}\right)_{2} \mathrm{SO}\right) \delta 8.88(\mathrm{dd}, J=4.1,1.7 \mathrm{~Hz}, 1 \mathrm{H}), 8.37(\mathrm{dd}, J=8.3$, $1.6 \mathrm{~Hz}, 1 \mathrm{H}), 7.64$ (d, $J=7.5 \mathrm{~Hz}, 1 \mathrm{H}), 7.61-7.52(\mathrm{~m}, 2 \mathrm{H}), 7.23$ (d, $J=6.9 \mathrm{~Hz}, 1 \mathrm{H}), 7.06(\mathrm{t}, J=6.9 \mathrm{~Hz}, 1 \mathrm{H}), 6.06(\mathrm{~d}, J=5.1 \mathrm{~Hz}, 1 \mathrm{H})$, $4.77(\mathrm{~m}, 2 \mathrm{H}), 4.54-4.45(\mathrm{~m}, 2 \mathrm{H}), 4.22(\mathrm{~d}, J=5.2 \mathrm{~Hz}, 1 \mathrm{H}), 3.58(\mathrm{~d}$, $J=10.5 \mathrm{~Hz}, 1 \mathrm{H}), 3.47$ (d, $J=10.5 \mathrm{~Hz}, 1 \mathrm{H}), 2.36-2.14(\mathrm{~m}, 4 \mathrm{H})$, $2.00(\mathrm{~m}, 1 \mathrm{H}), 1.87(\mathrm{~m}, 1 \mathrm{H}), 1.62(\mathrm{~m}, 1 \mathrm{H}), 1.48(\mathrm{~m}, 1 \mathrm{H}), 1.22(\mathrm{~m}$, $2 \mathrm{H}), 0.97(\mathrm{~m}, 1 \mathrm{H}), 0.80(\mathrm{~s}, 9 \mathrm{H}), 0.77(\mathrm{~s}, 3 \mathrm{H}), 0.69-0.63(\mathrm{~m}, 1 \mathrm{H})$, $0.56(\mathrm{~m}, 1 \mathrm{H}), 0.47(\mathrm{~s}, 3 \mathrm{H}),-0.07(\mathrm{~d}, J=2.3 \mathrm{~Hz}, 6 \mathrm{H}) ;{ }^{13} \mathrm{C} \mathrm{NMR}$ $\left(101 \mathrm{MHz},\left(\mathrm{CD}_{3}\right)_{2} \mathrm{SO}\right) \delta 169.27,152.18,150.02,149.36,148.25$, $140.20,136.03$, 129.42, 126.68, 126.20, 122.06, 121.40, 112.65, 107.18, 76.67, 72.24, 71.24, 64.12, 55.88, 53.68, 42.24, 38.75, $37.78,36.08,27.47,25.60$ (3C), 25.30, 24.88, 22.69, 17.73, 13.81, $-5.78,-5.81$; ESI-HRMS: $m / z 592.3453[\mathrm{M}+\mathrm{H}]^{+}$, calcd for $\mathrm{C}_{35} \mathrm{H}_{50} \mathrm{NO}_{5} \mathrm{Si}, 592.3458$.

4.2.5. Preparation of compound $8 \mathrm{~b} 1$ or $8 \mathrm{~b} 2$. At room temperature and under protection from light, $0.6 \mathrm{mmol}$ of $7 \mathbf{b 1}$ or $7 \mathbf{b} 2$ was dissolved in $8.0 \mathrm{~mL}$ dry DCM and treated with $0.50 \mathrm{~g}$ $(1.17 \mathrm{mmol})$ Dess-Martin periodinane. The oxidation reaction was complete in $3 \mathrm{~h}$, and the mixture was diluted with $100 \mathrm{~mL}$ ethyl acetate and then treated with sol. sat. $\mathrm{Na}_{2} \mathrm{~S}_{2} \mathrm{O}_{3}$. The organic phase was washed with sol. sat. $\mathrm{NaHCO}_{3}$, brine and distilled water. After drying over anhydrous $\mathrm{Na}_{2} \mathrm{SO}_{4}$, the solvent was evaporated and the residue was purified by silica gel chromatography (petroleum ether/ethyl acetate) to afford (14ß)-(quinolyl-8'-oxy)-3-keto-19-acetoxy andrographolide (8b1) or (14 $\beta$ )-(quinolyl-8'-oxy)-3-keto-19-( $t$-butyldimethyl silyloxy) andrographolide (8b2).

8b1. White solid; mp $56{ }^{\circ} \mathrm{C}$ to $59{ }^{\circ} \mathrm{C} ; 90 \%$ yield; ${ }^{1} \mathrm{H}$ NMR $(400$ $\left.\mathrm{MHz},\left(\mathrm{CD}_{3}\right)_{2} \mathrm{SO}\right) \delta 8.87(\mathrm{~d}, J=4.2 \mathrm{~Hz}, 1 \mathrm{H}), 8.37(\mathrm{~d}, J=8.3 \mathrm{~Hz}$, $1 \mathrm{H}), 7.71-7.47(\mathrm{~m}, 3 \mathrm{H}), 7.25(\mathrm{~d}, J=7.6 \mathrm{~Hz}, 1 \mathrm{H}), 7.02(\mathrm{t}, J=$ $7.2 \mathrm{~Hz}, 1 \mathrm{H}), 6.11(\mathrm{~d}, J=5.3 \mathrm{~Hz}, 1 \mathrm{H}), 4.88(\mathrm{~s}, 1 \mathrm{H}), 4.78(\mathrm{dd}, J=$ $10.9,5.5 \mathrm{~Hz}, 1 \mathrm{H}), 4.60(\mathrm{~s}, 1 \mathrm{H}), 4.50$ (d, $J=10.9 \mathrm{~Hz}, 1 \mathrm{H}), 4.35$ (d, $=11.3 \mathrm{~Hz}, 1 \mathrm{H}), 3.78(\mathrm{~d}, J=11.3 \mathrm{~Hz}, 1 \mathrm{H}), 2.31(\mathrm{q}, J=9.3,7.7 \mathrm{~Hz}$, 3H), 2.17-2.08 (m, 1H), 2.04-1.91 (m, 2H), 1.87 (s, 3H), 1.75-1.53 $(\mathrm{m}, 3 \mathrm{H}), 1.35(\mathrm{~s}, 1 \mathrm{H}), 1.27-1.11(\mathrm{~m}, 3 \mathrm{H}), 1.08-0.94(\mathrm{~m}, 2 \mathrm{H}), 0.86$ $(\mathrm{s}, 3 \mathrm{H}) ;{ }^{13} \mathrm{C}$ NMR $\left(101 \mathrm{MHz},\left(\mathrm{CD}_{3}\right)_{2} \mathrm{SO}\right) \delta 211.7,170.5,169.7$, $152.6,150.0$, 149.9, 147.4, 140.8, 136.6, 129.9, 127.2, 126.7, 122.5, 122.2, 113.9, 109.1, 73.1, 71.7, 65.8, 55.5, 54.9, 51.6, 38.9, 37.2, 37.0, 35.0, 25.7, 24.7, 20.9, 20.7, 14.3; ESI-HRMS: $m / z$ 518.2536 $[\mathrm{M}+\mathrm{H}]^{+}$, calcd for $\mathrm{C}_{31} \mathrm{H}_{36} \mathrm{NO}_{6}, 518.25426$.

8b2. White solid; mp $125{ }^{\circ} \mathrm{C}$ to $127{ }^{\circ} \mathrm{C}$; 86\% yield; ${ }^{1} \mathrm{H}$ NMR $\left(400 \mathrm{MHz},\left(\mathrm{CD}_{3}\right)_{2} \mathrm{SO}\right) \delta 8.85(\mathrm{dd}, J=4.1,1.7 \mathrm{~Hz}, 1 \mathrm{H}), 8.36(\mathrm{dd}, J=$ 8.4, 1.7 Hz, 1H), 7.64 (d, $J=7.4 \mathrm{~Hz}, 1 \mathrm{H}), 7.59-7.50(\mathrm{~m}, 2 \mathrm{H}), 7.24$ $(\mathrm{d}, J=6.8 \mathrm{~Hz}, 1 \mathrm{H}), 7.02(\mathrm{t}, J=6.8 \mathrm{~Hz}, 1 \mathrm{H}), 6.10(\mathrm{~d}, J=5.3 \mathrm{~Hz}$, $1 \mathrm{H}), 4.86(\mathrm{~s}, 1 \mathrm{H}), 4.77$ (dd, $J=10.8,5.5 \mathrm{~Hz}, 1 \mathrm{H}), 4.57(\mathrm{~s}, 1 \mathrm{H})$, $4.52-4.45(\mathrm{~m}, 1 \mathrm{H}), 3.67(\mathrm{~d}, J=10.1 \mathrm{~Hz}, 1 \mathrm{H}), 3.36$ (d, $J=10.3 \mathrm{~Hz}$, $1 \mathrm{H}), 2.28(\mathrm{~m}, 4 \mathrm{H}), 2.09(\mathrm{~m}, 1 \mathrm{H}), 1.97(\mathrm{~m}, 1 \mathrm{H}), 1.76-1.68(\mathrm{~m}, 1 \mathrm{H})$, 1.60 (m, 1H), 1.57-1.49 (m, 1H), 1.40-1.33 (m, 1H), 1.30-1.27 $(\mathrm{m}, 1 \mathrm{H}), 0.97-0.90(\mathrm{~m}, 1 \mathrm{H}), 0.79(\mathrm{~s}, 3 \mathrm{H}), 0.75(\mathrm{~s}, 9 \mathrm{H}), 0.63(\mathrm{~s}, 3 \mathrm{H})$, $-0.09(\mathrm{~d}, J=1.7 \mathrm{~Hz}, 6 \mathrm{H}) ;{ }^{13} \mathrm{C} \mathrm{NMR}\left(101 \mathrm{MHz},\left(\mathrm{CD}_{3}\right)_{2} \mathrm{SO}\right) \delta 212.4$,
169.7, 152.6, 150.1, 149.8, 147.9, 140.8, 136.6, 129.9, 127.2, 126.6, 122.5, 122.2, 113.9, 108.9, 73.1, 71.7, 65.9, 55.4, 55.0, 53.5, 38.9, 37.4, 36.9, 35.6, 26.8, 26.1, 26.0, 25.8, 24.9, 21.3, 18.2, 14.4, $-5.3,-5.4$; ESI-HRMS: $m / z 590.3297[\mathrm{M}+\mathrm{H}]^{+}$, calcd for $\mathrm{C}_{35} \mathrm{H}_{48} \mathrm{NO}_{5} \mathrm{Si}, 590.3302$.

4.2.6. Preparation of compound $9 \mathrm{~b}$ from $8 \mathrm{~b} 1$ or $8 \mathrm{~b} 2.0 .26 \mathrm{~g}$ $(0.50 \mathrm{mmol})$ of $\mathbf{8 b 1}$ was dissolved in $5 \mathrm{~mL}$ methanol and then treated with $0.17 \mathrm{~g}(1.0 \mathrm{mmol})$ of $p$-TSA at $40{ }^{\circ} \mathrm{C}$ for $8 \mathrm{~h}$. The mixture was diluted with ethyl acetate and washed with sat. $\mathrm{NaHCO}_{3}$ solution and brine; the organic phase was dried over anhydrous $\mathrm{Na}_{2} \mathrm{SO}_{4}$, filtered, and then concentrated under reduced pressure. The residue was purified by silica gel column chromatography to afford (14 $\beta$ )-(quinolyl-8'-oxy)-3-keto andrographolide (9b) in $80 \%$ yield.

A solution of $0.20 \mathrm{~g}$ ( $0.34 \mathrm{mmol}) 8 \mathrm{~b} 2$ in $4.0 \mathrm{~mL}$ dry DCM was cooled to $-20{ }^{\circ} \mathrm{C}$ and treated with $4.0 \mathrm{~mL}$ trifluoroacetic acid (TFA) for $20 \mathrm{~min}$. The reaction mixture was diluted with ethyl acetate and carefully treated with sol. sat. $\mathrm{NaHCO}_{3}$. The organic phase was washed with sol. sat. $\mathrm{NaHCO}_{3}$ and brine, then dried over anhydrous $\mathrm{Na}_{2} \mathrm{SO}_{4}$. The residue was filtered, dried and purified by silica gel column chromatography (petroleum ether/ ethyl acetate) to afford (14 $\beta$ )-(quinolyl-8'-oxy)-3-keto andrographolide (9b) in $81 \%$ yield. 9b: white solid; mp $141{ }^{\circ} \mathrm{C}$ to $143{ }^{\circ} \mathrm{C}$; ${ }^{1} \mathrm{H}$ NMR $\left(400 \mathrm{MHz},\left(\mathrm{CD}_{3}\right)_{2} \mathrm{SO}\right) \delta 8.85(\mathrm{dd}, J=4.1,1.7 \mathrm{~Hz}, 1 \mathrm{H})$, 8.36 (dd, $J=8.3,1.7 \mathrm{~Hz}, 1 \mathrm{H}), 7.64$ (d, $J=7.5 \mathrm{~Hz}, 1 \mathrm{H}), 7.60-7.50$ $(\mathrm{m}, 2 \mathrm{H}), 7.24(\mathrm{~d}, J=6.8 \mathrm{~Hz}, 1 \mathrm{H}), 7.01(\mathrm{dd}, J=7.3,6.1 \mathrm{~Hz}, 1 \mathrm{H})$, $6.10(\mathrm{~d}, J=5.3 \mathrm{~Hz}, 1 \mathrm{H}), 4.85(\mathrm{~s}, 1 \mathrm{H}), 4.77(\mathrm{dd}, J=10.8,5.5 \mathrm{~Hz}$, $1 \mathrm{H}), 4.56(\mathrm{~s}, 1 \mathrm{H}), 4.49(\mathrm{dd}, J=10.8,1.1 \mathrm{~Hz}, 1 \mathrm{H}), 4.43(\mathrm{t}, J=$ $5.4 \mathrm{~Hz}, 1 \mathrm{H}$ ), 3.66 (dd, $J=10.9,5.7 \mathrm{~Hz}, 1 \mathrm{H}), 3.16$ (dd, $J=10.9$, $5.2 \mathrm{~Hz}, 1 \mathrm{H}), 2.42$ (m, 1H), 2.28 (m, 3H), 2.06 (m, 1H), 2.00-1.90 $(\mathrm{m}, 1 \mathrm{H}), 1.67(\mathrm{~m}, 1 \mathrm{H}), 1.62-1.47$ (m, 2H), 1.34 (m, 1H), 1.25-1.18 (m, 1H), 0.99-0.87 (m, 1H), $0.80(\mathrm{~s}, 3 \mathrm{H}), 0.65$ (s, 3H); ${ }^{13} \mathrm{C}$ NMR (101 MHz, $\left.\left(\mathrm{CD}_{3}\right)_{2} \mathrm{SO}\right) \delta 212.64,169.30,152.13,149.76,149.45$, $147.42,140.31,136.18,129.50,126.72,126.19,122.12,121.79$, 113.51, 108.43, 72.64, 71.29, 63.84, 55.38, 54.75, 53.68, 38.55, 37.11, 36.98, 35.21, 25.32, 24.24, 20.10, 14.15; ESI-HRMS: $\mathrm{m} / \mathrm{z}$ $476.2431[\mathrm{M}+\mathrm{H}]^{+}$, calcd for $\mathrm{C}_{29} \mathrm{H}_{34} \mathrm{NO}_{5}, 476.2437$.

4.2.7. Antibacterial evaluation. The tested compound or ciprofloxacin (positive drug) was dissolved in DMSO and diluted with LB liquid medium into a stock solution containing $20 \%$ DMSO before use; the stock solution of the carrier was $20 \%$ DMSO in LB liquid medium. All the experiments, including blank controls, were performed in triplicate.

Bacteriostatic screening was performed by applying a modified protocol of the National Committee on Clinical Laboratory Standards (NCCLS). ${ }^{29}$ Briefly, E. coli, S. aureus and E. faecalis cells (American Type Culture Collection, ATCC) were grown in LB plate medium for one passage, then seeded in LB liquid medium and cultured at $37^{\circ} \mathrm{C}$ for $12 \mathrm{~h}$. After being diluted 1000 times, $190 \mu \mathrm{L}$ diluted cells were aliquoted to 96-well plates; then, $10 \mu \mathrm{L}$ stock solution of carrier or a gradient amount of the tested compound or the positive compound, ciprofloxacin, were added; the final concentration of DMSO was $1 \%$ in all wells. The blank controls contained 1\% DMSO and LB medium but no bacterial cells. The cultures were incubated at $37^{\circ} \mathrm{C}$ for $24 \mathrm{~h}$, and the growth data were expressed as $\mathrm{OD}_{630}$; the $\mathrm{IC}_{50}$ values were calculated based on growth data versus test concentration. 
4.2.8. Activity $\left(\mathrm{EC}_{50}\right)$ against signaling pathways and cytotoxicity $\left(\mathrm{CC}_{\mathbf{5 0}}\right)$ of testing compounds in $\mathrm{AD}-293$ cells. Cells from the AD-293 cell line, a derivative of the HEK293 cell line with improved adherence and plaque formation properties, were purchased from Stratagene (La Jolla, CA, USA). The protocols were adopted and modified from our previous report. ${ }^{25}$ All compounds were dissolved in DMSO at $10 \mathrm{mM}$ as a stock solution. The final concentration of DMSO was $0.1 \%$ in the culture medium. AD-293 cells bearing luciferase reporters with promoter regions of IL-6/STAT3 and TNF- $\alpha / \mathrm{NF}-\kappa \mathrm{B}$ in pGL4.20 vector (Promega) were maintained in DMEM high glucose medium supplemented with $10 \%$ FBS and $1 \%$ penicillin streptomycin in the presence of $1 \mu \mathrm{g} \mathrm{mL}^{-1}$ puromycin. AD-293 cells overexpressing TLR4 and stably transfected with NF- $\kappa$ B reporter were maintained in DMEM high glucose medium in the presence of $1 \mu \mathrm{g} \mathrm{mL}{ }^{-1}$ puromycin and $10 \mu \mathrm{g} \mathrm{mL} \mathrm{m}^{-1}$ blasticidin. All cells were maintained in a humidified incubator at $37{ }^{\circ} \mathrm{C}$ in $95 \%$ air and $5 \% \mathrm{CO}_{2}$.

Cytotoxicity of testing compounds. AD-293 cells were plated in a 96-well plate at a concentration of $1.0 \times 10^{5}$ cells per well overnight to allow cell attachment. Working solutions of the tested compounds, the positive drug, DCB- $3503{ }^{36}$ of a cryptopleurine analog, or the DMSO vehicle as a control were dispensed appropriately into the partitioned 96-well plates, which were then incubated for another $24 \mathrm{~h}$. Then, the medium was discarded and the cells were incubated for $4 \mathrm{~h}$ at $37^{\circ} \mathrm{C}$ in MTT solution (final concentration $0.5 \mathrm{mg} \mathrm{mL}{ }^{-1}$ ). The solution was then replaced with $100 \mu \mathrm{L}$ DMSO to dissolve the violet formazan crystals in the intact cells. Cell growth was assessed by MTT according to the manufacturer's protocol. The absorbance was measured at $570 \mathrm{~nm}$ as the reference wavelength. The cytotoxicity as the $\mathrm{CC}_{50}$ value (concentration of $50 \%$ cell growth/ viability inhibition) was calculated based on the percentage of cell viability data compared to the control group. Each concentration was repeated 3 times independently.

Signaling pathway reporter assay. Reporter cells were treated with $50 \mathrm{ng} \mathrm{mL}^{-1}$ TNF- $\alpha$ to stimulate the NF- $\kappa \mathrm{B}$ signaling pathway, $1 \mu \mathrm{g} \mathrm{mL}{ }^{-1}$ LPS to stimulate the TLR4/NF- $\kappa \mathrm{B}$ signaling pathway, and $2.5 \mu \mathrm{g} \mathrm{mL} \mathrm{mL}^{-1}$ IL-6 to stimulate the IL-6/STAT3 signaling pathway. The medium was removed at the end of the treatment, cell extracts were prepared, and the luciferase activity was measured using a Luciferase assay kit (Promega) according to the manufacturer's instructions. $\mathrm{EC}_{50}$ was defined as the concentration of drug that inhibited stimulatortriggered luciferase reporter activation by $50 \%$ after continuous drug exposure for 4 (TNF- $\alpha / \mathrm{NF}-\kappa \mathrm{B})$ or 16 (IL-6/STAT3 and TLR4/ $\mathrm{NF}-\kappa \mathrm{B})$ hours. Each concentration was repeated 3 times independently.

\section{Author contributions}

GCZ, DW and YW conceived and supervised the project, analyzed the data and wrote the paper. GCZ, FL, DS, XN, ZL and DW designed the andrographolide derivatives; FL, DS, XN, ZL and DW conducted the syntheses of andrographolide derivatives. YW, XML, SRC, QZ, and YTW designed the biological experiments. XML, SRC and QZ conducted the biology experiments. All authors have read and approved the final manuscript.

\section{Conflicts of interest}

There are no conflicts to declare.

\section{Acknowledgements}

This work was supported in part by the Natural Science Foundation of China (30973621) and Six Major Talents of Jiangsu Province of China (2014). This work was partially supported by the Macao Science and Technology Development Fund 041/ 2014/A1, Research Fund of the University of Macao MYRG 2016-00105-ICMS-QRCM, and MYRG 2017-00116-ICMS-QRCM to YW, and MYRG2015-00098-ICMS-QRCM to YTW.

\section{References}

1 (a) C. Abraham and J. H. Cho, N. Engl. J. Med., 2009, 361, 2066-2078; (b) A. N. Ananthakrishnan, Nat. Rev. Gastroenterol. Hepatol., 2015, 12, 205-217; (c) Inflammatory bowel disease, Nature, 2016, 540, S97-S140.

2 (a) L. Jostins, S. Ripke, R. K. Weersma, et al., Nature, 2012, 491, 119-124; (b) T. T. Macdonald and G. Monteleone, Science, 2005, 307, 1920-1925.

3 K. O. Arseneau, H. Tamagawa, T. T. Pizarro and F. Cominelli, Curr. Gastroenterol., 2007, 9, 508-512.

4 C. G. Knutson, A. Mangerich, Y. Zeng, A. R. Raczynski, R. G. Liberman, P. Kang, W. Ye, E. G. Prestwich, K. Lu, J. S. Wishnok, J. R. Korzenik, G. N. Wogan, J. G. Fox, P. C. Dedon and S. R. Tannenbaum, Proc. Natl. Acad. Sci. U. S. A., 2013, 110, E2332-E2341.

5 (a) M. F. Neurath, Nat. Rev. Immunol., 2014, 14, 329-342; (b) C. Luo and H. Zhang, Mediators Inflammation, 2017, 11, 5126048.

6 (a) P. P. Tak and G. S. Firestein, J. Clin. Invest., 2017, 107, 711; (b) K. Mitsuyama, S. Matsumoto, J. Masuda, H. Yamasakii, K. Kuwaki, H. Takedatsu and M. Sata, Anticancer Res., 2007, 27, 3749-3756.

7 L. Sherwood, W. Joanne and W. Christopher, Prescott's Microbiology, 2013, New York, McGraw Hill, 9th edn, pp. 713-721.

8 R. Saxena and V. K. Sharma, A Metagenomic Insight Into the Human Microbiome: Its Implications in Health and Disease, in Medical and Health Genomics, ed. D. Kumar and S. Antonarakis, Elsevier Science, 2016.

9 (a) A. Shawki and D. F. McCole, Nat. Rev. Gastroenterol. Hepatol., 2017, 3, 41-50; (b) E. Balish and T. Warner, Am. J. Pathol., 2002, 160, 2253-2257; (c) Y. Zhou, H. Chen, H. He, Y. Du, J. Hu, Y. Li, Y. Li, Y. Zhou, H. Wang, Y. Chen and Y. Nie, Medicine), 2016, 95, e5019.

10 (a) C. S. Pedamallu, A. S. Bhatt, S. Bullman, S. Fowler, S. S. Freeman, J. Durand, J. Jung, F. Duke, V. Manzo, D. Cai, A. Ananthakrishnan, A. I. Ojesina, A. Ramachandran, D. Gevers, R. J. Xavier, A. K. Bhan, M. Meyerson and V. Yajnik, Nat. Rev. Gastroenterol. 
Hepatol., 2016, 2, 563-566; (b) D. Bettenworth, T. M. Nowacki, A. Friedrich, K. Becker, J. Wessling and J. Heidemann, World J. Gastroenterol., 2013, 19, 4418-4421; (c) M. Chiba, S. Hoshina, M. Kono, M. Tobita, T. Fukushima, M. Iizuka and S. Watanabe, Scand. J. Gastroenterol., 2001, 36, 615-620.

11 F. Guarner and J. Malagelada, Lancet, 2003, 361, 512-519.

12 (a) M. K. Gorter, Recl. Trav. Chim. Pays-Bas, 1911, 30, 151160; (b) R. J. C. Kleipool, Nature, 1952, 169, 33-34; (c) M. P. Cava, W. R. Chan, L. J. Haynes, L. F. Johnson and B. Weinstein, Tetrahedron, 1962, 18, 397-403.

13 (a) R. N. Chakravarti and D. Chakravarti, Indian Med. Gaz., 1951, 86, 96-97; (b) T. Zhang, Zhongyaocai, 2000, 23, 366368; (c) X. Liu, Y. Wang and G. Li, Zhongyaocai, 2003, 26, 135-138; (d) P. K. Singha, S. Roy and S. Dey, Fitoterapia, 2003, 74, 692-694; (e) S. Gupta, K. P. Mishra and L. Ganju, Arch. Virol., 2017, 162, 611-623.

14 Chinese Pharmacopoeia Commission, Chinese Pharmacopoeia Part 2, 2015, pp. 619-620.

15 (a) R. S. Chan, L. Ding, G. Q. Chen, Q. C. Pan, Z. L. Zhao and K. M. Smith, Proc. Soc. Exp. Biol. Med., 1991, 197, 59-66; (b) A. Basak, S. Cooper, A. G. Roberg, U. K. Banik, M. Chretien and N. G. Seidah, Biochem. J., 1999, 338, 107-113.

16 (a) C. Aromdee, Expert Opin. Ther. Pat., 2014, 24, 1129-1138; (b) B. Zhou, D. Zhang and X. Wu, Mini-Rev. Med. Chem., 2013, 13, 298-309; (c) C. Aromdee, Expert Opin. Ther. Pat., 2012, 22, 169-180; (d) T. Kasemsuk, P. Piyachaturawat, R. Bunthawong, U. Sirion, K. Suksen, A. Suksamrarn and R. Saeeng, Eur. J. Med. Chem., 2017, 138, 952-963.

17 H. T. Li, H. R. Qin, W. H. Wang, C. J. Li, C. M. Wu and J. X. Song, China J. Chin. Mater. Med., 2006, 1, 1016-1017.

18 X. Jiang, P. Yu, J. Jiang, Z. Zhang, Z. Wang, Z. Yang, Z. Tian, S. C. Wright, J. W. Larrick and Y. Wang, Eur. J. Med. Chem., 2009, 4, 2936-2943.

19 (a) C. Calabrese, S. H. Berman, J. G. Babish, X. Ma, L. Shinto, M. Dorr, K. Wells, A. A. Wenner and L. J. Standish, Phytother. Res., 2000, 14, 333-338; (b) Y. C. Shen, C. F. Chen and W. F. Chiou, Br. J. Pharmacol., 2002, 35, 399-406; (c) Y. F. Xia, B. Q. Ye, Y. D. Li, J. G. Wang, X. J. He, X. Lin, X. Yao, D. Ma, A. Slungaard, R. P. Hebbel, N. S. Key and J. G. Geng, J. Immunol., 2004, 173, 4207-4217; (d) M. A. Hidalgo, A. Romero, J. Figueroa, P. Cortes, I. I. Concha, J. L. Hancke and R. A. Burgos, Br. J. Pharmacol., 2005, 144, 680-686.

$20 \mathrm{H}$. Gao and J. Wang, Andrographolide inhibits multiple myeloma cells by inhibiting the TLR4/NF-kappaB signaling pathway, Mol. Med. Rep., 2016, 13, 1827-1832.

21 M. T. Islam, Front. Pharmacol., 2017, 8, 571.

22 C. H. Yang, T. L. Yen, C. Y. Hsu, P. A. Thomas, J. R. Sheu and T. Jayakumar, Int. J. Mol. Sci., 2017, 18, E1638.

23 C. V. Chandrasekaran, P. Thiyagarajan, H. B. Deepak and A. Agarwal, Int. Immunopharmacol., 2011, 11, 79-84.
24 Y. Li, H. Yan, Z. Zhang, G. Zhang, Y. Sun, P. Yu, Y. Wang and L. Xu, Br. J. Pharmacol., 2015, 172, 3151-3158.

25 X. Nie, S.-R. Chen, K. Wang, Y. Peng, Y.-T. Wang, D. Wang, Y. Wang and G.-C. Zhou, Sci. Rep., 2017, 7, 4738.

26 (a) Z. Liu, W.-K. Law, D. Wang, X. Nie, D. Sheng, G. Song, K. Guo, P. Wei, P. Ouyang, C.-W. Wong and G.-C. Zhou, RSC Adv., 2014, 4, 13533-13545; (b) Y. Peng, J. Li, Y. Sun, J. Y.-W. Chan, D. Sheng, K. Wang, P. Wei, P. Ouyang, D. Wang, S. M. Y. Lee and G.-C. Zhou, $R S C A d v$., 2015, 5, 22510-22526.

27 W. Leung, G. Malhi, B. M. Willey, A. J. McGeer, B. Borgundvaag, R. Thanabalan, P. Gnanasuntharam, B. Le, A. V. Weizman, K. Croitoru, M. S. Silverberg, A. H. Steinhart and G. C. Nguyen, Journal of Crohn's \& Colitis, 2012, 6, 743-749.

28 WHO, Antimicrobial resistance: global report on surveillance, 2014.

29 (a) NCCLS, Methods for Dilution Antimicrobial Susceptibility Tests for Bacteria that Grow Aerobically M7-A5, National Committee on Clinical Laboratory Standards, 2000, vol. 20, p. 2; (b) NCCLS, Susceptibility Testing of Mycobacteria, Nocardia, and Other Aerobic Actinomycetes; Tentative Standard, Second Edition, M24-T2, National Committee on Clinical Laboratory Standards, 2000, vol. 20, p. 26; (c) V. Samoylenko, M. R. Jacob, S. I. Khan, J. Zhao, B. L. Tekwani, J. O. Midiwo, L. A. Walker and I. Muhammad, Nat. Prod. Commun., 2009, 4, 791-796.

30 (a) G. Bamias, M. R. Nyce, S. A. De La Rue and F. Cominelli, Ann. Intern. Med., 2005, 143, 895-904; (b) D. K. Podolsky, N. Engl. J. Med., 2002, 347, 417-429.

31 K. A. Shirey, W. Lai, A. J. Scott, M. Lipsky, P. Mistry, L. M. Pletneva, C. L. Karp, J. McAlees, T. L. Gioannini, J. Weiss, W. H. Chen, R. K. Ernst, D. P. Rossiqnol, F. Gusovsky, J. C. Blanco and S. N. Vogel, Nature, 2013, 497, 498-502.

32 J. Xing, R. Li, N. Li, J. Zhang, Y. Li, P. Gong, D. Gao, H. Liu and Y. Zhang, Mol. Cell. Biochem., 2015, 407, 89-95.

33 (a) R. Carey, I. Jurickova, E. Ballard, E. Bonkowski, X. Han, H. Xu and L. A. Denson, Inflammatory Bowel Dis., 2008, 14, 446-457; (b) S. Zundler and M. F. Neurath, Vaccines, 2016, 4, 5 .

34 (a) S. R. Vavricka, J. A. Galván, H. Dawson, A. Soltermann, L. Biedermann, M. Scharl, A. M. Schoepfer, G. Rogler, M. B. PrinzVavricka, L. Terracciano, A. Navarini, I. Zlobec, A. Lugli and T. Greuter, J. Crohn's Colitis, 2018, 12, 347354; (b) C. Luo and H. Zhang, Mediators Inflammation, 2017, 5126048.

35 A. Piechota-Polanczyk and J. Fichna, Naunyn-Schmiedeberg's Arch. Pharmacol., 2014, 387, 605-620.

36 Y. Wang, H. C. Wong, E. A. Gullen, W. Lam, X. Yang, Q. Shi, K. H. Lee and Y. C. Cheng, PLoS One, 2012, 7, e51138. 